\title{
ipen
}

AUTARQUIA ASSOCIADA À UNIVERSIDADE DE SÃO PAULO

\section{AVALIAÇÃO DA RADIOATIVIDADE NATURAL EM AREIAS DAS PRAIAS DA GRANDE VITÓRIA, ESPÍRITO SANTO}

\section{REGINALDO RIBEIRO DE AQUINO}

\begin{abstract}
Dissertação apresentada como parte dos requisitos para obtenção do Grau de Mestre em Ciências na Área de Tecnologia Nuclear - Aplicações

Orientadora:

Profa. Dra. Brigitte Roxana Soreanu Pecequilo
\end{abstract}




\section{ipen}

AUTARQUIA ASSOCIADA À UNIVERSIDADE DE SÃO PAULO

AVALIAÇÃO DA RADIOATIVIDADE NATURAL EM AREIAS DAS PRAIAS DA GRANDE VITÓRIA, ESPÍRITO SANTO

REGINALDO RIBEIRO DE AQUINO

Dissertação apresentada como parte dos requisitos para obtenção do grau de Mestre em Ciências na Área de Tecnologia NuclearAplicações.

Orientadora:

Dra. Brigitte Roxana Soreanu Pecequilo 
Dedico este trabalho Aos meus pais, irmão e demais familiares.

E em memória a minha Avó. 


\section{Agradecimentos}

- Ao Instituto de Pesquisas Energéticas e Nucleares pela oportunidade de realizar este trabalho.

- À Comissão Nacional de Energia Nuclear por viabilizar este estudo.

-À Dra. Brigitte Roxana Soreanu Pecequilo pela oportunidade, orientação, acompanhamento, por todo o conhecimento que me transmitiu em ensinamento e por toda a paciência e pelas merecidas broncas.

- A Dra. Sandra Regina Damatto pelas várias dicas ao meu trabalho.

- A Dra. Bárbara Paci Mazzilli, pelo o uso da infra-estrutura do LRA.

- A Dra. Linda V.E. Caldas, pelo apóio inicial, atenção.

- A Dra. Letícia Lucente Campos Rodrigues, pela atenção em todos os momentos que a procurei.

- Aos meus pais e irmão pelo apóio a todo o momento.

- A minha Tia Rizete e em memória meu Tio Egídio pelo incentivo à cultura.

- A minha Tia Marinéa pelas palavras e conselhos sempre bem vindos.

- A minha Tia Alice e ao Meu Tio Elcio, aos quais considero meus segundos pais.

- Ao amigo Dr. Victor Gentilli e Dra. Raquel L. Gentilli pelo incentivo.

- A amiga Clarice Lopes Gentilli pelo apóio no momento inicial da pesquisa. 
- Ao Dr. Marcos Tadeu D’Azeredo Orlando pelo apóio e disposição em ajudar, incentivar e encorajar este trabalho, nenhum professor acreditou tanto em mim.

- À Dra. Márcia Pires de Campos que em vários momentos com paciência e conhecimento se fez presente neste trabalho.

- Ao M. Sc. Marcelo Bessa que por várias vezes compartilhou seu conhecimento comigo tornando este trabalho muito mais completo.

- Ao Dr. Lúcio Leonardo por toda a ajuda e apóio

- À Dra. Cátia H. Saueia que em muitos momentos contribuiu direta ou indiretamente para este trabalho com seu conhecimento.

- Ao M. Sc. Marcos Medrado de Alencar pelas conversas e apóio.

- A Dra. Marinei Yuko Kijimura por todo o carinho.

- Aos amigos inesquecíveis Sueli Carvalho de Jesus, Ademar de Oliveira Ferreira e Lúcia Helena Vieira e aos demais que fiz aqui no Laboratório de Radiometria Ambiental (LRA) pelo apóio e incentivo. 
Dissertação editada em software livre BrOffice.org 3.2.1 


\section{AVALIAÇÃO DA RADIOATIVIDADE NATURAL EM AREIAS DAS PRAIAS DA GRANDE VITÓRIA, ESPÍRITO SANTO}

\section{Reginaldo Ribeiro de Aquino}

\section{RESUMO}

Neste trabalho foram determinadas as concentrações dos radionuclídeos naturais ${ }^{226} \mathrm{Ra}$, ${ }^{232} \mathrm{Th}$ e ${ }^{40} \mathrm{~K}$ em amostras de areias superficiais para 16 localizações ao longo da costa da Grande Vitória, região metropolitana do estado do Espírito Santo, sudeste do Brasil. As áreas de estudo compreendem as praias de Manguinhos e Jacaraípe no município da Serra, Camburi, Praia do Canto e Curva da Jurema no município de Vitória, Praia da Costa e Praia de Itapuã no município de Vila Velha, Praia de Setibão, Setibinha, Praia do Morro, Praia das Castanheiras e Praia da Areia Preta no Município de Guarapari e areia da Reserva Paulo Cesar Vinha também localizada no município de Guarapari. Para cada sítio de estudo, três amostras foram seladas em frascos de $100 \mathrm{ml}$ de polietileno de alta densidade. Após espera de aproximadamente 4 semanas para atingir o equilíbrio secular das séries do ${ }^{238} \mathrm{U}$ e ${ }^{232} \mathrm{Th}$, as amostras foram medidas por espectrometria gama de alta resolução e o espectro analisado com o software WinnerGamma. A correção da auto-absorção foi realizada para todas as amostras. A concentração do ${ }^{226} \mathrm{Ra}$ foi determinada pela média ponderada das concentrações do ${ }^{214} \mathrm{~Pb}$ e ${ }^{214} \mathrm{Bi}$, a concentração de ${ }^{232} \mathrm{Th}$ pela média ponderada das concentrações dos ${ }^{228} \mathrm{Ac},{ }^{212} \mathrm{~Pb}$ e ${ }^{212} \mathrm{Bi}$ e a concentração de ${ }^{40} \mathrm{~K}$ pela sua transição única de $1460 \mathrm{keV}$. O equivalente em rádio e o índice gama foram obtidos a partir das concentrações de ${ }^{226} \mathrm{Ra}$, ${ }^{232} \mathrm{Th}$ e ${ }^{40} \mathrm{~K}$. As concentrações de ${ }^{226} \mathrm{Ra}$ variaram de $3 \pm 1 \mathrm{~Bq} \cdot \mathrm{kg}^{-1}$ a $738 \pm 38 \mathrm{~Bq} \cdot \mathrm{kg}^{-1}$, com o maior valor na localidade central da Praia de Camburi. As concentrações de ${ }^{232} \mathrm{Th}$ variaram de $7 \pm 3 \mathrm{~Bq} \cdot \mathrm{kg}^{-1}$ a $7422 \pm 526 \mathrm{~Bq} \cdot \mathrm{kg}^{-1}$, com o maior valor na Praia da Areia Preta. As concentrações de ${ }^{40} \mathrm{~K}$ variaram de $14 \pm 6 \mathrm{~Bq} \mathrm{~kg}^{-1}$ a $638 \pm 232 \mathrm{~Bq} \cdot \mathrm{kg}^{-1}$, com o maior valor na Praia da Areia Preta. O cálculo do equivalente em rádio e do índice gama mostrou duas faixas distintas. Na primeira, para a maioria das praias, o equivalente em rádio variou de $15 \pm 6 \mathrm{~Bq} \cdot \mathrm{kg}^{-1}$ a $257 \pm 18 \mathrm{~Bq} \cdot \mathrm{kg}^{-1}$, abaixo do limite inferior de $370 \mathrm{~Bq} \cdot \mathrm{kg}^{-1}$ recomendado pela OECD como adequado para uso em material de construção e o índice gama externo foi inferior ao limite aceitável de 1 sugerido pelo UNSCEAR. Na 
segunda, para as praias de Setibinha, Curva da Jurema, Camburi Sul e Camburi Central e Praia da Areia Preta, o equivalente em rádio variou de $820 \pm 40 \mathrm{~Bq} \cdot \mathrm{kg}^{-1}$ até $11200 \pm 580 \mathrm{~Bq} \cdot \mathrm{kg}^{-1}$, excedendo de 2 a 30 vezes o limite mínimo recomendado para aplicação na construção civil e o índice gama superou de 3 até quase 40 vezes o limite sugerido pelo UNSCEAR. 


\title{
ASSESSMENT OF NATURAL RADIATION OF BEACHS SANDS IN GREAT VITÓRIA, ESPÍRITO SANTO
}

\section{Reginaldo Ribeiro de Aquino}

\begin{abstract}
In this work the concentrations of natural radionuclides ${ }^{226} \mathrm{Ra},{ }^{232} \mathrm{Th}$ and ${ }^{40} \mathrm{~K}$ were determined in superficial sand samples for 16 locations throughout the coast of the Great Victory, metropolitan region of the state of Espírito Santo, Southeast of Brazil. The assessed beaches were Manguinhos and Jacaraípe in Serra county, Camburi, Praia do Canto and Curva da Jurema in Vitória county, Praia da Costa and Itapuã in Vila Velha county, Setibão, Setibinha, Praia do Morro, Praia das Castanheiras and Areia Preta in Guarapari county and sand of the Paulo Cesar Vinha Reserve also located in Guarapari county. Three sand samples of each beach were sealed in $100 \mathrm{~mL}$ high density polyethylene flasks. After approximately 4 weeks in order to reach secular equilibrium in the ${ }^{238} \mathrm{U}$ and ${ }^{232} \mathrm{Th}$ series, the samples were measured by high resolution gamma spectrometry and the spectra analyzed with the WinnerGamma software. The selfabsorption correction was performed for all samples. The ${ }^{226} \mathrm{Ra}$ concentration was determined from the weighted average concentrations of ${ }^{214} \mathrm{~Pb}$ and ${ }^{214} \mathrm{Bi}$, the ${ }^{232} \mathrm{Th}$ concentration was determined from the weighted average concentrations of ${ }^{228} \mathrm{Ac},{ }^{212} \mathrm{~Pb}$ and ${ }^{212} \mathrm{Bi}$ and the concentration of ${ }^{40} \mathrm{~K}$ is determined by its single gamma transition of $1460 \mathrm{keV}$. The radium equivalent concentration and the external hazard index where obtained from the concentrations of ${ }^{226} \mathrm{Ra},{ }^{232} \mathrm{Th}$ and ${ }^{40} \mathrm{~K}$. ${ }^{226} \mathrm{Ra}$ concentrations show values varying from $3 \pm 1 \mathrm{~Bq} \cdot \mathrm{kg}^{-1}$ to $738 \pm 38 \mathrm{~Bq} \cdot \mathrm{kg}^{-1}$, with the highest values for the central locality of the Camburi beach. ${ }^{232} \mathrm{Th}$ concentrations show values varying from $7 \pm 3 \mathrm{~Bq} \cdot \mathrm{kg}^{-1}$ to $7422 \pm 526 \mathrm{~Bq} \cdot \mathrm{kg}^{-1}$, with the highest values for Areia Preta beach. ${ }^{40} \mathrm{~K}$ concentrations show values varying from $14 \pm 6 \mathrm{~Bq} \cdot \mathrm{kg}^{-1}$ to $638 \pm 232 \mathrm{~Bq} \cdot \mathrm{kg}^{-1}$, with the highest values for Areia Preta beach. Calculation of the radium equivalent and the external hazard index showed two distinct groups. In the first one, for the majority of the beaches, the radium equivalent activities are in the range from $15 \pm 6 \mathrm{~Bq} \cdot \mathrm{kg}^{-1}$ to $257 \pm 18 \mathrm{~Bq} \cdot \mathrm{kg}^{-1}$, below the lower limit of $370 \mathrm{~Bq} \cdot \mathrm{kg}^{-1}$ recommended by OECD for the safe use of building materials and external hazard index was below the acceptable limit of 1 suggested by UNSCEAR. In the second one, for Setibinha, Curva da Jurema, South and
\end{abstract}


Central locations of Camburi and Areia Preta beaches, the radium equivalent results are in the range from $820 \pm 40 \mathrm{~Bq} \cdot \mathrm{kg}^{-1}$ to $11200 \pm 580 \mathrm{~Bq} \cdot \mathrm{kg}^{-1}$, exceeding 2 to 30 times the recommended minimum value for safe application in the civil construction industry and the external hazard index surpassed almost 3 to 40 times the UNSCEAR suggested limit. 


\section{SUMÁRIO}

Página

\section{INTRODUÇÃO}

1.1 Radioatividade natural 1

1.1.1 Radioatividade natural e séries naturais..............................................

1.1.2 Equilíbrio radioativo das séries naturais............................................... 4

1.2 Justificativa do trabalho e objetivo.................................................... 4

1.3 Aspectos gerais e localização do sítio de estudo ....................................... 7

1.3.1 Clima e geografia do Espírito Santo....................................................... 7

1.3.2 Aspectos climáticos, geográficos e populacionais da Grande Vitória ........... 9

1.3.3 Outros aspectos relevantes sobre os sítios selecionados.......................... 10

2 METODOLOGIA ............................................................................. 12

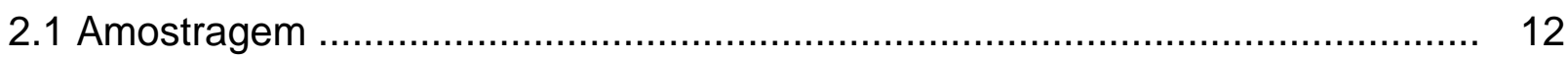

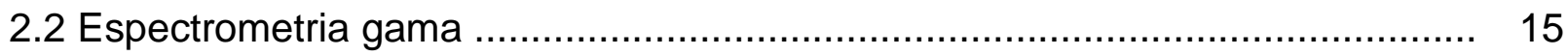

2.3 Fator de correção por atenuação .............................................................. 16

2.4 Cálculo da concentração de atividade do radionuclídeo................................. 19

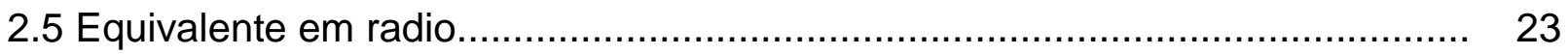

2.6 Índice de risco a exposição gama externo e interno.................................... 24

2.7 Estimativa de taxa de dose absorvida no ar................................................ 25

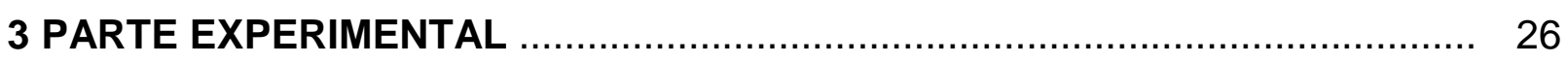

3.1 Coleta e preparo das amostras ........................................................ 26

3.2 Espectrômetro gama e contagem das amostras ......................................... 28

3.3 Correção por atenuação .............................................................. 31

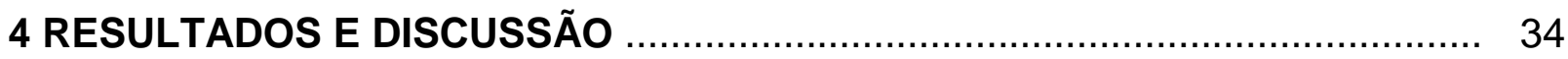

4.1 Fatores de atenuação para as areias estudadas.................................. 34

4.2 Concentração de atividade para as regiões selecionadas................................. 39

4.3 Equivalente em rádio e Índice de risco para as areias da Grande Vitória........... 42

4.4 Estimativa de dose nas areias da Grande Vitória ........................................ 46

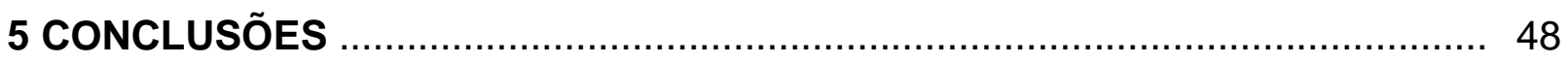

6 SUGESTÕES PARA NOVOS TRABALHOS .............................................. 52

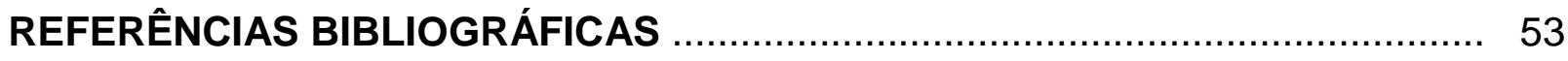

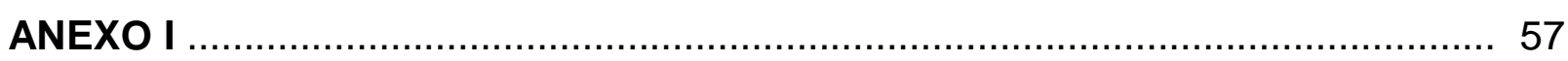


Figura 1 Famílias de decaimento radioativo. Na parte superior a família de decaimento do urânio e abaixo a família de decaimento do tório (NNDC, 2010)

Figura 2 Reserva Paulo Cesar Vinha, Guaraparí, verão de 2007. Extração de areia para construção civil. A imagem mostra um sitio de extração e a degradação ambiental causada no processo. Foto acervo pessoal.

Figura 3 Aspectos gerais do estado Espírito Santo. O destaque mostra a região metropolitana da Grande Vitória, ao centro do destaque está localizada a capital Vitória. Ao norte é indicada a foz do Rio Doce e ao sul a foz do rio Itapemirim. IBGE (2007).

Figura 4 Localização da Região metropolitana da Grande Vitória e localidades de estudo.

Figura 5 Praia das Castanheiras, Guaraparí. Foto: H. Capai.

Figura 6 Praia de Jacaraípe, Serra. Foto L. Torres-A Gazeta (26/05/2010).

Figura 7 Praia da Curva da Jurema, Vitória. Foto H. Capai.

Figura 8 Tipos de minerais encontrados ao longo da costa da Grande Vitória. A)Ilmenita, B)monazita, C)rutílo em cristal de quartzo, D)zircão. (MACHADO et al, 2009)

Figura 9 Praia de Camburí central, Vitória. Na areia é observável o padrão de manchas devido à concentração de ilmenita que se estende ao logo da praia. Foto Flávio Santos.

Figura 10 Detalhe do padrão de tonalidade da mancha na areia. Foto acervo pessoal

Figura 11 Esquema da montagem convencional do espectrômetro gama utilizado no presente trabalho 
Figura 12 Amostra preparada para contagem. Em À, almofariz com amostras. Em $B$, estufa com amostra. Foto acervo pessoal

Figura 13 Frascos padrão de polietileno, F100. Em "A" tampa e batoque de $52,5 \mathrm{~mm}$, em "B" amostra selada com fita PVC e em "C" amostra revestida com filme PVC para evitar contaminação do detector. Foto acervo pessoal

Figura 14 Parte inferior da blindagem convencional de chumbo destacando parte do detector (modelo GEM15200) e o dewar (modelo DWR-30) de resfriamento. Foto acervo pessoal.

Figura 15 Vista interna detector HPGe com amostra envasada em frasco F100. No detalhe é vista a proteção de filme PCV para evitar contaminação no detector. Foto acervo pessoal.

Figura 16 Eletrônica associada. Da direita pra esquerda, são vistas a fonte de alimentação ORTEC 659 e o amplificador ORTEC EG\&G 672. Foto acervo pessoal.

Figura 17 Ao centro é visto analisador multicanal ORTEC EG\&G 919 Spectrum Master. Foto acervo pessoal.

Figura 18 Visão de saída do software para análise dos espectros.

Figura 19 Detalhe do anel colimador com uma fonte padrão de ${ }^{152} \mathrm{Eu}$, deslocada da posição central para melhor visualização. Foto acervo pessoal..

Figura 20 Suporte de lucite, colimador e fonte ajustados. Foto acervo pessoal.

Figura 21 À direita parede e visão interna da blindagem convencional de chumbo e no detalhe aparato experimental composto de fonte, suporte e colimador, ao centro amostra em frasco F100 e o detector HPGe ambos recobertos com filme PVC. Foto acervo pessoal..

Figura 22 Curva de atenuação da amostra de areia da Praia de Jacaraípe. 34

Figura 23 Relação fator-energia para o grupo de amostragem de densidade aproximadamente $1,6 \mathrm{~kg} \cdot \mathrm{m}^{-3}$....... 
Figura 24 Relação fator-energia para o grupo de amostragem de densidade aproximadamente a $1,64 \mathrm{~kg} \cdot \mathrm{m}^{-3}$...

Figura 25 Relação fator-energia para o grupo de amostragem de densidade aproximada $1,70 \mathrm{~kg} \cdot \mathrm{m}^{-3}$

Figura 26 Relação fator-energia para o grupo de amostragem de densidade aproximada $1,78 \mathrm{~kg} \cdot \mathrm{m}^{-3}$

Figura 27 Relação fator-energia para o grupo de amostragem de densidade aproximada $2,14 \mathrm{~kg} \cdot \mathrm{m}^{-3}$

Figura 28 Concentrações de atividade para as areias das praias da Grande Vitória.

Figura 29 Índice de risco interno e externo para as areias das praias da Grande Vitória. 44

Figura 30 Estimativa de dose em relação à atividade realizada. 46 


\section{Lista de tabelas}

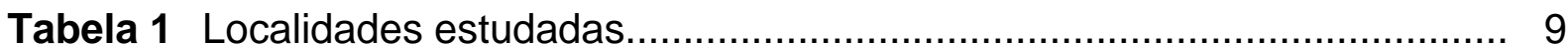

Tabela 2 Transições gama utilizadas para a determinação da concentração de radionuclídeos....................................................................... 18

Tabela 3 Transições gama selecionadas para a curva de atenuação ................... 21

Tabela 4 Limites para o equivalente em rádio recomendados para materiais de

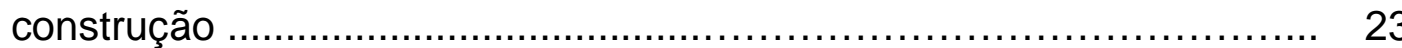

Tabela 5 Tempo anual para estimativa de dose, considerando a atividade realizada durante o dia

Tabela 6 Fatores de correção para atenuação agrupada por faixa de densidade aparente para as praias estudadas.

Tabela 7 Concentrações de ${ }^{40} \mathrm{~K},{ }^{226} \mathrm{Ra}$ e ${ }^{232} \mathrm{Th}$ encontradas nas areias das praias da Grande Vitória, ES

Tabela 8 Faixas de concentrações de ${ }^{40} \mathrm{~K},{ }^{226} \mathrm{Ra}$ e ${ }^{232} \mathrm{Th}$ nas areias das praias da Grande Vitória (presente trabalho) e valores da literatura................. 41

Tabela 9 Equivalente em rádio e índice de risco para as areias das praias da Grande Vitória.

Tabela 10 Comparativo para a contribuição do equivalente em rádio para o material de construção. 43

Tabela 11 Estimativa de dose em relação à atividade anual realizada. 46 


\section{INTRODUÇÃO}

\subsection{RADIOATIVIDADE NATURAL}

\subsubsection{Radioatividade natural e series naturais.}

A radioatividade natural é a principal fonte de irradiação externa e interna do corpo humano (UNSCEAR $\left.{ }^{3}, 2000\right)$. Grande parte desta radioatividade natural é oriunda de solos e rochas, em cuja constituição encontram-se os radionuclídeos ${ }^{40} \mathrm{~K}$ (meia-vida de $1,27 \times 10^{9}$ anos) que não pertence a uma série natural decaindo para um isótopo estável e os elementos das series naturais do ${ }^{232} \mathrm{Th}$ (meia-vida de $1,4 \times 10^{10} \mathrm{anos}$ ), ${ }^{235} \mathrm{U}$ (meia vida de $7,038 \times 10^{8}$ anos) e ${ }^{238} \mathrm{U}$ (meia-vida de $4,5 \times 10^{9}$ anos) denominados radionuclídeos primordiais que decaem para isótopos estáveis do chumbo (EISENBUD, 1987) formando uma família de decaimento radioativo (FIG.1).

Tais radionuclídeos podem ser encontrados em toda a crosta terrestre, bem como os radionuclídeos formados a partir da interação da radiação cósmica com átomos componentes da atmosfera terrestre como o argônio, oxigênio e nitrogênio, originando radionuclídeos como ${ }^{7} \mathrm{Be},{ }^{10} \mathrm{Be},{ }^{14} \mathrm{C},{ }^{22} \mathrm{Na},{ }^{39} \mathrm{Cl}$ e ${ }^{35} \mathrm{~S}$ (SABOL e WENG, 1995) denominados cosmogênicos, cuja quantidade varia como dependência da latitude e altitude.

A contribuição dos radionuclídeos primordiais é avaliada como sendo de $55,8 \%$ para $\circ{ }^{226} \mathrm{Ra}, 14 \%$ para $\circ{ }^{232} \mathrm{Th}$, e $13,8 \%$ para $\circ{ }^{40} \mathrm{~K}$ e cerca de $15 \%$ para os radionuclídeos de origem cosmogênica para regiões ao nível do mar com radiação natural de fundo não anômala (ISINKAYE e SHITTA, 2009).

A exposição do homem à radiação ocorre por duas formas: irradiação externa devido à emissão gama no processo de decaimento radioativo dos radionuclídeos naturais presentes nos solos, atmosfera, materiais de construção e radiação cósmica e irradiação interna, devido à ingestão ou inalação de radionuclídeos como $0{ }^{222} \mathrm{Rn}$ (meia-vida de 3,8dias) e $0{ }^{220} \mathrm{Rn}$ (meia-vida de 55,6segundos) e seus produtos de decaimento radioativo.(MEDHAT, 2009). 

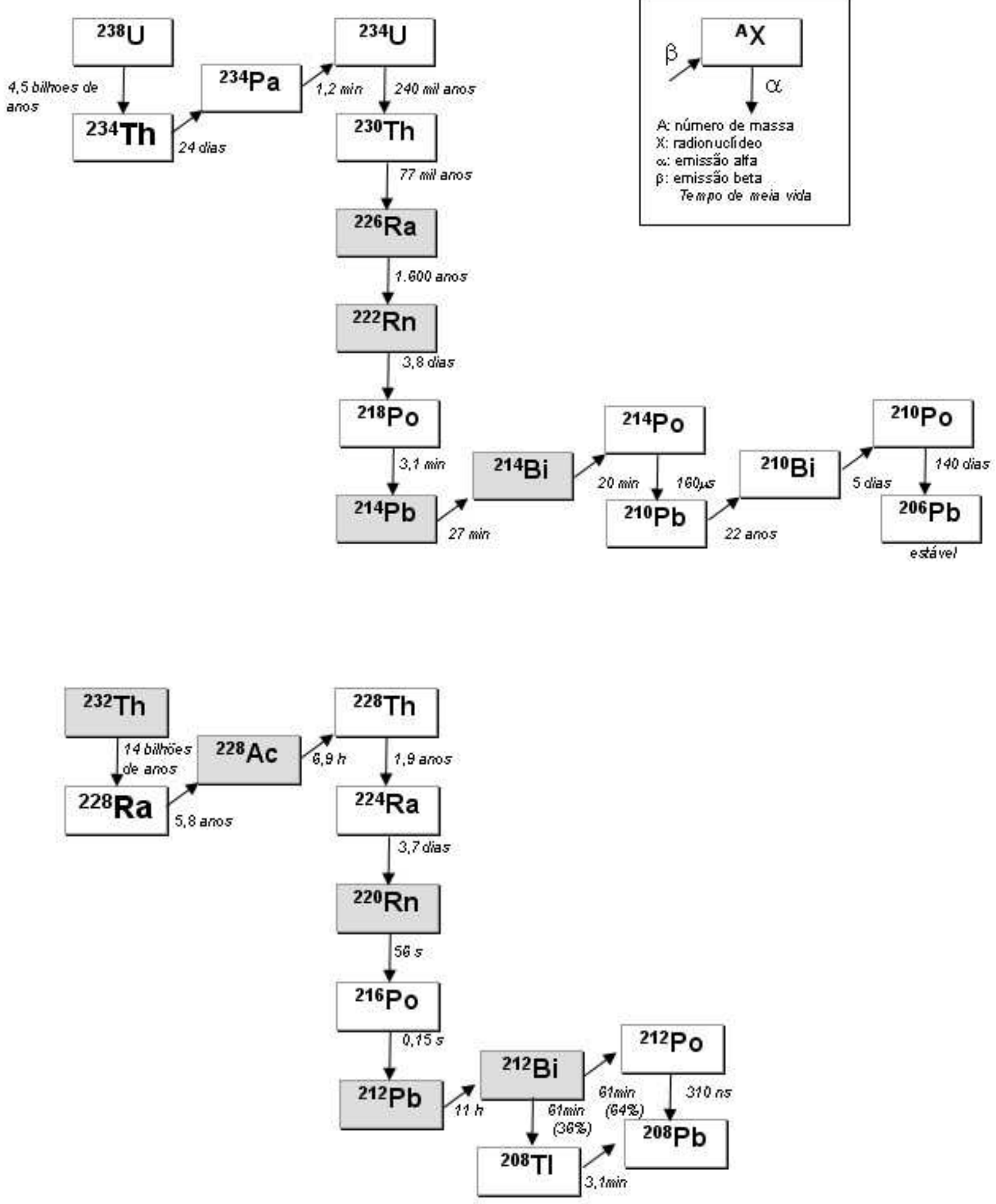

FIGURA 1 - Famílias de decaimento radioativo. Na parte superior a família de decaimento do urânio e abaixo a família de decaimento do tório (NNDC, 2010). 
Algumas das contribuições da radiação de fundo natural para a exposição total, como a do ${ }^{40} \mathrm{~K}$, são constantes no espaço e no tempo e praticamente independentes das atividades e costumes humanos (UNSCEAR ${ }^{1}, 1988$ ). $\mathrm{O}^{238} \mathrm{U}$ representa $99,27 \%$ do urânio natural que é encontrado em toda a crosta terrestre na forma de minérios de urânio e em quantidades traço em todos os tipos de rochas e minerais. O tório é encontrado em diversas rochas e solos com $100 \%$ de ${ }^{232} \mathrm{Th}$. Na maioria das rochas e minerais, a concentração de ${ }^{232} \mathrm{Th}$ está numa faixa entre $7 \mathrm{~Bq} \cdot \mathrm{kg}^{-1}$ e $50 \mathrm{~Bq} \cdot \mathrm{kg}^{-1}$, sendo que as maiores concentrações são encontradas em granitos e gnaisses (STEINHÄUSLER, 1994).

Em algumas regiões do mundo, devido a processos de sedimentação que levam à formação de minerais contendo tório, a concentração de tório nas rochas alcalinas pode ultrapassar $500 \mathrm{~Bq} \cdot \mathrm{kg}^{-1}$. A ocorrência mais importante de membros da série do ${ }^{232}$ Th é a monazita, um mineral de terras raras altamente insolúvel, presente em algumas areias de praias (UNSCEAR $\left.{ }^{2}, 1993\right)$, sendo que o Brasil é considerado como um dos maiores e mais importante depósitos deste material (RIEDEL e EISENMENGER, 1999), com destaque a região de anomalia de concentração de tório no solo do Brasil, os depósitos de areia monazítica localizados no município de Guaraparí (EISENBUD, 1987), porção sul da região metropolitana do Espírito Santo, a Grande Vitória. Com considerável extensão litorânea, as praias da Grande Vitória possuem em sua constituição quantidades expressivas de areias monazíticas ((Ce, La, $\left.\mathrm{Nd}, \mathrm{Th}) \mathrm{PO}_{4}\right)$, ilmeníticas $\left(\mathrm{FeTiO}_{3}\right)$, responsáveis pela elevação da radioatividade de fundo, bem como areias do grupo da sílica $\left(\mathrm{SiO}_{2}\right)$ (MACHADO et al, 2009). 


\subsubsection{Equilíbrio radioativo das séries naturais}

Em uma série natural, o radionuclídeo "pai" se transmuta em outro dando origem a radionuclídeos "filhos" cujo processo é puramente probabilístico (EVANS, 1972).

Quando a meia vida do pai é maior ou muito maior do que a meia vida do radionuclídeo filho, após um período grande de tempo, relacionado com as meias vidas dos radionuclídeos envolvidos, temos o equilíbrio secular ou equilíbrio transitório.

No dado momento em que o equilíbrio radioativo é atingido, é possível afirmar que a concentração de atividade mensurada para os radionuclídeos filhos é igual à atividade do radionuclídeo pai. Para o caso particular da série do ${ }^{238} \mathrm{U}$ (FIG.1, item 1.1.1) a atividade do ${ }^{226} \mathrm{Ra}$ pode ser inferida a partir da atividade do ${ }^{214} \mathrm{~Pb}$ e ${ }^{214} \mathrm{Bi}$ supondo que o ${ }^{222} \mathrm{Rn}$ não escape da amostra. No caso da série No caso do ${ }^{232} \mathrm{Th}$ a quantidade do $232 \mathrm{Th}$ pode ser inferida a partir da atividade do ${ }^{228} \mathrm{Ac}$ e supondo que o ${ }^{220} \mathrm{Rn}$ a partir do ${ }^{212} \mathrm{~Pb}$ e ${ }^{212} \mathrm{Bi}$ (FIG.1, item 1.1.1).

\subsection{Justificativa do trabalho e objetivo}

A região litorânea da Grande Vitória tem como sitio amplamente estudado a Praia da Areia Preta no município de Guaraparí, região conhecida como de anomalia radioativa. Entretanto, em um estudo preliminar, AQUINO e PECEQUILO, (2009), determinaram concentrações em atividade para ${ }^{226} \mathrm{Ra}$ e ${ }^{232} \mathrm{Th}$ em outras localidades da região da Grande Vitória, distantes cerca de $30 \mathrm{~km}$ da localização da Praia da Areia Preta, com destaque para a concentração em ${ }^{226}$ Ra nas areias da Praia de Camburí superiores às determinadas para as areias de Guaraparí. Uma das grandes dificuldades quanto à metodologia de amostragens quando comparadas a sítios próximos ou praias de grande extensão é a relevância da amostragem em diferentes porções ao longo da praia, e não somente em uma localização extrapolada para toda a extensão do sitio em estudo. Em outros trabalhos consultados, por exemplo, MALANCA (1995) e VEIGA (2006) percebe-se a carência na precisão da localização da amostragem, o que pode conduzir a erros de conclusão significativos acerca da avaliação radiométrica. Em um estudo preliminar com amostragens de pontos da Praia 
de Camburí, mostrou-se que a concentração de atividade varia significativamente ao longo da extensão da praia (AQUINO e PECEQUILO, 2009).

Um ponto que motiva este trabalho é a caracterização de localizações não estudadas previamente em outros trabalhos (MALANCA (1995), VEIGA (2006)), mostrando a importância da avaliação dos radionuclídeos que compõem estas areias bem como a correta caracterização da localização de coleta da amostra.

Considera-se também como relevante a influência da exposição da população a estas áreas de anomalia radioativas não estudadas anteriormente, tendo em consideração que a permanência nestas áreas pode conduzir a exposição externa pelo contato com estes radionuclídeos, bem como a exposição interna a partir da inalação do ar nestas áreas de anomalia. Considerando que a quantidade de ${ }^{226} \mathrm{Ra}$ em algumas áreas é relevante, a ingestão ou inalação destes particulados levará ao contato com elementos de radiotoxicidade considerável como os provenientes do decaimento radioativo do ${ }^{226} \mathrm{Ra}$ como o ${ }^{218} \mathrm{Po}$ cuja meia vida é de $3,20 \mathrm{~min}$ e ${ }^{214} \mathrm{Po}$ com meia vida de $164 \mu \mathrm{s}$, ambos alfa emissores que aderem às células do epitélio, decaindo e liberando considerável energia considerada causa de câncer de pulmão (NRC, 1999)

Outro aspecto considerado neste trabalho é a utilização de algumas destas areias em aplicações ilegais como base de materiais de construção de moradias para pessoas que vivem nestas áreas.

Estudos realizados mostram que tal uso pode estar limitado segundo a granulação e sais solúveis que reduzem a durabilidade da aplicação destas areias como base para o concreto, pois aumentam a corrosão das armaduras, alterando o tempo de pega do cimento e a velocidade de endurecimento (PINIWEB, 2000). Os efeitos podem ser minimizados a teores aceitáveis a partir de um processo de dessalinização intrínseca (lavagem) restringindo a granulometria da areia utilizada. Entretanto o estudo não considera os radionuclídeos naturais primordiais existentes nestas areias, dentre eles o nuclídeo filho do decaimento do ${ }^{226} \mathrm{Ra},{ }^{222} \mathrm{Rn}$ (radônio-222) cuja meia vida é de aproximadamente 3,8 dias, tempo suficiente para que se acumule em locais fechados e de pouca ventilação. Sendo um gás nobre, $0{ }^{222} \mathrm{Rn}$ pode se difundir pelas paredes e solo por emanação ou por difusão molecular, chegando às 
vias respiratórias. Para o caso da Grande Vitória, a caracterização adequada destas bases de material de construção poderá levar a um fator limitante para o uso em tal aplicação explicitando a contribuição destes materiais na atividade total da construção, não somente a considerável degradação ambiental causada no processo de extração (FIG.2).

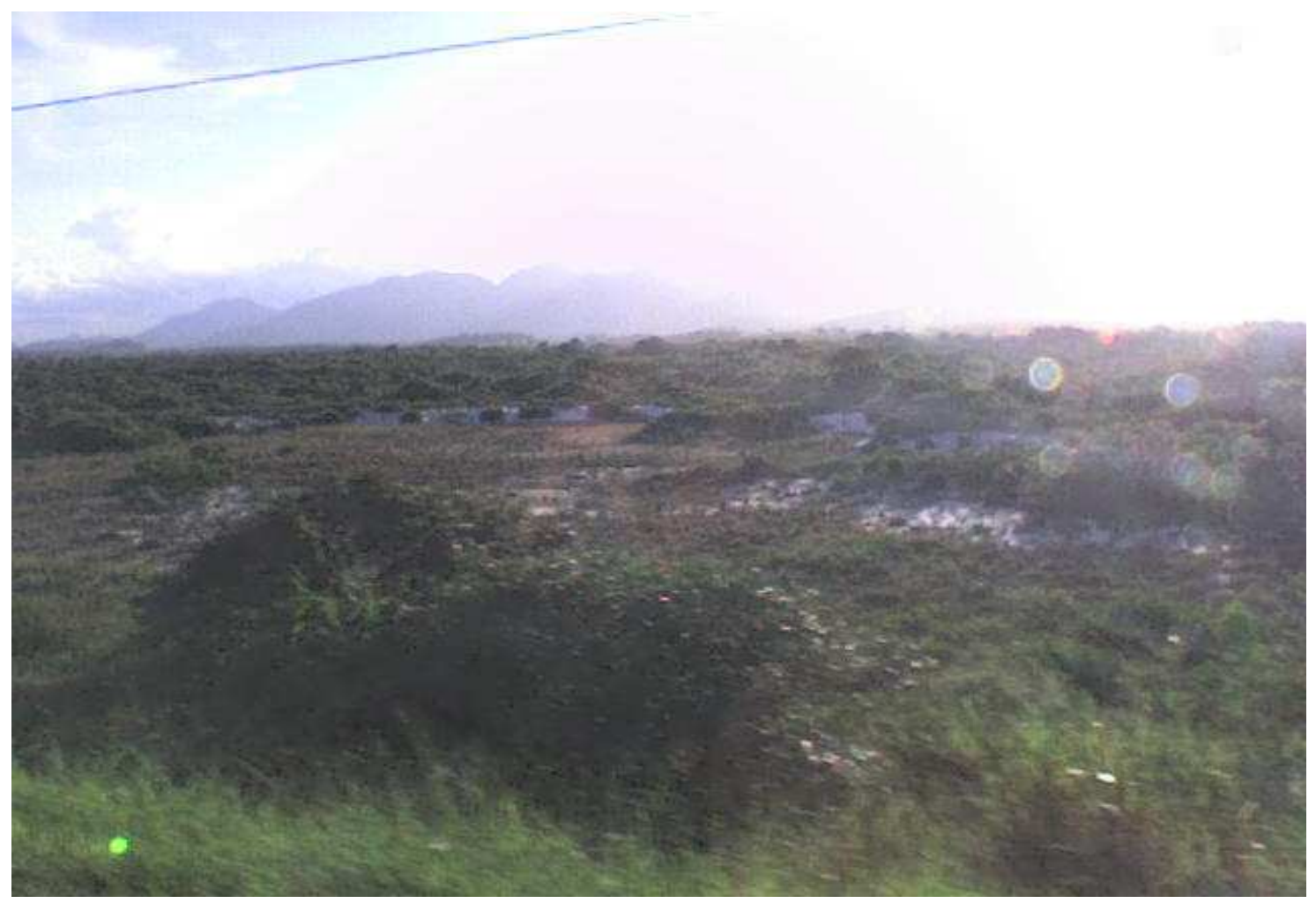

FIGURA 2 - Reserva Paulo Cesar Vinha, Guaraparí, verão de 2007. Extração de areia para construção civil. A imagem mostra um sitio de extração e a degradação ambiental causada no processo. Foto acervo pessoal. 
Considerando a relevância destes fatos para o cotidiano da população este trabalho tratará os seguintes aspectos: O conhecimento da radioatividade existente nestas areias bem como a avaliação do risco para os indivíduos nestas regiões, a determinação das quantidades das concentrações de atividade destes radionuclídeos presentes nas areias da costa da Grande Vitória e a avaliação da contribuição destas areias como possíveis agregados para a concentração de atividade total em materiais de construção e a relação destas quantidades com algumas normas aplicáveis internacionalmente e valores encontrados em literatura. Objetiva-se também estimar por fatores pré-estabelecidos a taxa de exposição em áreas específicas conhecidas como regiões de anomalia radioativa.

\subsection{ASPECTOS GERAIS E LOCALIZAÇÃO DO SÍTIO DE ESTUDO}

\subsubsection{Clima e geografia do Espírito Santo}

Localizado na porção oriental da região sudeste, limitado ao norte pelo Estado da Bahia, ao oeste pelo Estado de Minas Gerais, ao sul pelo Estado do Rio de Janeiro e a leste pelo Oceano Atlântico, encontra-se o Estado do Espírito Santo, abrangendo uma área de $46.077,5 \mathrm{~km}^{2}$ equivalente à fração de $0,54 \%$ do território brasileiro. Sua porção leste apresenta relevo de planície ao longo da costa atlântica, com extensão de $400 \mathrm{~km}$ representando $40 \%$ do seu território e, na porção oeste, avançando para o interior, o relevo passa a ser de planalto dando origem à região serrana atingindo altitudes superiores à 1000m de elevação com destaque para o Pico da Bandeira na Serra do Caparaó com 2.890m de altitude (FIG.3). 


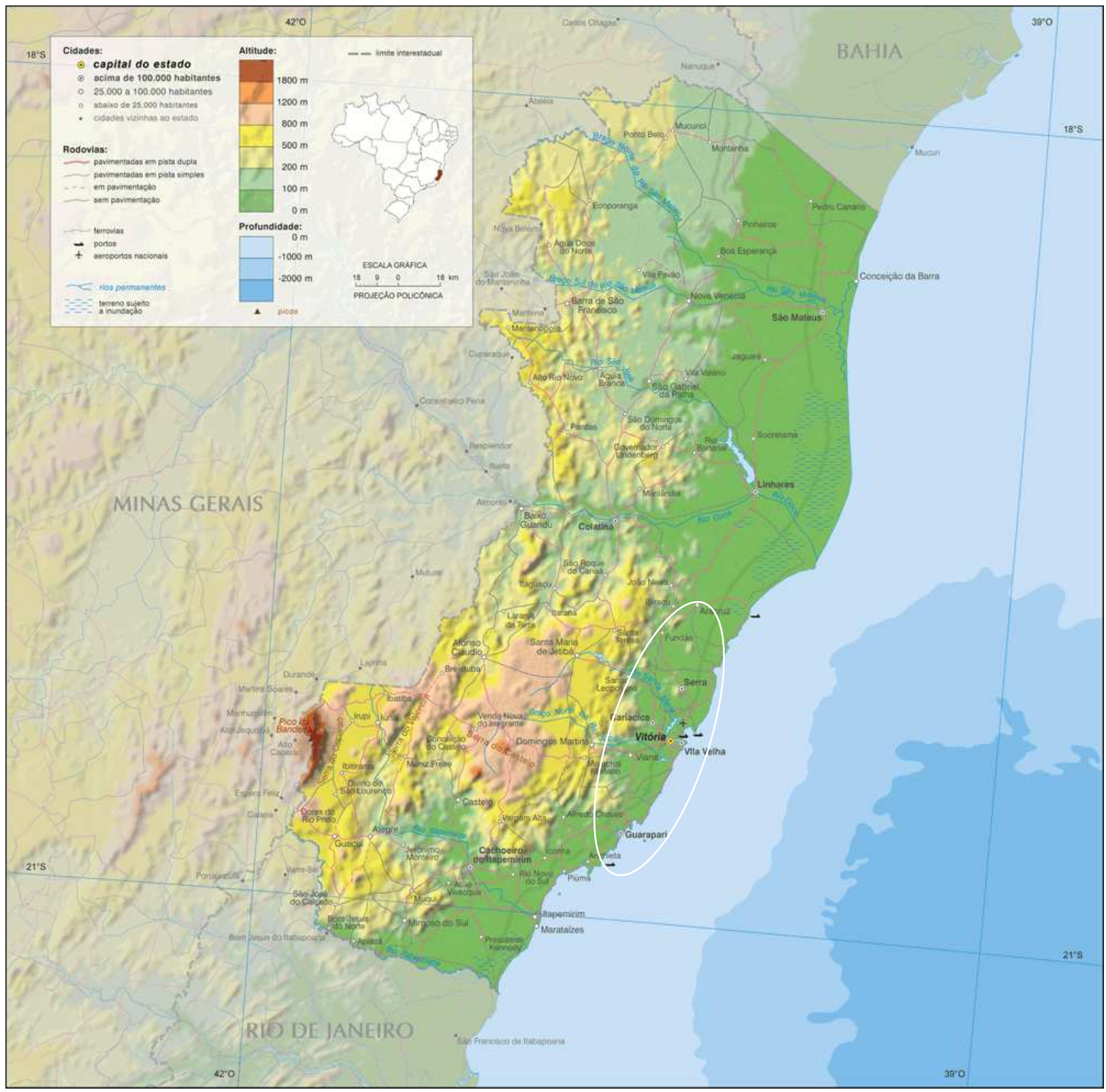

FIGURA 3 - Aspectos gerais do Estado do Espírito Santo. O destaque mostra a região metropolitana da Grande Vitória, ao centro do destaque está localizada a capital Vitória. Ao norte é indicada a foz do Rio Doce e ao sul a foz do rio Itapemirim. IBGE (2007) 


\subsubsection{Aspectos climáticos, geográficos e populacionais da Grande Vitória}

Com um clima tropical úmido, cuja temperatura média anual é de $23^{\circ} \mathrm{C}$, podendo atingir valores superiores a $35^{\circ} \mathrm{C}$ no verão, o litoral do Espírito Santo é visitado constantemente pelo público em geral, com maior concentração nas praias da região metropolitana da Grande Vitória (FIG.4 e TAB.1), situada na porção central do Espírito Santo, na porção de terras quentes, planas e transição chuvoso-seca (EMCAPA/NETUP, 1999).

A área territorial da Grande Vitória é de $2.331,01 \mathrm{~km}^{2}$, sendo constituída pela capital Vitória e dos municípios de Fundão, Serra, Vila Velha, Cariacíca, Viana e Guaraparí. A região metropolitana abriga $46 \%$ da população do Estado, cerca de 1.594.234 habitantes conforme dados do censo de 2010 (IBGE, 2010).

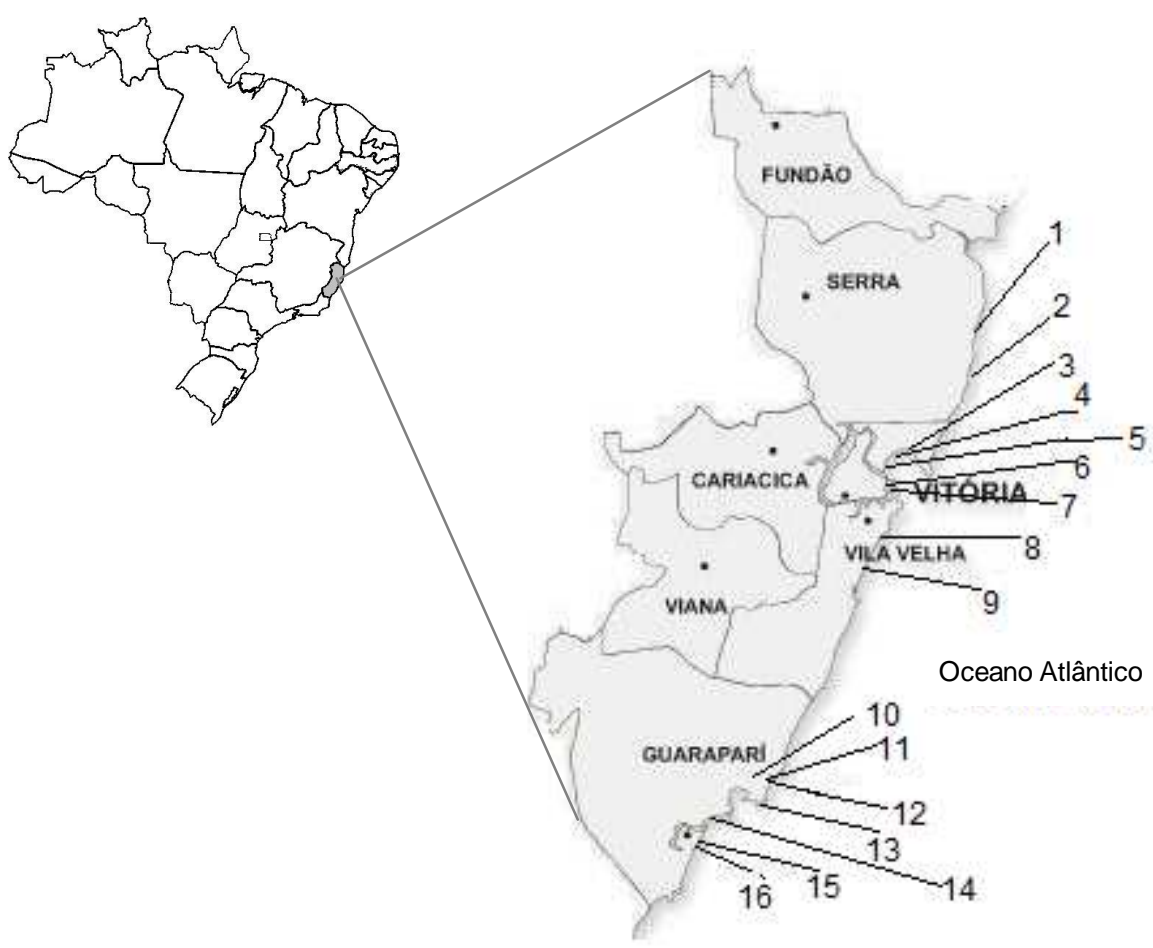

\begin{tabular}{|c|c|c|}
\hline ID & Município & Localidade \\
\hline \multicolumn{3}{|c|}{ Serra } \\
\hline 1 & & Jacaraípe \\
\hline 2 & & Manguinhos \\
\hline \multicolumn{3}{|c|}{ Vitória } \\
\hline 3 & & Camburí Norte \\
\hline 4 & & Camburí Central \\
\hline 5 & & Camburí Sul \\
\hline 6 & & Praia do Canto \\
\hline 7 & & Curva da Jurema \\
\hline \multicolumn{3}{|c|}{ Vila Velha } \\
\hline 8 & & Praia da Costa \\
\hline 9 & & Itapuã \\
\hline \multicolumn{3}{|c|}{ Guaraparí } \\
\hline 10 & & Reserva Asfalto \\
\hline 11 & & Reserva solo \\
\hline 12 & & Setibão \\
\hline 13 & & Setibinha \\
\hline 14 & & Praia do Morro \\
\hline 15 & & Praia das Castanheiras \\
\hline 16 & & Praia da Areia Preta \\
\hline
\end{tabular}

FIGURA 4 - Localização da Região metropolitana da Grande Vitória e localidades de estudo. 


\subsubsection{Outros aspectos relevantes sobre os sítios selecionados}

A concentração para o turismo citada anteriormente (item 1.3.2), principalmente em época de veraneio e alguns períodos ao longo do ano, é para a região metropolitana da Grande Vitória tendo como destaque o litoral sul que recebe o triplo da sua população em turismo durante os meses de novembro até fevereiro (FIG.5).

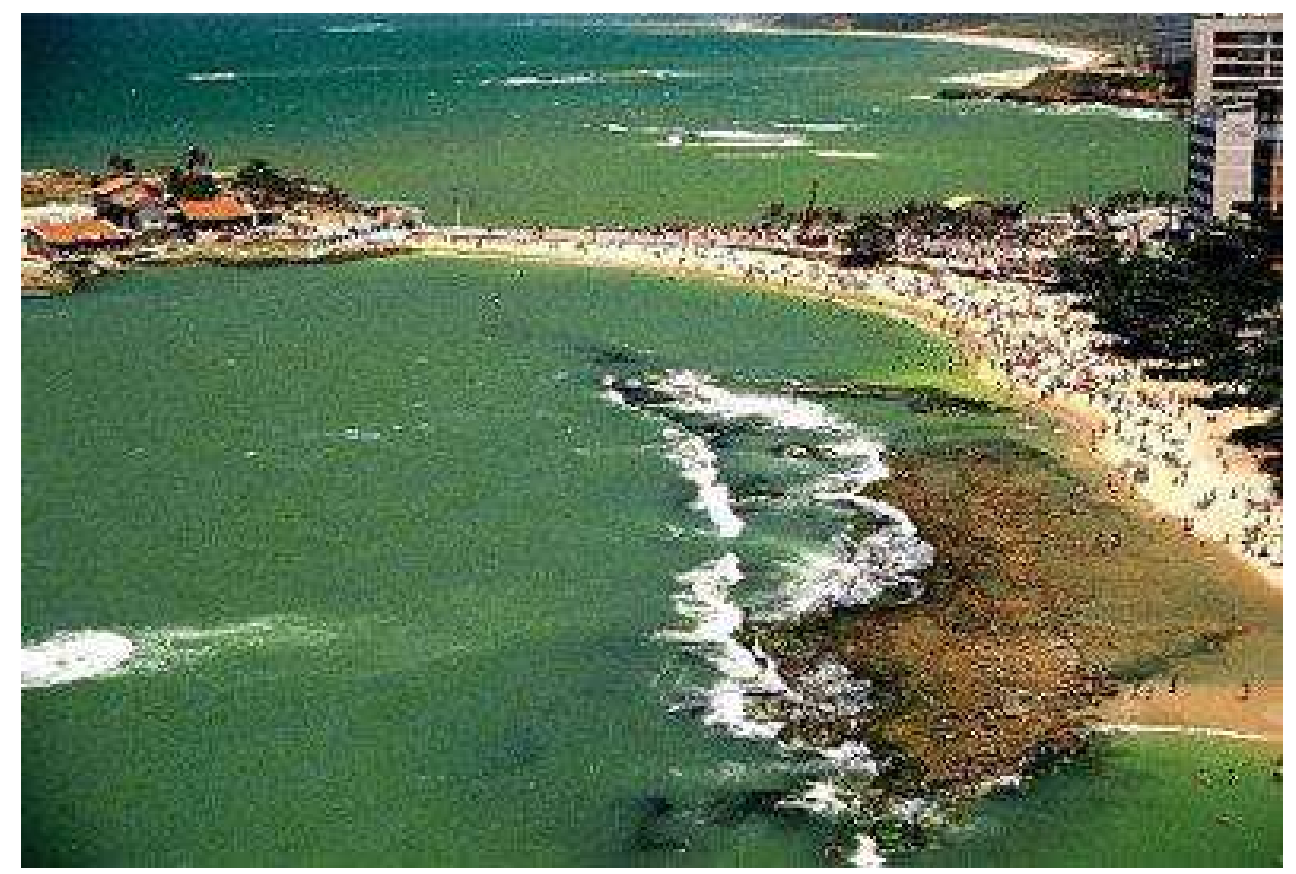

FIGURA 5 - Praia das Castanheiras, Guaraparí. Foto: H. Capai

Os fatores que foram considerados como relevantes para o processo de seleção e coleta das amostras nos sítios de estudo ao longo da orla foram as concentrações humanas para moradia, como o exemplo da Praia de Jacaraípe (FIG.6), onde as construções foram realizadas sobre a areia da praia, os casos onde há concentração humana para fins de trabalho, o que levaria a uma maior exposição a radiação como visto na FIG.7 na praia da Curva da Jurema em Vitória, casos estes de normal ocorrência em toda a orla da Grande Vitória e a variação da tonalidade da areia da região que pode ajudar a caracterizar o tipo mineralógico constituinte. 


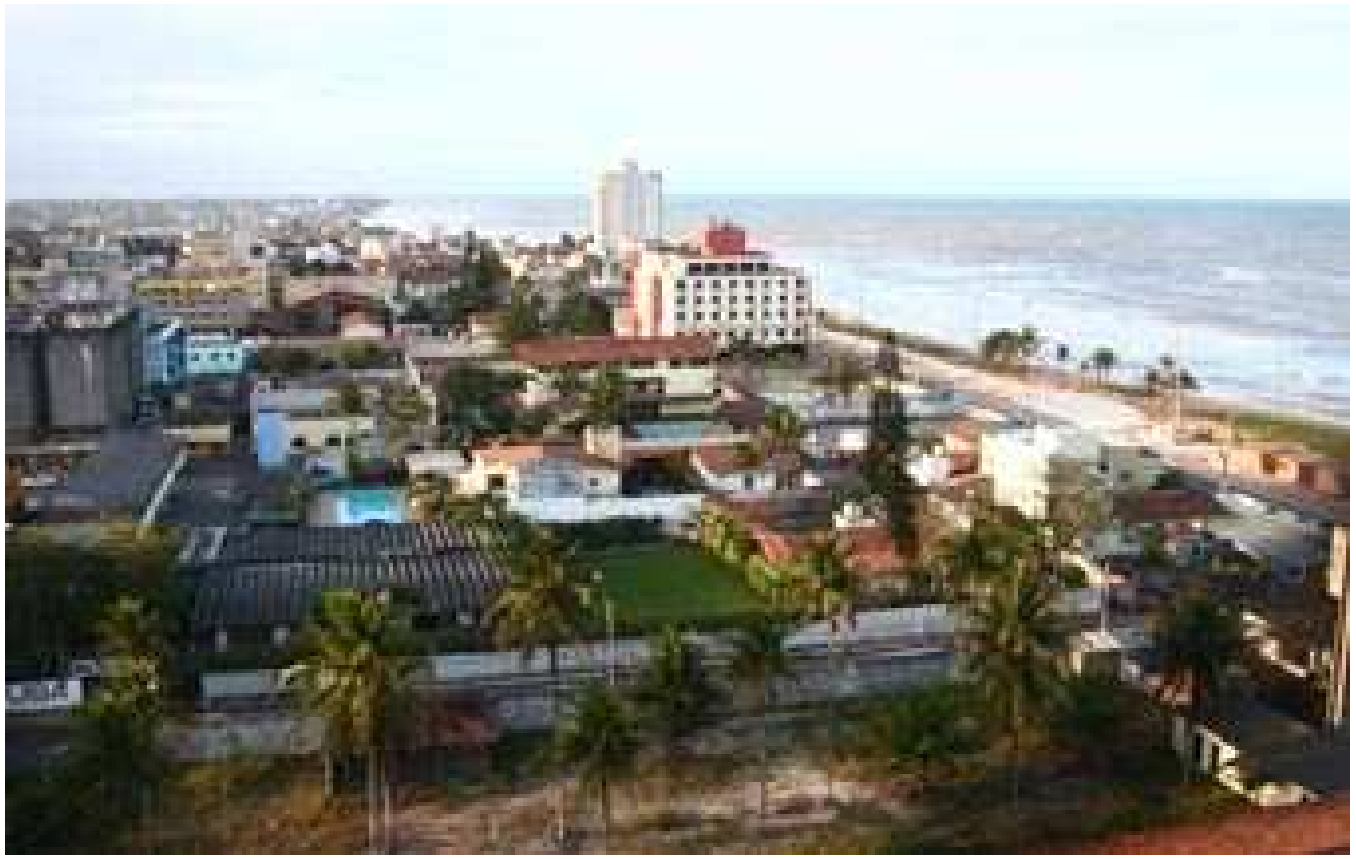

FIGURA 6 - Praia de Jacaraípe, Serra. Foto L. Torres-A Gazeta(26/05/2010)

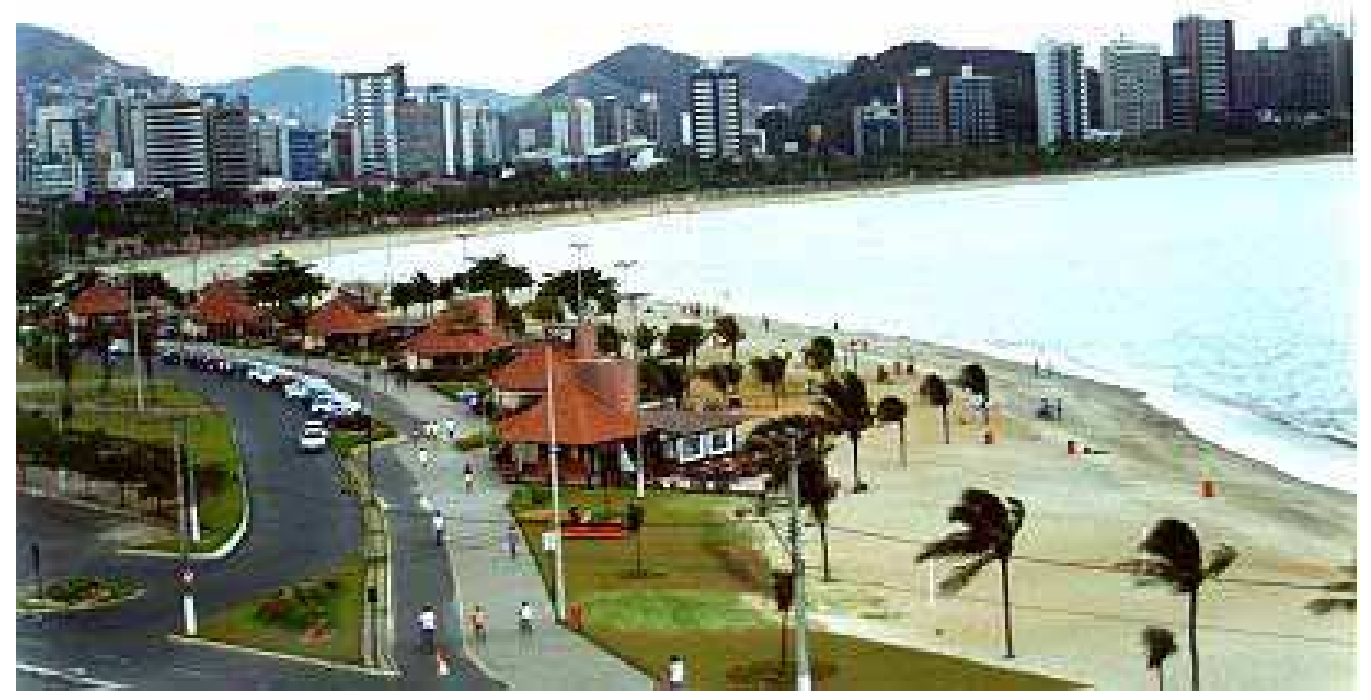

FIGURA 7 - Praia da Curva da Jurema, Vitória. Foto H. Capai 


\section{METODOLOGIA}

\subsection{Amostragem}

A escolha dos pontos teve como critério a concentração humana (item 1.3.3) e a composição mineral definida a partir da observação da variação de tonalidade das areias ao longo da costa da Grande Vitória (item 1.3.2). A variação da tonalidade da areia conduz a intuir sobre a variação na composição mineralógica da areia, pois estes podem diferir consideravelmente em forma e tonalidade(PHILANDER, 2009). Dentre os minerais de interesse estão a monazita, a ilmenita, o rutilo e o zircão (FIG.8), cujas propriedades radioativas são oriundas dos elementos das séries radioativas do urânio $e$ tório e o potássio (ALAM, 1998).

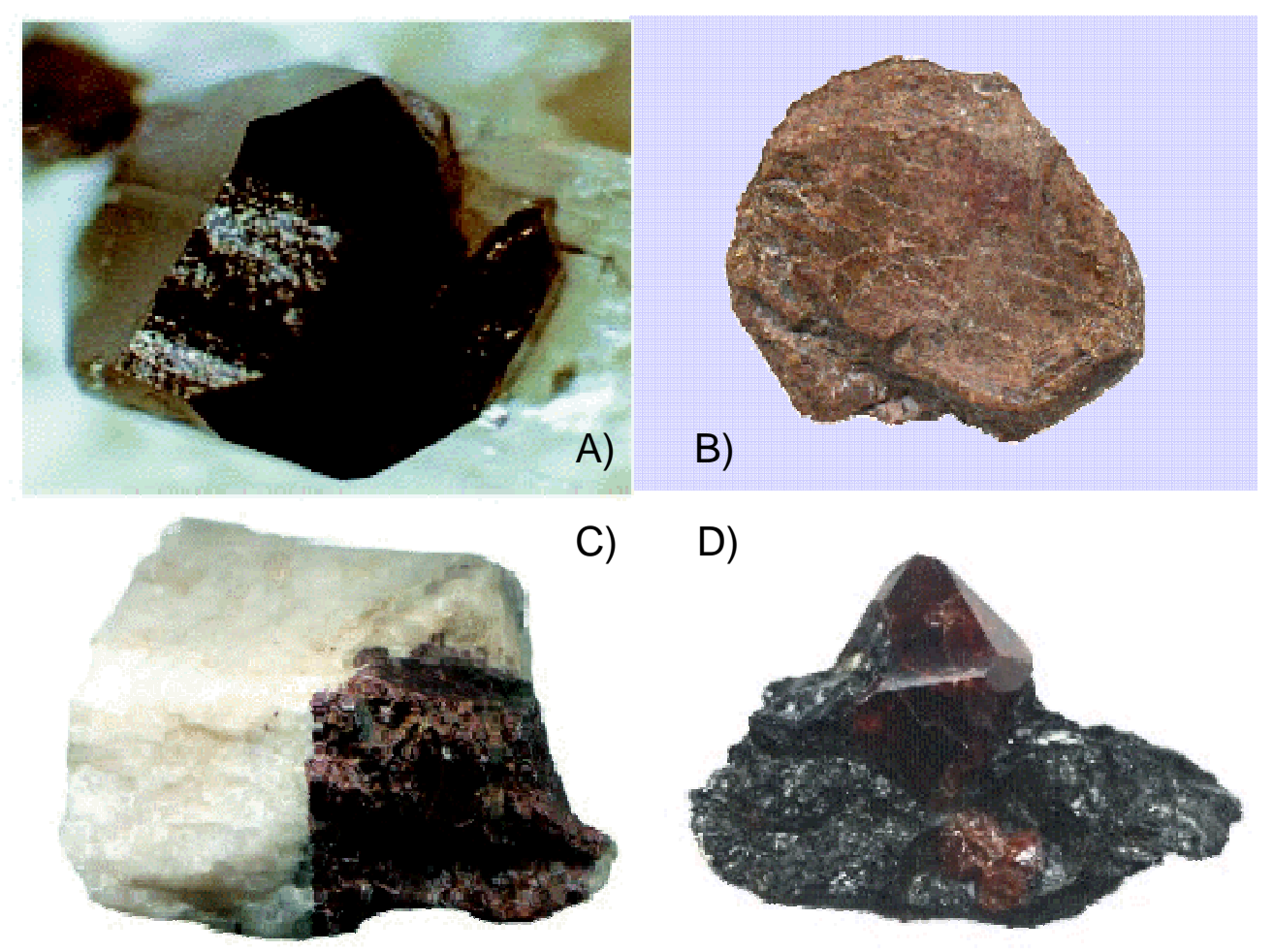

FIGURA 8 - Tipos de minerais encontrados ao longo da costa da Grande Vitória. A)llmenita, B)monazita, C)rutílo em cristal de quartzo, D)zircão. (MACHADO et al, 2009)

O zircão ou silicato de zircônio $\left(\mathrm{ZrSiO}_{4}\right.$ onde: $22 \%$ de $\mathrm{ZrO}_{2}$ e $32,78 \%$ de $\left.\mathrm{SiO}_{2}\right)$, mineral apresentando forma bipiramidal tetragonal, cuja a tonalidade varia do amarelo esverdeado ao marrom, pertencente pertence dos silicato apresenta radioatividade a partir da substituição do átomo de zircônio por tório ou urânio 
(DICKSON, 1997 e ALAM, 1998), podendo também em um grande percentual, ter como elemento associado o háfnio (PHILANDER, 2009).

A monazita ou fosfato de tório, cério, lantânio e neodímio (((Ce, La, Nd, Th), $\mathrm{PO}_{4}$ onde: $\left.16,9 \% \mathrm{La}_{2} \mathrm{O}_{3}, 34,1 \% \mathrm{Ce}_{2} \mathrm{O}_{3}, 5,5 \% \mathrm{ThO}_{2}, 29,5 \% \mathrm{P}_{2} \mathrm{O}_{5}, 14,0 \% \mathrm{Nd}_{2} \mathrm{O}_{3}\right)$ apresenta forma monoclínico prismático cuja tonalidade pode variar entre o marrom escuro e o avermelhado tonalizando a areia em tons dourados (MACHADO et al, 2009) e não em preto como se acredita que seja. A monazita responde por quantidades superiores a 1000 ppm de tório sendo este elemento constituinte deste mineral (DICKSON, 1997).

A ilmenita ou óxido de ferro e titânio $\left(\mathrm{FeTiO}_{2}\right.$ onde: $52,6 \%$ de $\mathrm{Ti}_{2} \mathrm{O}, 47,4 \%$ de $\mathrm{FeO})$ possui forma trigonal romboédrica, com cor preta e brilho submetálico (MACHADO et al, 2009), apresenta quantidades traços de urânio substituinte do titânio (DICKSON, 1997). Uma característica deste mineral é apresentar resposta magnética.

O rutilo ou óxido de titânio $\left(\mathrm{TiO}_{2}\right.$ onde: $60,0 \%$ de $\mathrm{Ti}, 40,0 \%$ de 0$)$ apresenta forma bipiramidal ditetragonal apresentando tonalidades vermelha, marron, azul, amarelo violeta ou preto e brilho metálico(MACHADO et al, 2009). O rutílo assim como a ilmenita apresenta quantidades traços de urânio em substituição ao átomo de titânio(DICKSON, 1997) dentre outros minerais como o K, Ca, Sc, Mn, Rb, Sr, Y, Mo, $\mathrm{Sn}, \mathrm{Sb}, \mathrm{Cs}, \mathrm{Ba}, \mathrm{Hf}, \mathrm{Ta}, \mathrm{W}, \mathrm{Pb}$ em quantidades detectáveis e $\mathrm{V}, \mathrm{Cr}, \mathrm{Fe}, \mathrm{Nb}$ e $\mathrm{Zr}$ em quantidades mais expressivas nas variedades de coloração vermelha e amarela(PHILANDER, 2009).

Observou-se também que as areias estudadas apresentam homogeneidade regular quando a granulação e tonalidade conforme o local de coleta reforçando a formulação que a composição mineral para este local seja a mesma considerando que tais fatores estejam diretamente ligados aos componentes mineralógicos encontrados nas areias onde prevalece o grupo dos silicatos $(\mathrm{SiO})$.

É observável também a presença de minério de ferro ou hematita $\left(\mathrm{Fe}_{2} \mathrm{O}_{3}\right.$ onde: $70,0 \%$ de $\mathrm{Fe}, 30,0 \%$ de O) apresentando forma trigonal romboédrica e coloração vermelho sangue, cinza metálico e preto sendo a principal fonte de ferro (MACHADO et al, 2009), sobre a forma de um pó fino depositado sobre a areia, na região central da 
Grande Vitória, em função de agentes antrópicos ou antropogênicos relacionados a atividades industriais com este minério na região (GAZETAONLINE, 2010), levando a areia a assumir uma tonalidade acinzentada perceptível com maior intensidade na região norte da Praia de Camburí e em outras localidades da grande Vitória. Na porção central e sul da praia de Camburí são notáveis a distribuição dos padrões de manchas cuja suposta causa, por observação, é a concentração de grãos de ilmenita ou minério de ferro.(FIG.9) e (FIG.10).

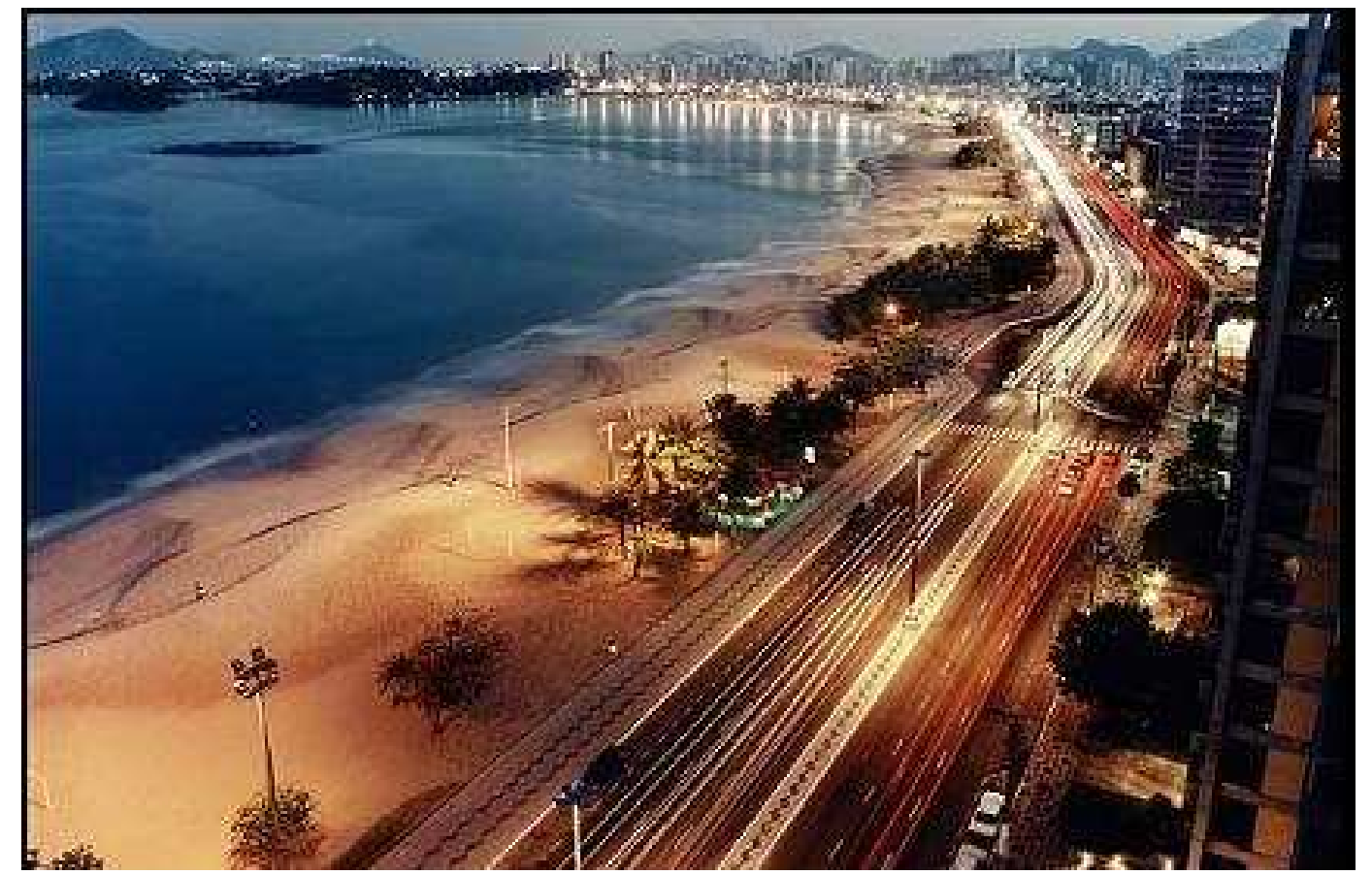

FIGURA 9 - Praia de Camburí central, Vitória. Na areia é visível o padrão de manchas devido à concentração de ilmenita que se estende ao logo da praia. Foto Flávio Santos.

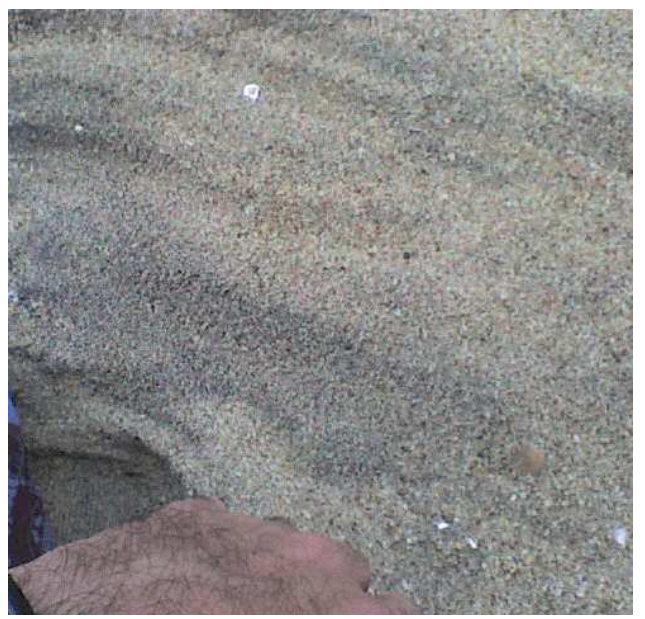

FIGURA 10 - Detalhe do padrão de tonalidade da mancha na areia. Foto acervo pessoal. 


\subsection{Espectrometria gama}

A FIG.11 representa o esquema de detecção e aquisição de dados para o espectrômetro gama de alta resolução.

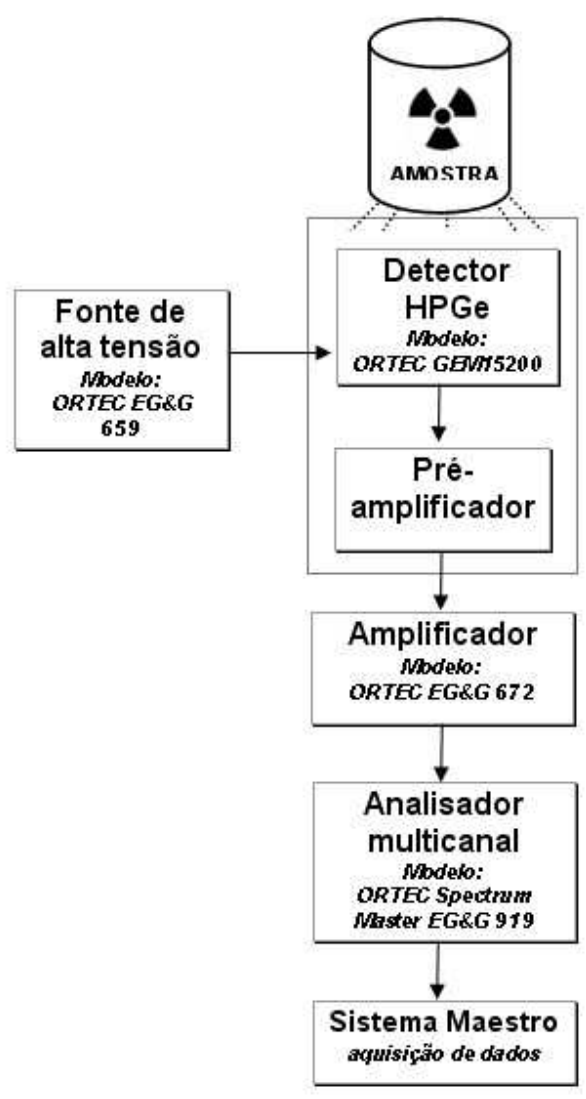

FIGURA 11 - Esquema da montagem convencional do espectrômetro gama utilizado no presente trabalho.

Um pulso elétrico é gerado devido à interação da radiação gama emitida pela fonte radioativa com o cristal do detector. Este pulso é amplificado, analisado e posteriormente armazenado. A altura do pulso gerado possui dependência com a energia do fóton gama incidente no cristal, sendo relacionado com um determinado número de canal pelo analisador multicanal. A localização canal-pico é determinada a partir da altura do centróide do pico fazendo com que a localização da energia em relação ao canal-pico sejam associados por uma curva de calibração do detector. A curva de calibração canal-energia possui dependência com o ajuste do ganho do amplificador de sinal. 
A área total sob o pico é proporcional à atividade da amostra, considerando que há correção por eficiência absoluta do sistema de contagem. A área é determinada por um software que por ajuste de uma curva gaussiana sobre a área do pico determina a contagem no intervalo de canais do espectro gama subtraindo desta a contagem referente à radiação natural de fundo. Desta forma é obtida a área líquida para o pico analisado.

A relação entra a área líquida do pico e a atividade do radionuclídeo é estabelecida a partir da curva de eficiência. Para casos em que os radionuclídeos presentes na amostra possuam tempo de meia vida relativamente curto em relação ao tempo de contagem é necessário realizar a correção considerando o decaimento radioativo da amostra, cuja atividade reduz devido o decaimento radioativo em função do tempo. Para o caso de radionuclídeos no presente trabalho, cuja meia vida é relativamente longa, tal correção não é necessária, pois a atividade pode ser considerada constante no tempo de medida.

\subsection{Fator de correção por atenuação}

A radiação gama é uma onda eletromagnética emitida pelo núcleo excitado do átomo no momento em que este retorna ao seu estado fundamental. Conforme sua energia a radiação gama emitida pode interagir com a matéria por efeito fotoelétrico, efeito Compton e ou produção de pares que ocorrem tanto no detector quanto na própria matéria constituinte da amostra, causando o efeito de auto atenuação gama.

O efeito causado pela atenuação gama devido à interação com a matéria constituinte da amostra é modificado por fatores como composição, densidade, volume entre outros variantes.

No processo de calibração do detector é utilizado um padrão em água deionizada contendo radionuclídeos calibrados (fonte multielemento) e dissolvidos para uma mesma geometria utilizada nas amostras (VENTURINI E NISTI, 1997). Cada amostra estudada apresenta uma densidade específica conforme a sua composição cristalográfica. Considerando que as amostras diferem em sua composição e densidade, este fator de correção deve ser determinado para cada amostra. 
O método consiste em submeter um padrão em água deionizada na mesma geometria das amostras a uma fonte padrão previamente selecionada, contando por um tempo determinado. $\mathrm{O}$ mesmo processo é aplicado às demais amostras sob as mesmas condições.

O fator de correção aplicado é obtido a partir da razão entre o valor contado para a área líquida do pico de transição gama da fonte para o padrão em água e a área líquida para as transições gama da fonte para a amostra. Segundo o modelo descrito pelo método de Cutshall (CUTSHALL et al, 1983), para o fator de correção de atenuação;

$$
\frac{A_{C}}{A}=\frac{\ln \left(\frac{T}{I}\right)}{\frac{T}{I}-1}
$$

Sendo que:

$A_{C}=$ atividade corrigida em Bq. $\mathrm{kg}^{-1}$

$A=$ atividade calculada pelo software em Bq. $\mathrm{kg}^{-1}$

$T$ = área líquida do pico da amostra

$I$ = área líquida do pico do padrão em água.

A expressão 1, em função da concentração de atividade corrigida assume a forma:

$$
A_{C}=\frac{\ln \left(\frac{T}{I}\right)}{\frac{T}{I}-1} \cdot A \therefore A_{C}=f \cdot A
$$

Conduzindo a expressão para o fator de atenuação $f$;

$$
f=\frac{\ln \left(\frac{T}{I}\right)}{\frac{T}{I}-1}
$$

Para a determinação do fator de atenuação foram consideradas as transições gama de maior intensidade das fontes padrão (TAB.2), de tal modo que todas as 
transições gama dos radionuclídeos estudados (TAB.3 item 2.4) estejam dentro dos limites das curvas de atenuação.

TABELA 2 - Transições gama selecionadas para a curva de atenuação.

\begin{tabular}{cccc}
\hline & Energia $\gamma$ & & Intensidade $\gamma$ \\
\cline { 2 - 3 } & {$[\mathrm{keV}]$} & {$[\%]$} \\
\hline${ }^{152} \mathrm{Eu}$ & $121,781(3)$ & 28,70 \\
& $244,956(8)$ & 7,58 \\
${ }^{137} \mathrm{Cs}$ & $344,278(12)$ & 26,60 \\
${ }^{60} \mathrm{Co}$ & $661,657(3)$ & 85,10 \\
& $1173,24(3)$ & 99,85 \\
${ }^{152} \mathrm{Eu}$ & $1332,5(4)$ & 99,98 \\
& $1457,63(11)$ & 0,50 \\
\hline
\end{tabular}

* Valores de referência da base de dados NNDC (1996-2003).

** Valores entre parênteses correspondem à incerteza.

Os valores obtidos para a correção por atenuação são aplicados a cada transição gama utilizada para determinação da concentração de atividade. A partir destas correções é traçada uma curva para o fator de atenuação em função da energia.

$$
f(E)=C_{1} \cdot E^{-C_{2}}
$$

Sendo que:

$$
\begin{aligned}
& f(E)=\text { atividade corrigida em Bq.kg-1 } \\
& C_{1}, C_{2}=\text { são constantes ajustadas pelo software } \\
& E \quad=\text { energia referente à transição gama a ser ajustada }
\end{aligned}
$$


A função correspondente à curva traçada fornece os valores para o fator de atenuação para as energias das transições gama do radionuclídeo em estudo. O fator de correção assume valores maiores para energias menores e tende para um valor unitário para energias maiores correspondendo a teoria da interação gama como a matéria.

\subsection{Cálculo da concentração de atividade do radionuclídeo}

A concentração de atividade de um dado radionuclídeo é obtida a partir de um pico de absorção total correspondente a uma determinada transição gama $E \gamma$ a partir da expressão (5) pelo software WinnerGamma (ORTEC, 2004).

$$
A=\frac{C}{\varepsilon_{\gamma} \cdot I_{\gamma} \cdot t_{u} \cdot m}
$$

Sendo que:

$A=$ Concentração de atividade em Bq. $\mathrm{kg}^{-1}$

$C=$ Área líquida do pico de absorção total

$\varepsilon_{\gamma}=$ Eficiência de detecção para a transição gama considerada

$I_{\gamma}=$ Probabilidade de emissão do fóton gama por desintegração.

$t_{u}=$ Intervalo de tempo útil de medida (do inglês "live time") em segundos.

$m$ = Massa da amostra em [kg].

Devido à meia vida longa dos radionuclídeos estudados (FIG.1), não é feita a correção por decaimento radioativo da amostra durante a medida. 
A incerteza associada $\sigma_{A}$ é determinada a partir da incerteza expandida, conforme a expressão 6;

$$
\sigma_{A}=A \cdot \sqrt{\left[\frac{\sigma_{C}}{C}\right]^{2}+\left[\frac{\sigma_{\varepsilon_{\gamma}}}{\varepsilon_{\gamma}}\right]^{2}+\left[\frac{\sigma_{I_{\gamma}}}{I_{\gamma}}\right]^{2}+\left[\frac{\sigma_{t u}}{t_{u}}\right]^{2}+\left[\frac{\sigma_{m}}{m}\right]^{2}}
$$

Onde cada $\sigma_{x}$ corresponde respectivamente às incertezas para cada termo especificado na expressão (5).

Os valores para a concentração de atividade dos radionuclídeos, bem como a incerteza associada à medida foram calculados a partir das expressões (5) e (6) e fornecidos pelo software WinnerGamma 6 para posterior processo de importação de dados para uma planilha onde serão analisados em separado ao programa, corrigindo os resultados para atenuação dos fatores nas próprias amostras (item 2.3).

Para casos em que a concentração de atividade fornecida para um determinado radionuclídeo possua mais de uma transição gama detectável, o valor da atividade para o radionuclídeo é uma média ponderada considerando a atividade de cada uma das transições consideradas, ponderada pelo inverso da variância desta atividade segundo a expressão 7;

$$
\bar{A}=\frac{\sum_{i} \frac{A_{i}}{\sigma_{i}^{2}}}{\sum_{i} \frac{1}{\sigma_{i}^{2}}}
$$

Sendo que:

$\bar{A}=$ Concentração média ponderada para a atividade do radionuclídeo, em $\left[\mathrm{Bq} \cdot \mathrm{kg}^{-1}\right]$.

$A_{i}=$ Concentração de atividade em $\left[\mathrm{Bq} \cdot \mathrm{kg}^{-1}\right]$ para a transição gama $i$ detectável.

$\sigma_{i}=$ Incerteza associada à concentração de atividade em [Bq.kg $\left.{ }^{-1}\right]$. 
Com a incerteza associada;

$$
\sigma_{A}=\frac{1}{\sqrt{\sum_{i} \frac{1}{\sigma_{i}^{2}}}}
$$

Considerando o equilíbrio radioativo (EVANS, 1972), a concentração de atividade de ${ }^{232}$ Th foi determinada a partir da concentração média ponderada dos radionuclídeos ${ }^{228} \mathrm{Ac},{ }^{212} \mathrm{~Pb}$ e ${ }^{212} \mathrm{Bi}$ e a concentração de ${ }^{226} \mathrm{Ra}$ foi determinada a partir da concentração média ponderada dos radionuclídeos ${ }^{214} \mathrm{~Pb}$ e ${ }^{214} \mathrm{Bi}$. A concentração de ${ }^{40} \mathrm{~K}$ é determinada diretamente a partir da área da transição gama única. Para cada radionuclídeo foram consideradas as transições gama de maior intensidade detectável conforme exposto na TAB.3.

TABELA 3: Transições gama utilizadas para a determinação da concentração de radionuclídeos

\begin{tabular}{|c|c|c|c|}
\hline Radionuclídeo & $\begin{array}{c}\text { Radionuclídeos utilizados } \\
\text { para a determinação da } \\
\text { atividade. }\end{array}$ & $\begin{array}{c}\text { Transição gama Energia } \\
\qquad(\mathrm{keV})\end{array}$ & $\begin{array}{l}\text { Transição gama } \\
\text { Intensidade (\%) }\end{array}$ \\
\hline \multirow{3}{*}{$\begin{array}{c}{ }^{226} \mathrm{Ra} \\
\text { (“Pai”) } \\
\text { (Série }{ }^{238} \mathrm{U} \text { ) }\end{array}$} & ${ }^{214} \mathrm{~Pb}$ ("Filho") & 295,21 & 18,7 \\
\hline & & 351,92 & 35,8 \\
\hline & ${ }^{214} \mathrm{Bi}$ ("Filho") & 609,32 & 45 \\
\hline \multirow{5}{*}{$\begin{array}{c}{ }^{232} \mathrm{Th} \\
\text { (“'Pai”') } \\
\text { (Série }{ }^{232} \mathrm{Th} \text { ) }\end{array}$} & ${ }^{212} \mathrm{~Pb}$ ("Filho") & 238,63 & 43,5 \\
\hline & & 300,09 & 3,25 \\
\hline & ${ }^{212} \mathrm{Bi}$ (“Filho") & 727,33 & 6,6 \\
\hline & ${ }^{228}$ Ac ("Filho") & 911,07 & 27,8 \\
\hline & & 968,90 & 16,7 \\
\hline${ }^{40} \mathrm{~K}$ & ${ }^{40} \mathrm{~K}$ & 1460,83 & 10,7 \\
\hline
\end{tabular}

(ORTEC, 2004) 
A atividade mínima detectável ou AMD corresponde ao menor valor de concentração de atividade que a amostra deve conter para que uma medida permita a detecção de um determinado radionuclídeo seja possível a partir dos métodos analíticos adotados. $O$ valor da quantidade AMD para um determinado radionuclídeo corresponde é fornecido pela expressão (9) pelo software WinnerGamma(ORTEC, 2004);

$$
A M D_{i}=\frac{4,66 \cdot \sqrt{B_{i}}}{\varepsilon_{\gamma} \cdot I_{\gamma} \cdot t_{u}}
$$

Sendo que:

$A M D=$ Concentração de atividade mínima detectável para a atividade do radionuclídeo, em [Bq.kg $\left.{ }^{-1}\right]$.

$B_{i}=$ Área das contagens correspondente a radiação de fundo na região da transição gama $i$.

$\varepsilon_{\gamma}=$ Eficiência de detecção para a transição gama considerada

$I_{\gamma}=$ Probabilidade de emissão do fóton gama por desintegração.

$t_{u}=$ Intervalo de tempo útil de medida (do inglês "live time") em segundos. 


\subsection{Equivalente em radio}

Para representar as atividades de ${ }^{226} \mathrm{Ra},{ }^{232} \mathrm{Th}$ e ${ }^{40} \mathrm{~K}$ por uma grandeza única que leva em consideração o risco por radiação, foi introduzido um índice comum em Bq. $\mathrm{kg}^{-1}$ denominado equivalente em rádio (BERETKA e MATHEW, 1985). Este índice é um guia útil na avaliação das normas de segurança de proteção radiológica para os indivíduos do público que residem nas construções.

A atividade equivalente em rádio é a soma ponderada das concentrações dos três radionuclídeos ${ }^{226} \mathrm{Ra},{ }^{232} \mathrm{Th}$ e ${ }^{40} \mathrm{~K}$ e supõe que $370 \mathrm{~Bq} \cdot \mathrm{kg}^{-1}$ de ${ }^{226} \mathrm{Ra}, 259 \mathrm{~Bq} \cdot \mathrm{kg}^{-1}$ de ${ }^{232} \mathrm{Th}$ e $4810 \mathrm{~Bq} \cdot \mathrm{kg}^{-1}$ de ${ }^{40} \mathrm{~K}$ produzam a mesma taxa de dose de radiação gama. O equivalente em rádio é determinado pela expressão (MEDHAT, 2009);

$$
R a_{e q}=370\left(\frac{A_{R a}}{370}+\frac{A_{T h}}{259}+\frac{A_{K}}{4810}\right)
$$

Onde $A_{R a}, A_{T h} \mathrm{e} A_{K}$ representam as concentrações de atividades para $0{ }^{226} \mathrm{Ra}$, ${ }^{232} \mathrm{Th}$ e ${ }^{40} \mathrm{~K}$ respectivamente. É recomendado para o uso seguro em material de construção que o valor do equivalente em rádio não exceda o limite de $370 \mathrm{~Bq} \cdot \mathrm{kg}^{-1}$ (OECD, 1979). Outros valores de referência estão dispostos na TAB.4.

TABELA 4 - Limites para o equivalente em rádio recomendados para materiais de construção.

\begin{tabular}{|c|c|c|}
\hline $\begin{array}{c}\text { Equivalente em rádio } \\
\text { Bq. } \mathrm{kg}^{-1}\end{array}$ & Classe & Aplicação possível \\
\hline$<370$ & 1 & Residencial \\
\hline $370-740$ & 2 & Industrial \\
\hline $740-2220$ & 3 & Estradas e pontes \\
\hline $2220-3700$ & 4 & Fundação ou não residencial \\
\hline$>3700$ & 5 & Sem aplicação possível \\
\hline
\end{tabular}

* (HASSAN, 2010) e (ADEMOLA, 2008) 


\section{6 Índice de risco a exposição gama externa e interna}

Segundo a ICRP (1977), o limite de dose para materiais de construção é de $1,5 \mathrm{mSv} \cdot \mathrm{a}^{-1}$. Para avaliar por um índice que limite a este fator, KRIEGER (KRIEGER apud HASSAN 2010) propõe um modelo conservativo baseado em um quarto com paredes infinitamente finas isento de janelas e portas como critério para formular o índice de risco a exposição gama externo $H_{\mathrm{ex}}$, definido pela expressão 11 (HASSAN, 2010);

$$
H_{e x}=\frac{A_{R a}}{370}+\frac{A_{T h}}{259}+\frac{A_{K}}{4810} \leq 1
$$

onde $A_{R a}, A_{T h}$ e $A_{K}$ correspondem às concentrações de atividades em Bq.kg ${ }^{-1}$ para o ${ }^{226} \mathrm{Ra},{ }^{232} \mathrm{Th}$ e ${ }^{40} \mathrm{~K}$ respectivamente. O resultado da expressão remete a um valor adimensional que deve ser menor ou igual a 1 para que tenhamos a dose aproximada de $1,5 \mathrm{mSv} \cdot \mathrm{a}^{-1}$.

É definido também um índice de risco para exposição gama interna $H_{i n}$, que considera o radônio e seus produtos de decaimento de meia vida curta e o risco da inalação destes por acúmulo nos ambientes. $O$ índice $H_{\text {in }}$ é calculado a pela expressão 12 (UNSCEAR ${ }^{1}, 1988$ );

$$
H_{\text {in }}=\frac{A_{R a}}{185}+\frac{A_{T h}}{259}+\frac{A_{K}}{4810} \leq 1
$$

onde $A_{R a}, A_{T h}$ e $A_{K}$ correspondem às concentrações de atividades em Bq.kg ${ }^{-1}$ para $0{ }^{226} \mathrm{Ra},{ }^{232} \mathrm{Th}$ e ${ }^{40} \mathrm{~K}$ respectivamente. Para a aplicação segura este índice deve ser menor ou igual a 1. 


\subsection{Estimativa da taxa de dose absorvida no ar}

A estimativa de taxa de dose absorvida em nGy. $\mathrm{h}^{-1}$ é definida pela dose absorvida no ar a $1 \mathrm{~m}$ do solo considerando a exposição gama emitida pelos radionuclídeos naturais ${ }^{226} \mathrm{Ra},{ }^{232} \mathrm{Th}$ e ${ }^{40} \mathrm{~K}$ (SOWMYA, 2010) como sendo;

$$
D=0,462 A_{R a}+0,604 A_{T h}+0,0417 A_{K}
$$

onde $\mathrm{D}$ é a dose definida em nGy.h ${ }^{-1}$ e, $A_{R a}, A_{T h}$ e $A_{K}$ correspondem às concentrações de atividades em Bq. $\mathrm{kg}^{-1}$ para $0{ }^{226} \mathrm{Ra},{ }^{232} \mathrm{Th}$ e ${ }^{40} \mathrm{~K}$ respectivamente.

A estimativa de dose efetiva anual considerando o tempo diário em horas de exposição à radioatividade destes materiais é dada pela expressão;

$$
E=D\left[n G y \cdot h^{-1}\right] \times \operatorname{Exp}\left[h \cdot a^{-1}\right] \times 0,7\left[S v G y^{-1}\right] \times 10^{-6}
$$

Sendo que:

$E=$ Dose efetiva anual em mSv. $\mathrm{a}^{-1}$

$D=$ Dose estimada em nGy. $\mathrm{h}^{-1}$

Exp $=$ Número de horas de exposição por ano, $24 h \times$ Dias $\times F t$, onde Ft corresponde à fração de tempo do dia relacionado com a atividade realizada.

$0,7=$ Fator de conversão Sv.Gy ${ }^{-1}$ para a dose absorvida no ar

O valor anual recomendado para a dose estimada não deve exceder $1 \mathrm{mSv} \cdot \mathrm{a}^{-1}$. Expostos na (TAB.5) estão os fatores determinados para cada modelo de estimativa.

TABELA 5 - Tempo anual para estimativa de dose, considerando a atividade realizada durante o dia

Modelo de atividade Tempo de atividade anual

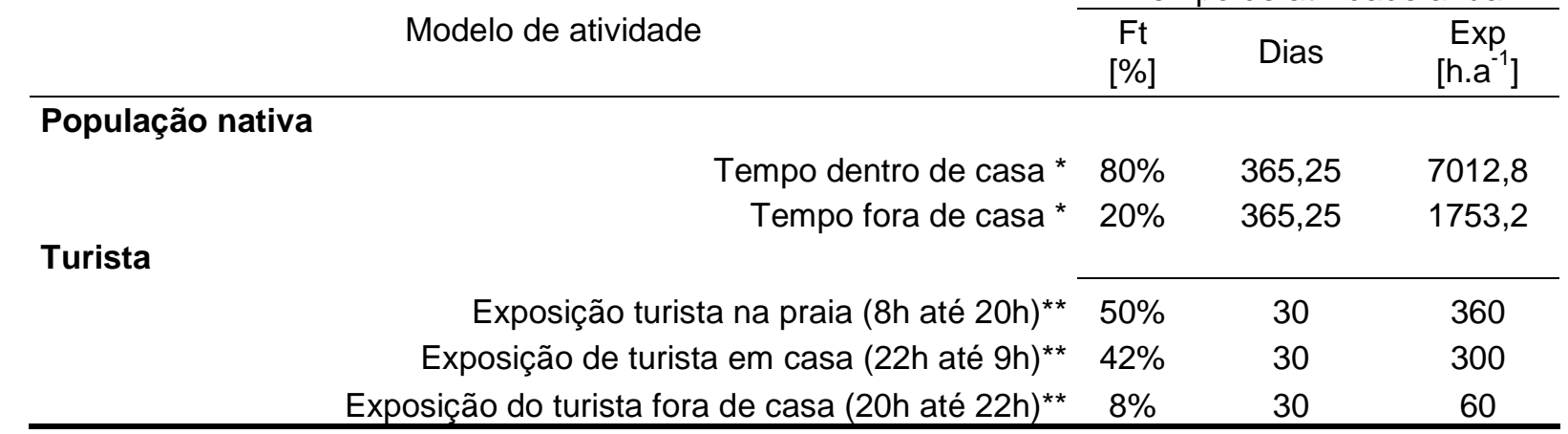

${ }^{*}\left(\mathrm{UNSCEAR}^{3}, 2000\right)$

** Avaliação pessoal baseada em informações de habitantes locais. 


\section{PARTE EXPERIMENTAL}

\subsection{Coleta e preparo das amostras}

Foi coletado para cada localidade cerca de $1 \mathrm{~kg}$ de areia considerado como padrão para a amostragem. As amostras coletadas destas areias superficiais foram realizadas em época de verão considerando que ao longo do ano ocorrem variações sazonais (MOURA 2003), com uma profundidade de cerca de $2 \mathrm{~cm}$ equivalendo à profundidade média de uma pessoa sentada na areia da praia e considerando uma distância de $3 \mathrm{~m}$ da linha d'água que em geral é a região de maior concentração e permanência humana.

Os agregados não desejados foram removidos manualmente em laboratório (conchas, resto de alimentos, madeira, entre outros) por um processo simples de cata. Posteriormente, as amostras foram submetidas a um processo de secagem em estufa a temperatura constante de $80^{\circ}$ por $24 \mathrm{~h}$ (FIG.12).

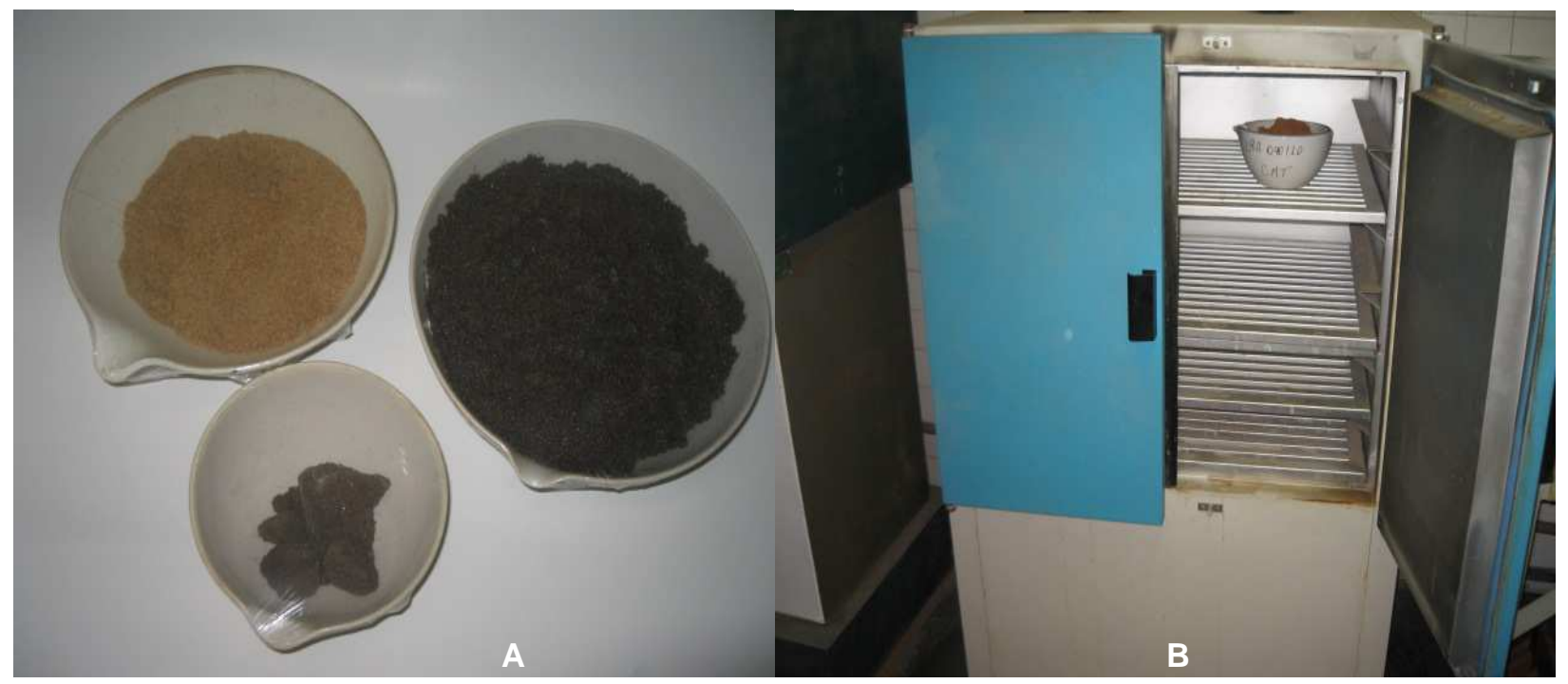

FIGURA 12 - Amostra preparada para contagem. Em À, almofariz com amostras. Em B, estufa com amostra. Foto acervo nessoal.

Após o procedimento de desumidificação, as amostras foram acondicionadas em triplicata em frascos padrão de polietileno de 100mL - F100 (FIG.13) que não apresenta porosidade par a gás ${ }^{222} \mathrm{Rn}$ e ${ }^{220} \mathrm{Rn}$. Em seguida a massa das amostras foi mensurada em uma balança semi-analítica modelo GEHAKA BK3000 sendo posteriormente 
selados com fita de PVC e armazenados por aproximadamente quatro semanas para posterior contagem no detector gama. O procedimento garante que o gás ${ }^{222} \mathrm{Rn}$ e ${ }^{220} \mathrm{Rn}$ estejam contidos no frasco F100, garantindo assim que seja obtido o equilíbrio radioativo para as séries do ${ }^{238} \mathrm{U}$ e ${ }^{232} \mathrm{Th}$ (EVANS, 1972).

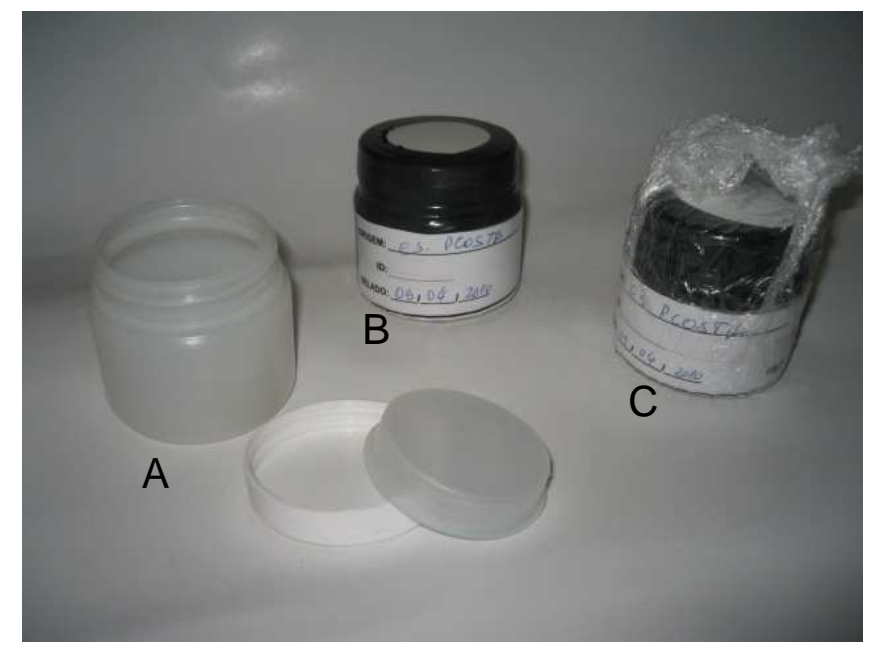

FIGURA 13 - Frascos padrão de polietileno, F100. Em "A" tampa e batoque de 52,5mm, em "B" amostra selada com fita PVC e em "C" amostra revestida com filme PVC para evitar contaminação do detector. Foto acervo pessoal 


\subsection{Espectrômetro gama e contagem das amostras}

A FIG.14 mostra o detector HPGe dentro da blindagem de chumbo e a FIG.15 mostra a amostra colocada sobre o cristal do detector. As FIG.16 e 17 mostram a eletrônica associada ao detector HPGe.

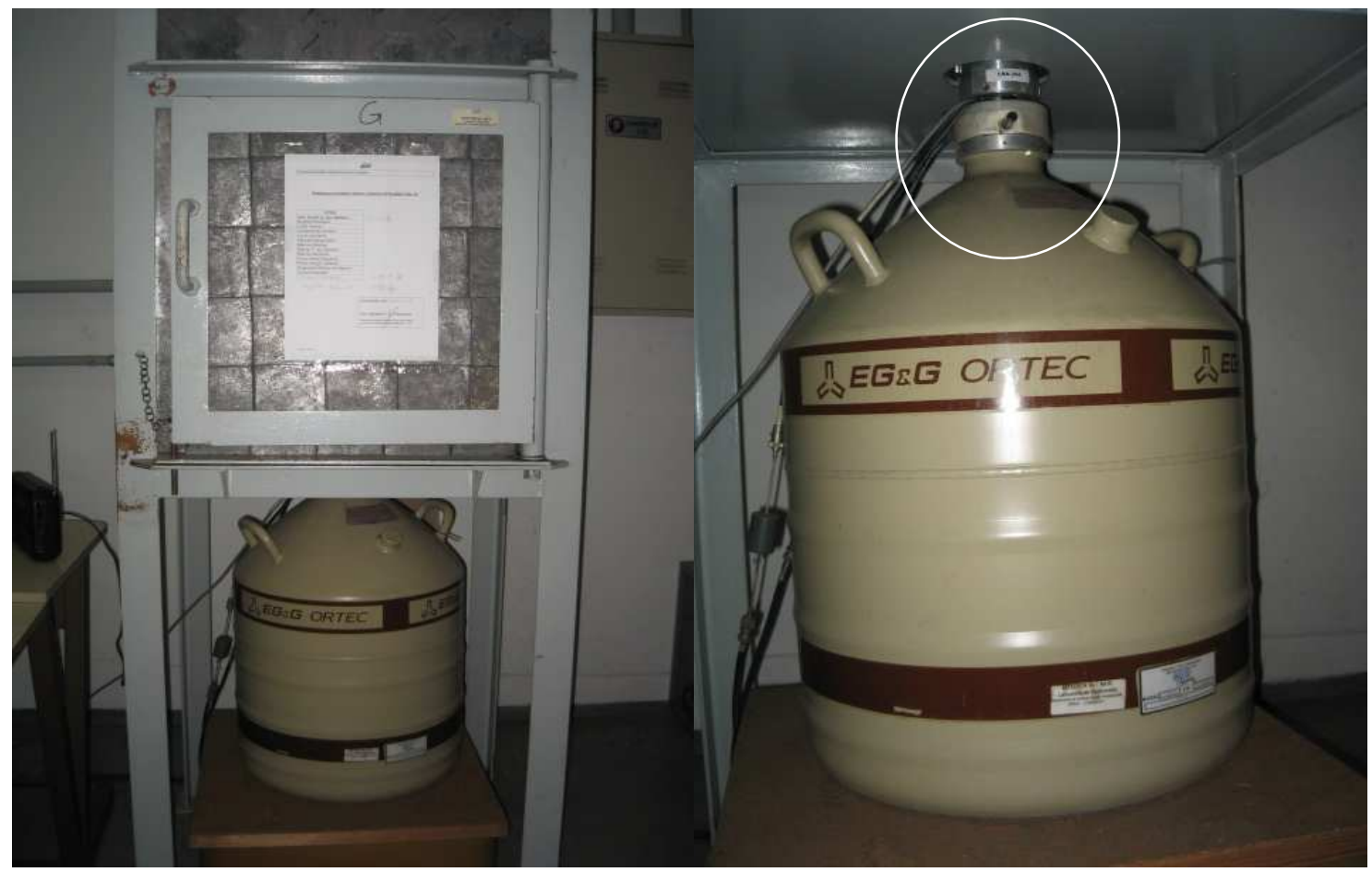

FIGURA 14 - Parte inferior da blindagem convencional de chumbo destacando parte do detector (modelo GEM15200) e o dewar (modelo DWR-30) de resfriamento. Foto acervo pessoal.

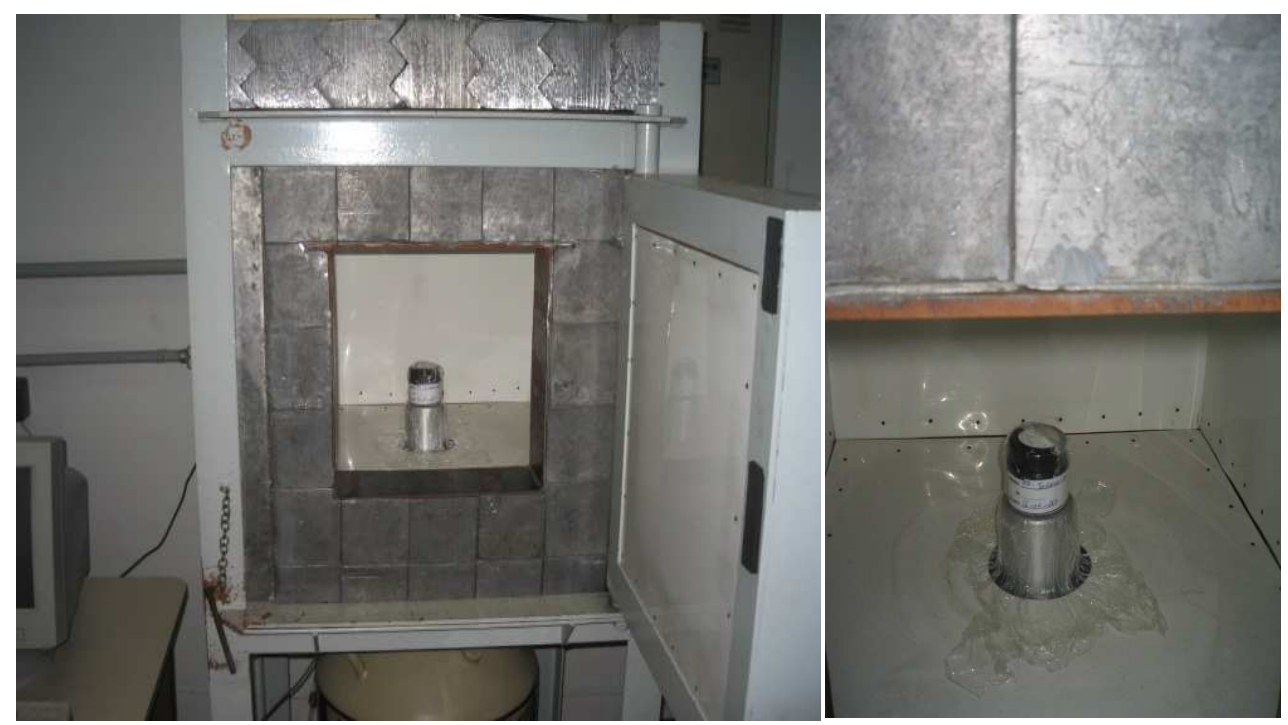

FIGURA 15 - Vista interna detector HPGe com amostra envasada em frasco F100. No detalhe é vista a proteção de filme PCV para evitar contaminação no detector. Foto acervo pessoal. 


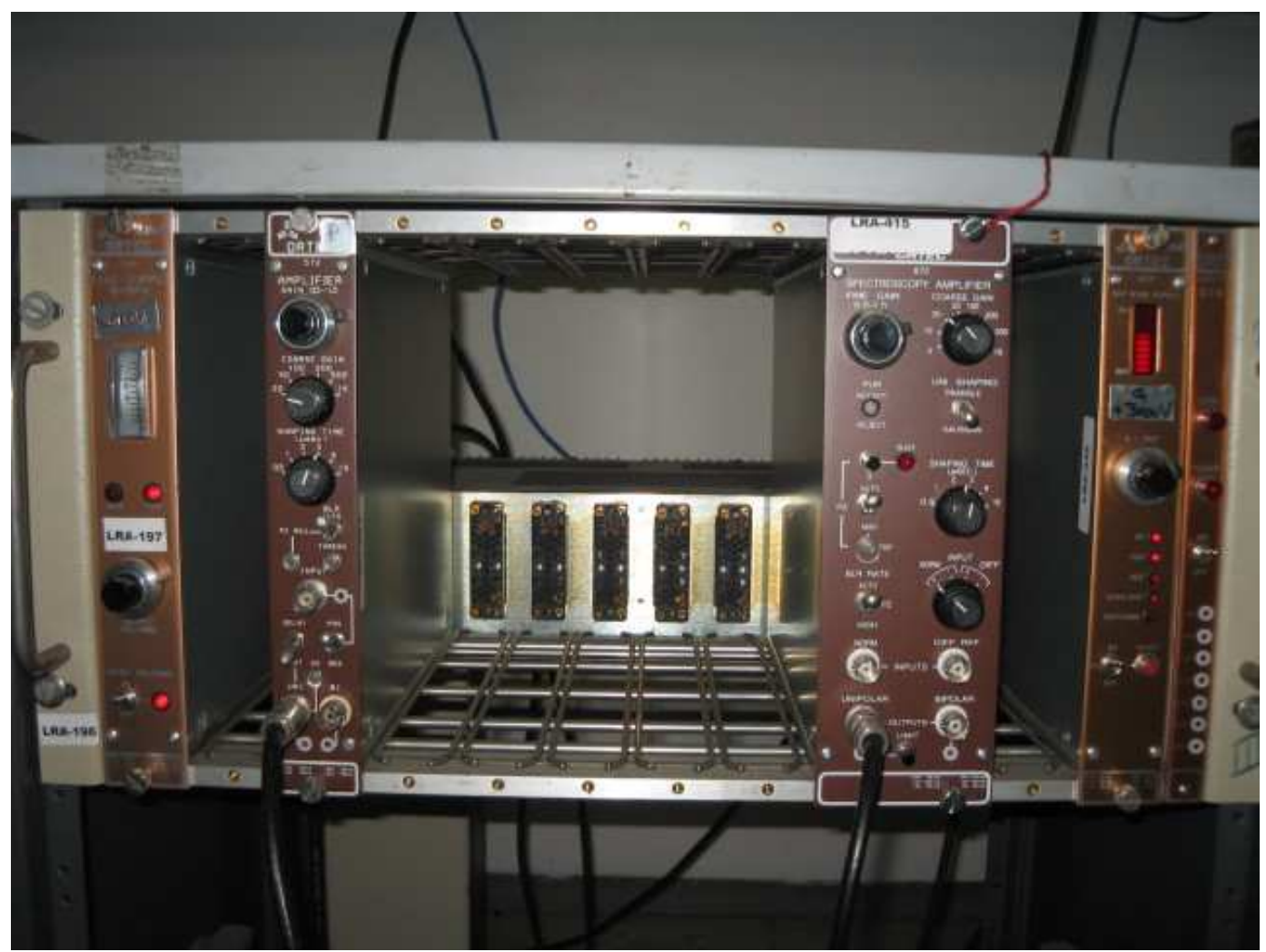

FIGURA 16 - Eletrônica associada. Da direita pra esquerda, são vistas a fonte de alimentação ORTEC 659 e o amplificador ORTEC EG\&G 672. Foto acervo pessoal.

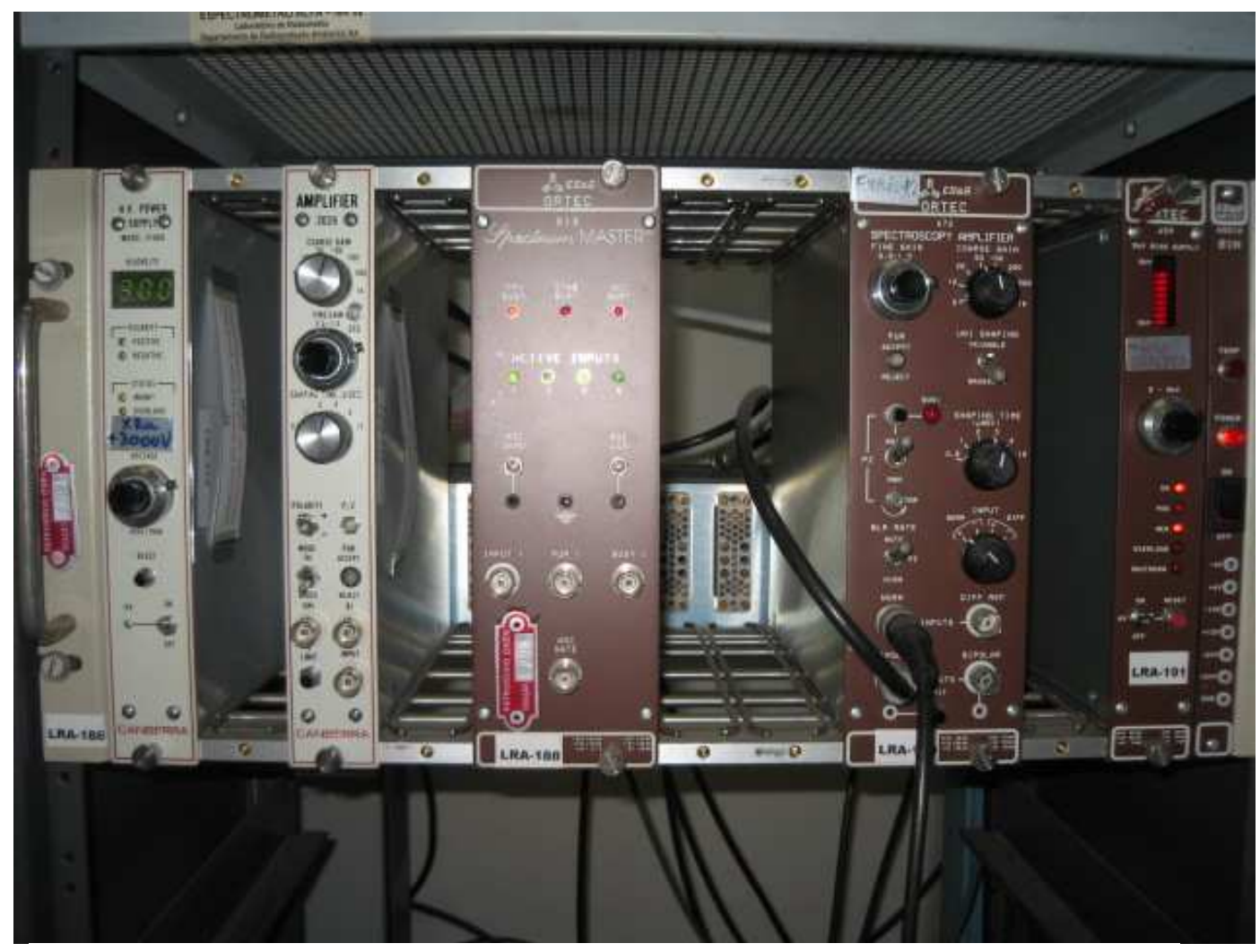

FIGURA 17 - Ao centro é visto o analisador multicanal ORTEC EG\&G 919 Spectrum Master. Foto acervo pessoal. 
Todas as amostras, com exceção para a da Praia da Areia Preta, foram medidas durante 150000s. As amostras da Praia da Areia Preta apresentam níveis altos de radioatividade, e foram medidos durante 3000s. As amostras foram medidas em triplicata.

Todos os espectros foram analisados com o software WinnerGamma (ORTEC, 2004). Na FIG.18 é mostrada uma saída típica do software de análise, onde em amarelo é vista a localizados pelo software que representam o fotopico no espectro referente a cada transição gama detectada.

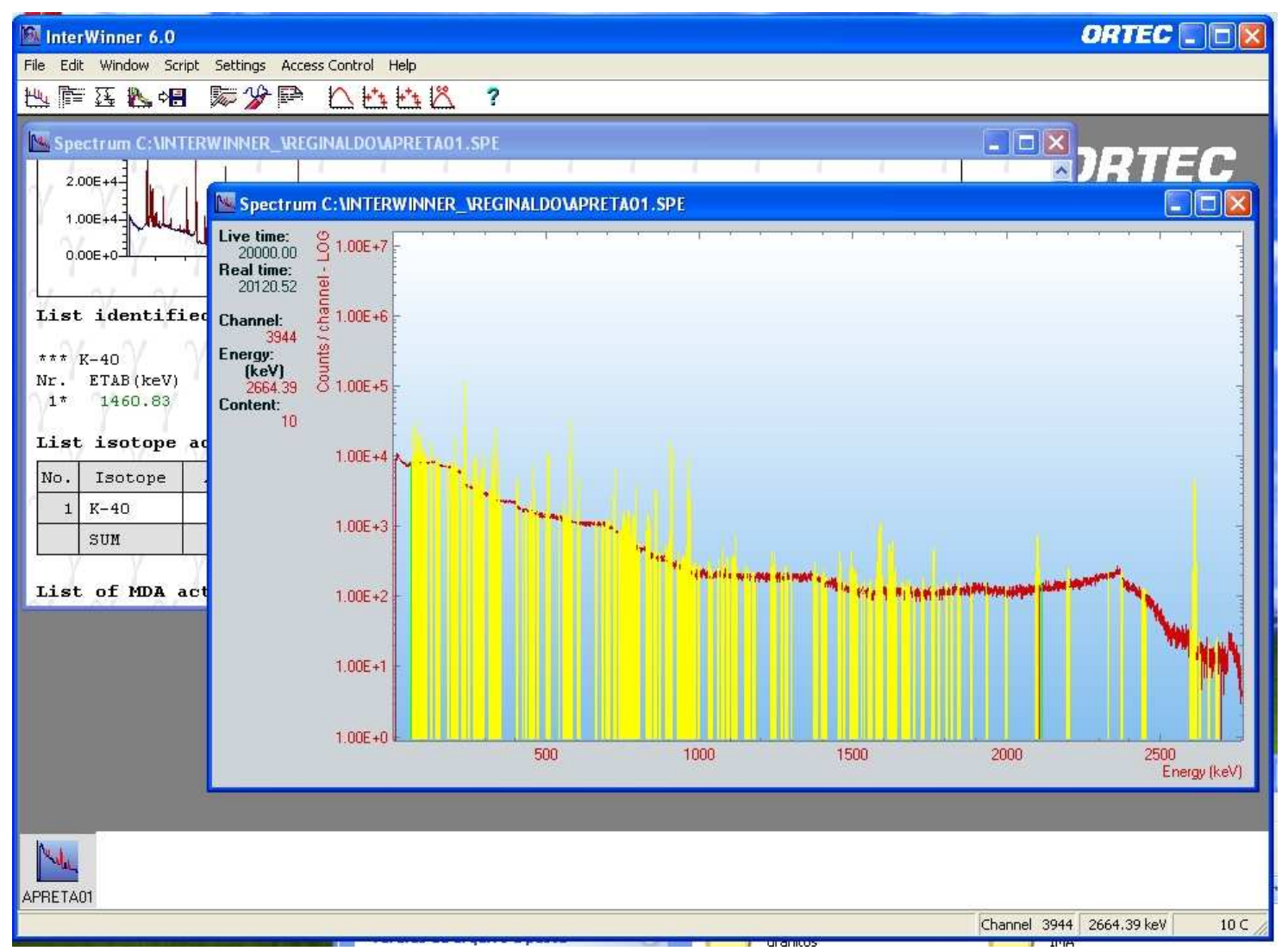

FIGURA 18 - Visão da saída do software para análise dos espectros.

A eficiência do detector foi determinada previamente com uma solução aquosa multielemento padrão (TAUHATA et al., 2002), para a mesma geometria da amostra. A radiação de fundo foi determinada pela medida de uma amostra de água deionizada com a mesma geometria das amostras. 


\subsection{Correção por atenuação}

No processo foi utilizado um aparato colimador onde são posicionadas fontes padrão puntiformes de ${ }^{152} \mathrm{Eu},{ }^{137} \mathrm{Cs}$ e ${ }^{60} \mathrm{Co}$ previamente escolhidas segundo suas transições gama (TAB.3, item 2.4). As fontes foram contadas durante $1000 \mathrm{~s}$ tanto para a água deionizada, como com as amostras e os espectros analisados com o software WinnerGamma 6 (ORTEC 2004)

O feixe gama proveniente da fonte padrão foi colimado utilizando um anel de chumbo (FIG.19) afixado sobre o suporte de lucite (FIG. 20). O suporte de lucite encaixa e centraliza a fonte sobre a amostra. Tomado o cuidado de não modificar a posição da fonte em relação à amostra e ao detector, o processo é repetido para todas as amostras subsequentes ao padrão de água deionizada obtido inicialmente, assegurando assim que todas as amostras estiveram localizadas sobre o mesmo ponto entre o feixe gama e o detector (FIG.21).

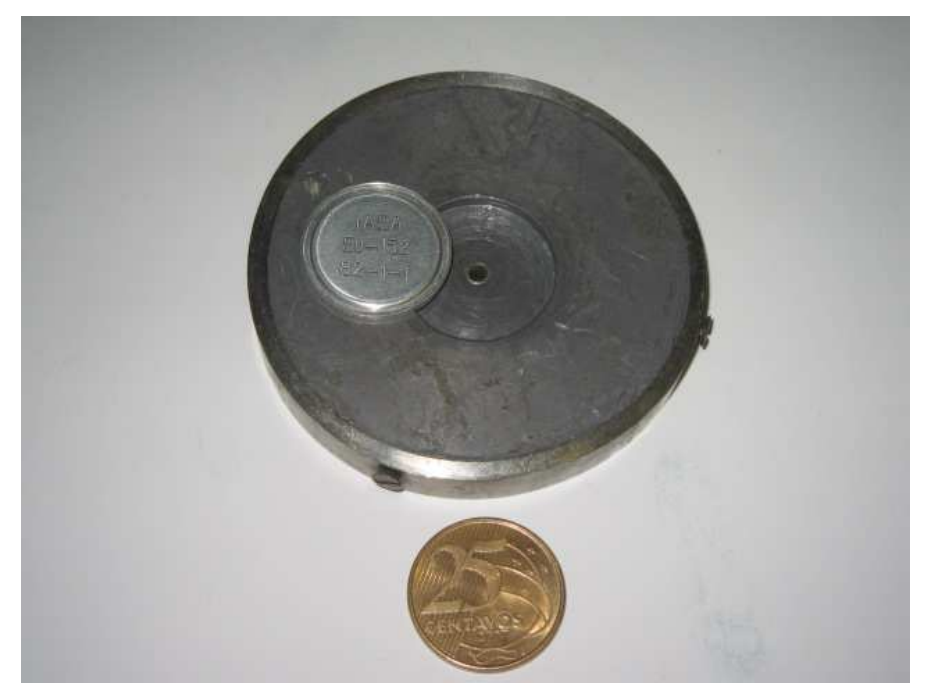

FIGURA 19 - Detalhe do anel colimador com uma fonte padrão de ${ }^{152} \mathrm{Eu}$, deslocada da posição central para melhor visualização. Foto acervo pessoal. 


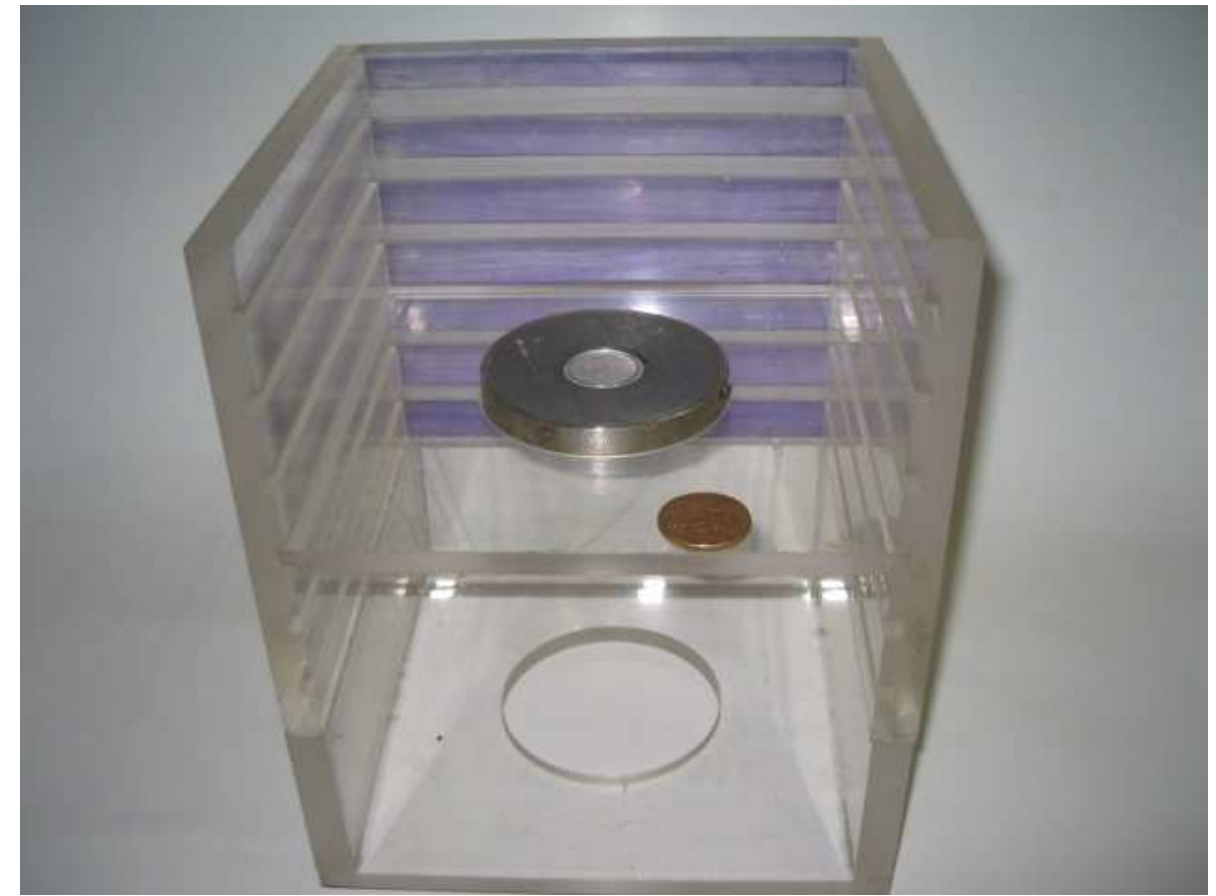

FIGURA 20 - Suporte de lucite, colimador e fonte ajustados. Foto Acervo pessoal
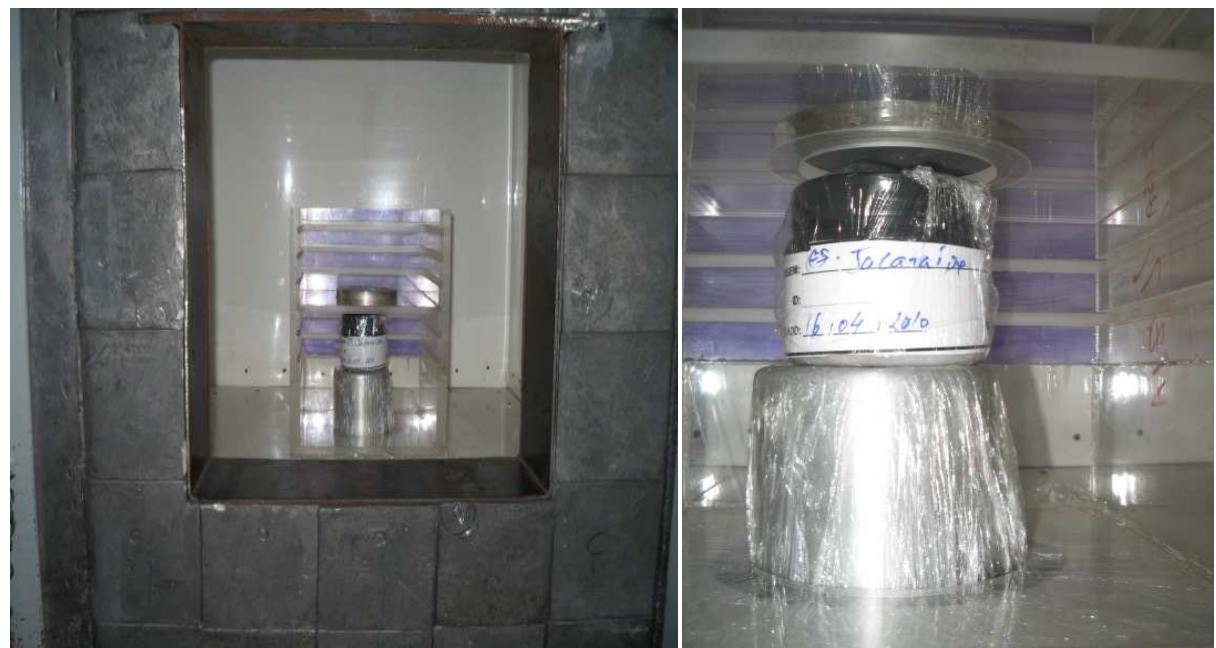

FIGURA 21 - À direita parede e visão interna da blindagem convencional de chumbo e No detalhe aparato experimental composto de fonte, suporte e colimador, ao centro amostra em frasco F100 e o detector HPGe ambos recobertos com filme PVC. Foto acervo pessoal. 
Selecionadas as energias nas regiões de interesse (localização dos radionuclídeos utilizados para a determinação da atividade) é traçada a curva característica de atenuação a partir da qual foram obtidos os fatores para a correção dos valores para cada transição gama selecionada (TAB.2, item 2.3). O mesmo processo foi efetuado para todas as amostras de areia estudadas.

Para o cálculo da atividade, a área líquida de cada transição gama dos radionuclídeos estudados (TAB2, item 2.3) foi corrigida pelo respectivo fator de atenuação obtido a partir das curvas da FIG.22 e ANEXO I. 


\section{RESULTADOS E DISCUSSÃO}

\subsection{Fatores de atenuação para as areias estudadas}

O fator de atenuação para cada amostra foi determinado a partir da interpolação utilizando a planilha eletrônica OpenOffice.Br Calc para as transições gama selecionadas(TAB.3, item 2.4). Na FIG.22 é mostrada a curva de atenuação para uma amostra de areia da Praia de Jacaraípe. As demais curvas e expressões podem ser vistas no ANÉXO I.

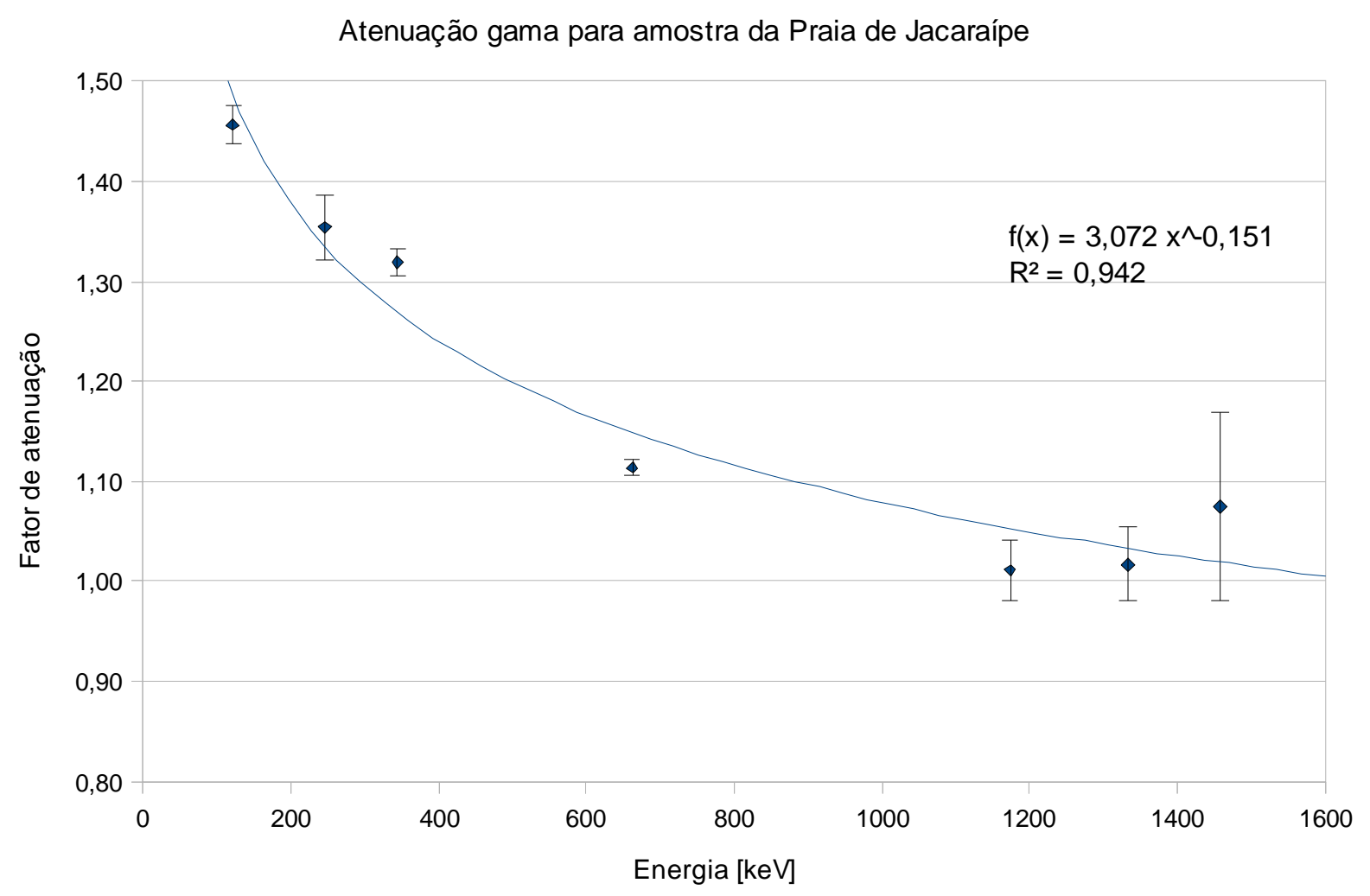

FIGURA 22 - Curva de atenuação da amostra de areia da Praia de Jacaraípe.

Foi observada uma variação nos valores do fator de atenuação gama dependendo da localidade. Esta alteração pode ser devido à composição mineralógica nas areias, esta por sua vez pode ser resultado de fatores naturais referentes à localidade, bem como por fatores antropogênicos(GAZETAONLINE, 2010). Tais fatores levam a uma variação na densidade aparente e composição das areias. Buscando uma correlação entre estes fatores, as areias foram separadas em cinco grupos 
diferenciados por faixas de densidade aparente. Na TAB.6 estão apresentados os valores dos fatores de atenuação para as areias estudadas, agrupados em faixas de densidade aparente das amostras.

TABELA 6 - Fatores de correção para atenuação agrupados por faixas de densidade aparente para as praias estudadas.

\begin{tabular}{|c|c|c|c|c|c|c|c|c|c|}
\hline \multirow{3}{*}{ Grupo } & \multirow{3}{*}{ Localidade } & \multirow{3}{*}{$\frac{\text { Densidade }}{\mathrm{kg} \cdot \mathrm{m}^{-3}}$} & \multicolumn{7}{|c|}{ Energia [keV] } \\
\hline & & & \multicolumn{3}{|c|}{${ }^{152} \mathrm{Eu}$} & ${ }^{137} \mathrm{Cs}$ & \multicolumn{2}{|c|}{${ }^{60} \mathrm{Co}$} & \multirow{2}{*}{$\begin{array}{c}{ }^{152} \mathrm{Eu} \\
1457,63 \\
\end{array}$} \\
\hline & & & 121,70 & 245 & 344,30 & 661,66 & 1173,24 & 1332,50 & \\
\hline \multirow{2}{*}{ A } & Reserva solo & 1,55 & 1,17 & 1,11 & 1,10 & 1,08 & 1,00 & 1,03 & 1,00 \\
\hline & Praia do Canto & 1,60 & 1,18 & 1,14 & 1,12 & 1,11 & 1,02 & 1,07 & 0,99 \\
\hline \multirow{3}{*}{ B } & Reserva Asfalto & 1,63 & 1,21 & 1,15 & 1,14 & 1,10 & 1,02 & 1,09 & 1,02 \\
\hline & Jacaraípe & 1,64 & 1,46 & 1,35 & 1,32 & 1,11 & 1,01 & 1,02 & 1,07 \\
\hline & Praia das Castanheiras & 1,64 & 1,19 & 1,15 & 1,13 & 1,12 & 1,01 & 0,99 & 1,01 \\
\hline \multirow{5}{*}{ C } & Setibão & 1,70 & 1,22 & 1,14 & 1,14 & 1,11 & 1,02 & 0,99 & 1,01 \\
\hline & Itapuã & 1,70 & 1,21 & 1,16 & 1,14 & 1,11 & 1,02 & 0,99 & 1,02 \\
\hline & Praia do Morro & 1,71 & 1,22 & 1,14 & 1,14 & 1,13 & 1,03 & 1,06 & 1,01 \\
\hline & Manguinhos & 1,71 & 1,27 & 1,18 & 1,15 & 1,12 & 1,02 & 1,05 & 1,07 \\
\hline & Camburí Norte & 1,73 & 1,22 & 1,18 & 1,16 & 1,11 & 1,03 & 1,04 & 1,05 \\
\hline \multirow{3}{*}{ D } & Camburí Sul & 1,78 & 1,34 & 1,18 & 1,17 & 1,13 & 1,03 & 1,00 & 1,06 \\
\hline & Setibinha & 1,78 & 1,57 & 1,41 & 1,35 & 1,12 & 1,04 & 1,02 & 1,09 \\
\hline & Praia da Costa & 1,79 & 1,38 & 1,26 & 1,24 & 1,13 & 1,04 & 1,01 & 1,10 \\
\hline \multirow{3}{*}{ E } & Curva da Jurema & 1,87 & 1,34 & 1,23 & 1,19 & 1,14 & 1,05 & 1,01 & 1,10 \\
\hline & Camburí Central & 2,22 & 1,72 & 1,33 & 1,29 & 1,21 & 1,09 & 1,12 & 1,05 \\
\hline & Praia da Areia Preta & 2,33 & 1,88 & 1,37 & 1,30 & 1,23 & 1,10 & 1,07 & 0,99 \\
\hline
\end{tabular}

Nas FIG. 23, 25 e 27, é observada relação de composição entre as amostras dos grupos $A, C$ e $D$ cujas amostras pertencem a regiões distintas e distantes, onde os fatores de atenuação considerando mesma densidade em função da energia tendem a se aproximar, tanto para energias das transições gama de maior intensidade quanto para as de menor intensidade. Tal relação não se repete no grupo E (FIG.27) cuja densidade e variação na composição mineralógica das areias têm influência significativa no fator de atenuação. O Grupo B (FIG.24) apresenta amostras com densidades iguais porem com visível variação em relação as demais amostras. Este fato poderia ser explicado pela diferenciação mineralógica entre as amostras do grupo B. 


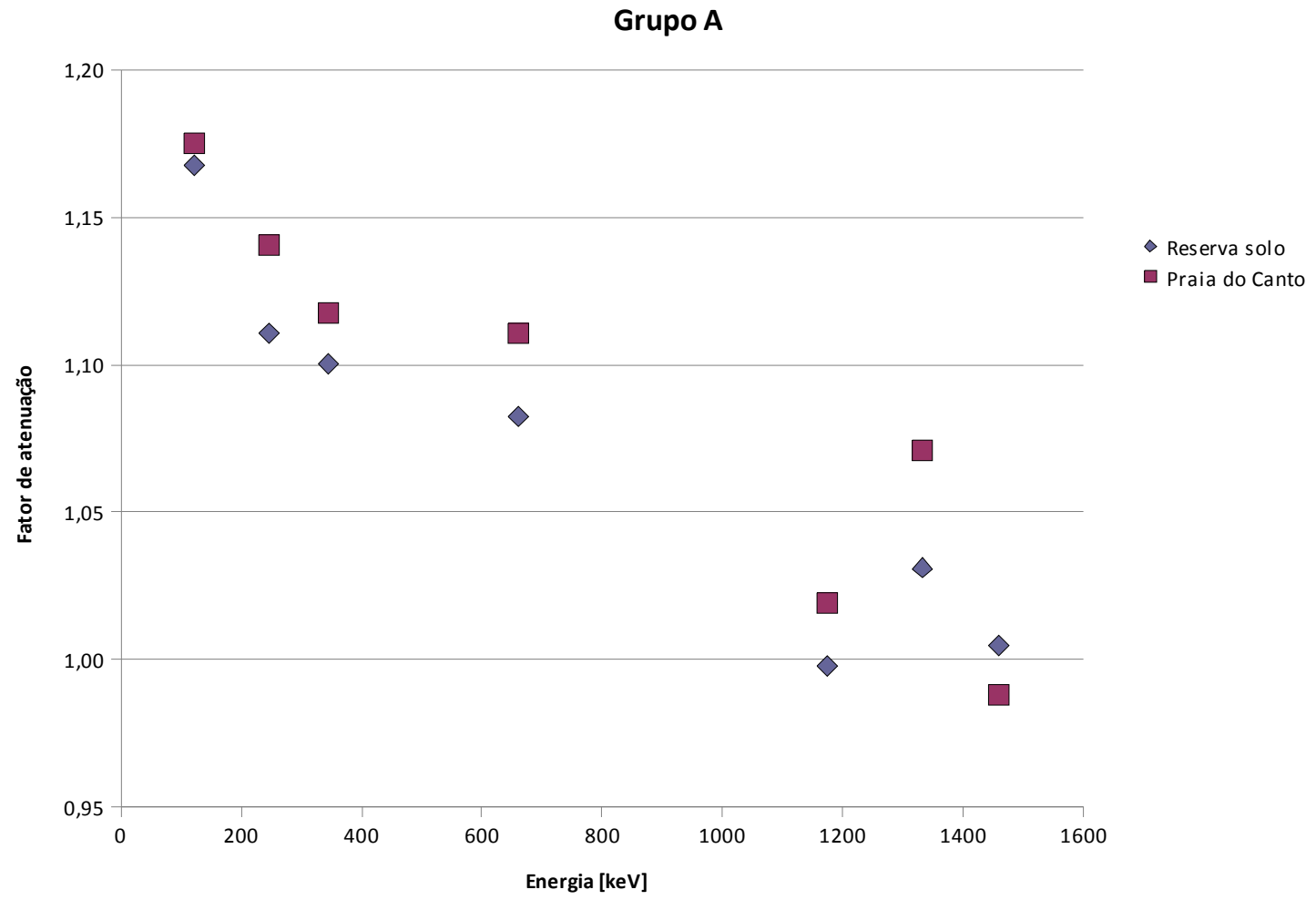

FIGURA 23 - Relação fator-energia para o grupo de amostragem de densidade aproximada 1,6kg.m ${ }^{-3}$.

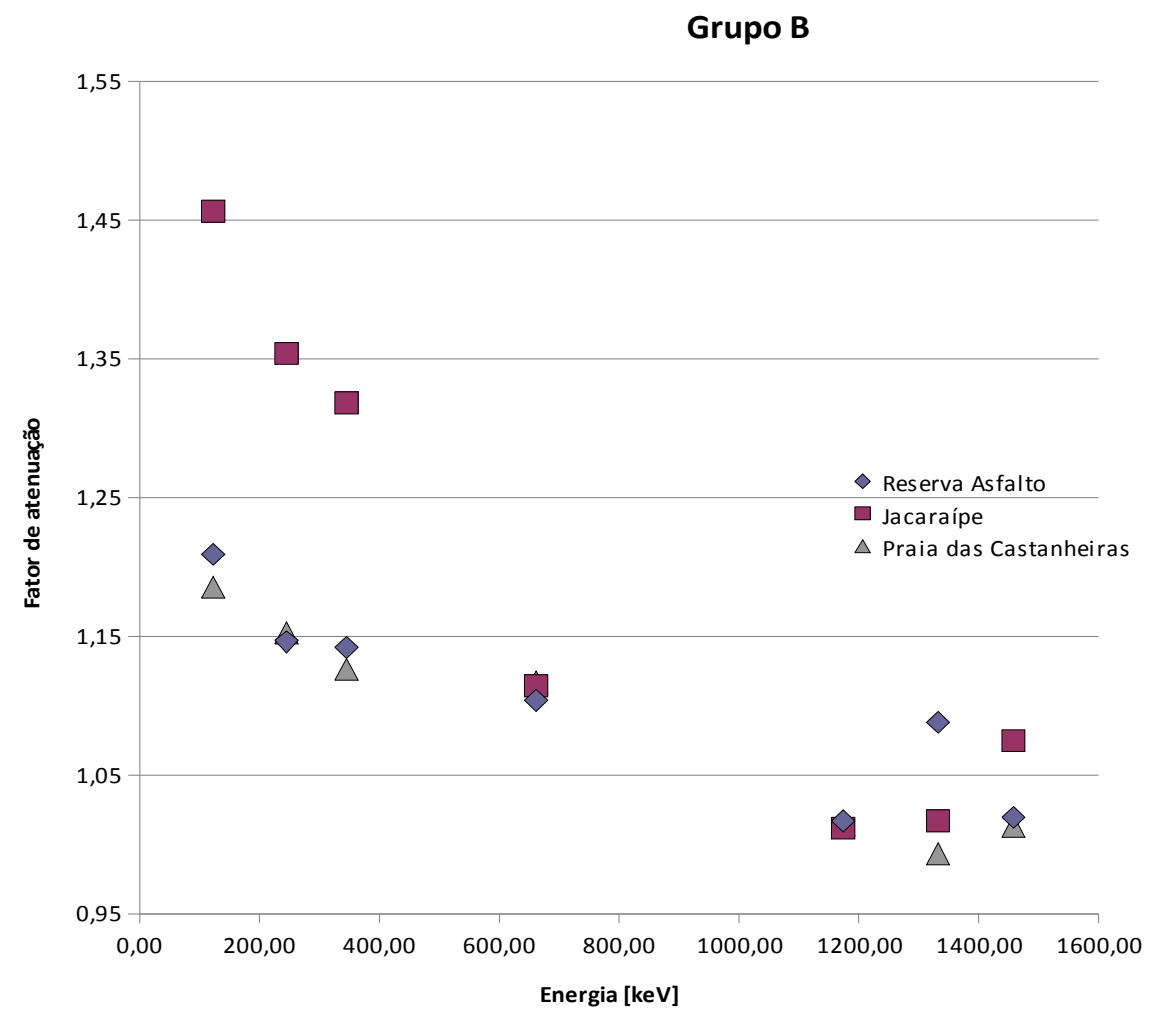

FIGURA 24 - Relação fator-energia para o grupo de amostragem de densidade aproximada 1,64kg.m ${ }^{-3}$. 


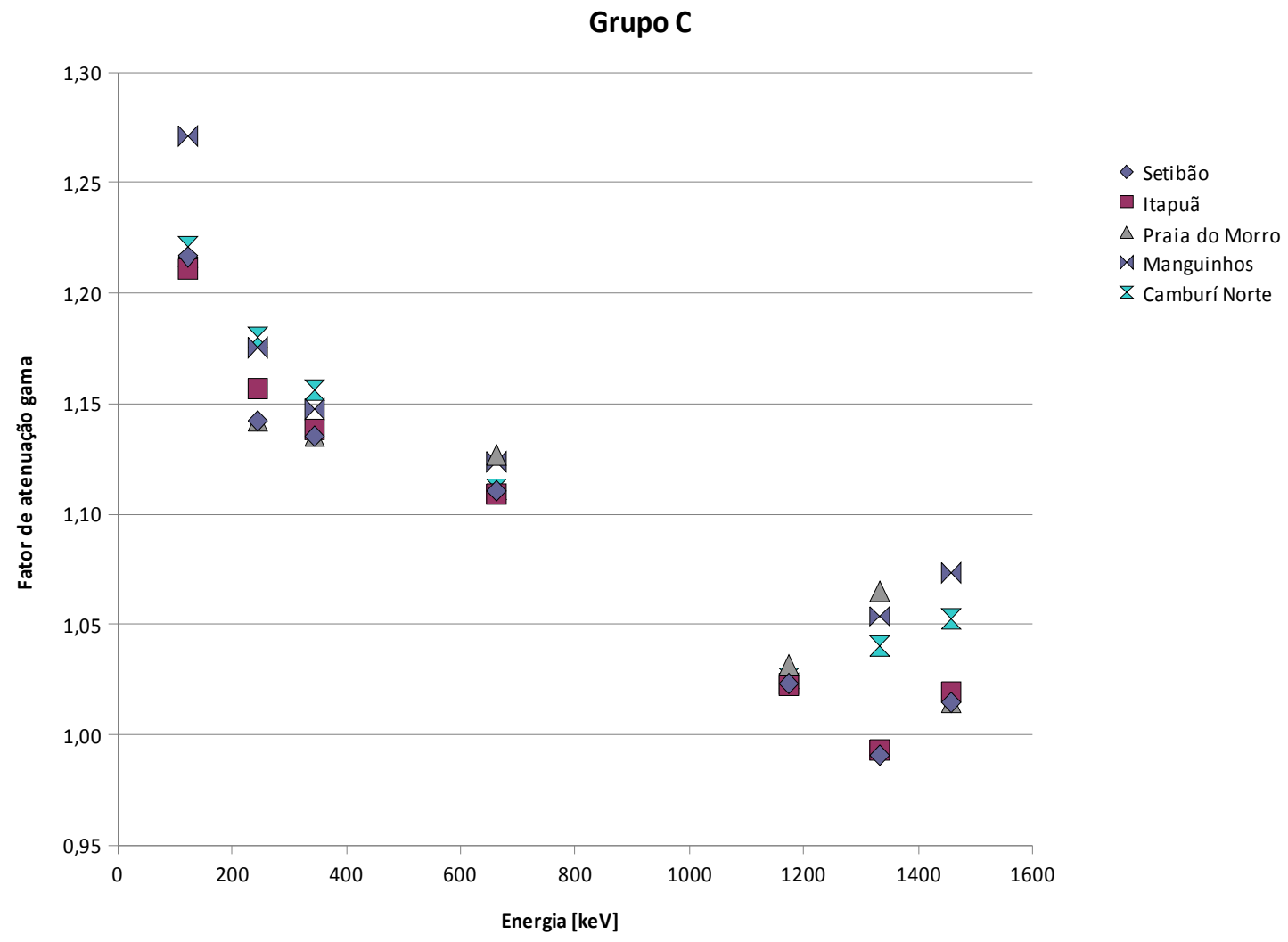

FIGURA 25 - Relação fator-energia para o grupo de amostragem de densidade aproximada 1,70 kg.m ${ }^{-3}$.

Grupo D

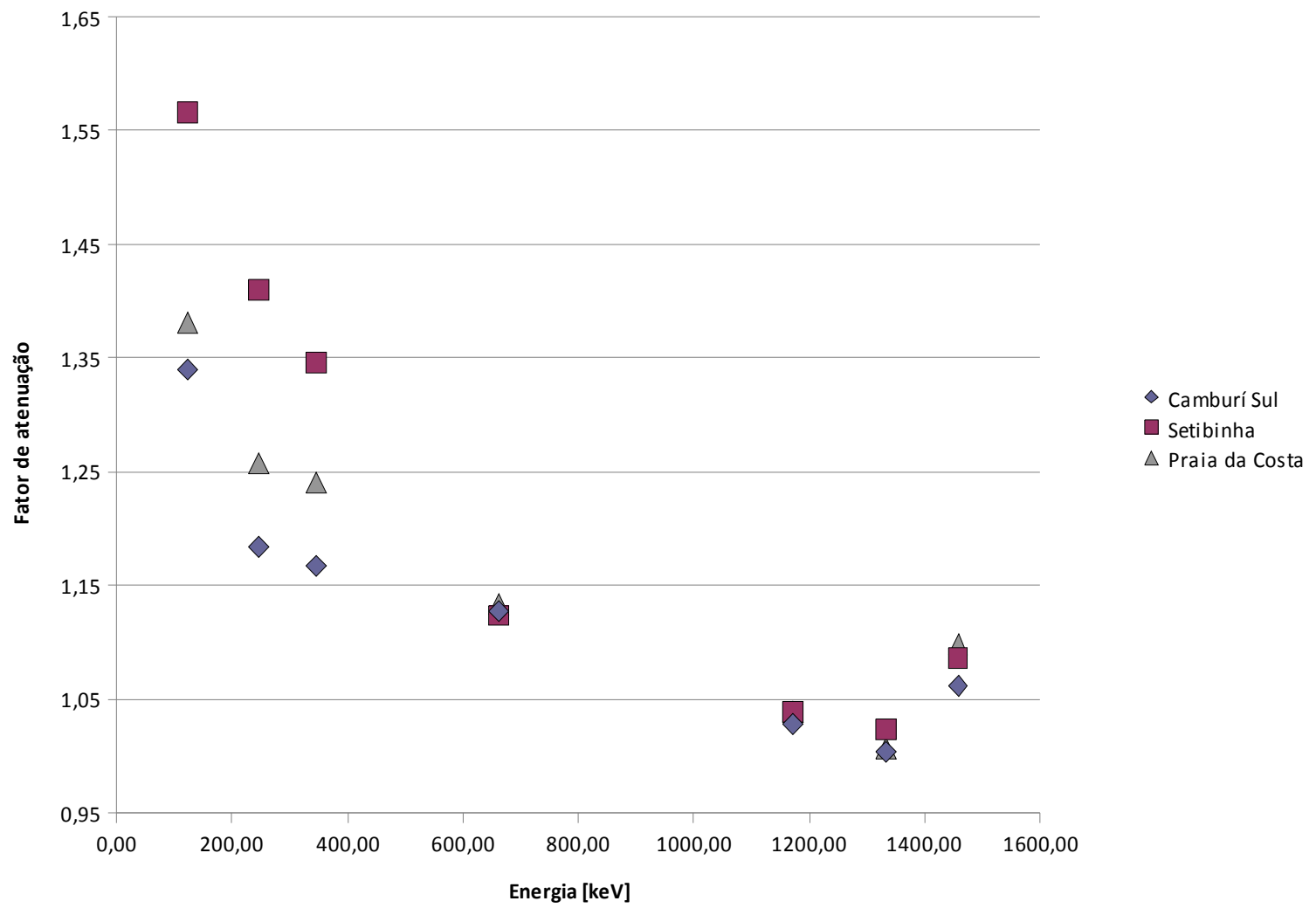

FIGURA 26 - Relação fator-energia para o grupo de amostragem de densidade aproximada 1,78kg.m ${ }^{-3}$. 


\section{Grupo E}

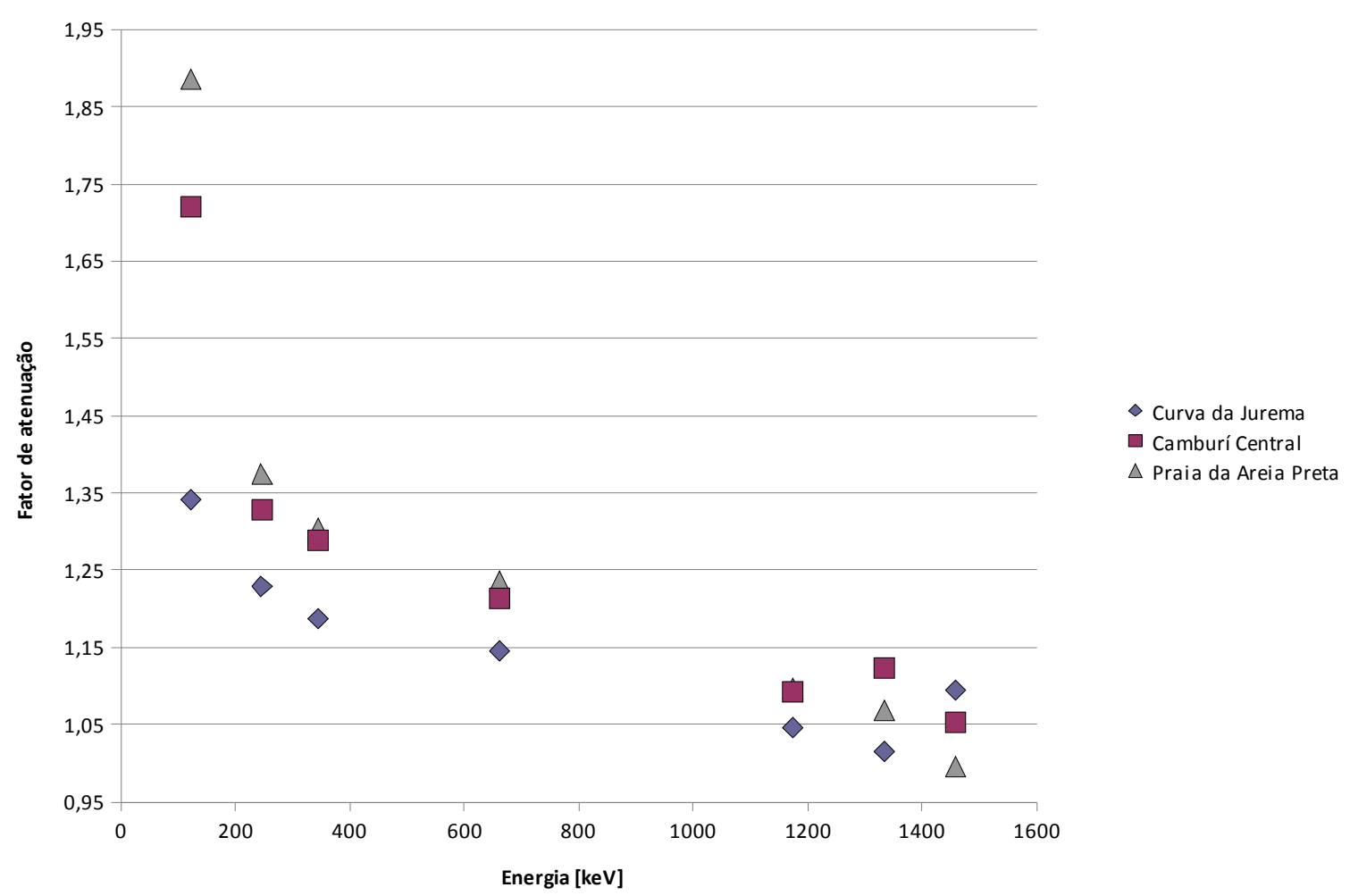

FIGURA 27 - Relação fator-energia para o grupo de amostragem de densidade aproximada 2,14kg. ${ }^{-3}$. 


\subsection{Concentração de atividade para as regiões selecionadas}

As atividades determinadas para cada localidade podem ser visualizadas na TAB.7 e FIG.28.

TABELA 7 - Concentrações de ${ }^{40} \mathrm{~K},{ }^{226} \mathrm{Ra}$ e ${ }^{232} \mathrm{Th}$ encontradas nas areias das praias da Grande Vitória, ES.

Município / Localidade $\quad$ ID $\frac{{ }^{40} \mathrm{~K}}{\mathrm{~Bq}_{\mathrm{kg}}{ }^{-1}} \frac{{ }^{226} \mathrm{Ra}}{\mathrm{Bq} \cdot \mathrm{kg}^{-1}} \quad \frac{{ }^{232} \mathrm{Th}}{\mathrm{Bq} \cdot \mathrm{kg}^{-1}}$

Serra

$\begin{array}{rrrrr}\text { Jacaraípe } & 1 & 42 \pm 8 & 8 \pm 1 & 28 \pm 5 \\ \text { Manguinhos } & 2 & 202 \pm 10 & 31 \pm 2 & 111 \pm 10\end{array}$

Vitória

$\begin{array}{rcrrrr}\text { Camburí Norte } & 3 & 29 \pm 6 & 6 \pm 1 & 16 \pm 4 \\ \text { Camburí Central } & 4 & 377 \pm 20 & 755 \pm 39 & 4155 \pm 261 \\ \text { Camburí Sul } & 5 & 140 \pm 11 & 258 \pm 13 & 1441 \pm 92 \\ \text { Praia do Canto } & 6 & 99 \pm 8 & 12 \pm 1 & 33 \pm 5 \\ \text { Curva da Jurema } & 7 & 150 \pm 17 & 188 \pm 11 & 703 \pm 52\end{array}$

Vila Velha

\section{Guaraparí}

$\begin{array}{rrrrr}\text { Praia da Costa } & 8 & 64 \pm 8 & 19 \pm 2 & 49 \pm 7 \\ \text { Itapuã } 9 & 58 \pm 7 & 5 \pm 1 & 12 \pm 4\end{array}$

Valores encontrados na literatura

$\begin{array}{rrrrr}\text { Reserva Asfalto } & 10 & 26 \pm 6 & 3 \pm 1 & 7 \pm 3 \\ \text { Reserva solo } & 11 & 33 \pm 9 & 6 \pm 1 & 17 \pm 4 \\ \text { Setibão } & 12 & 14 \pm 6 & 4 \pm 1 & 9 \pm 3 \\ \text { Setibinha } & 13 & 89 \pm 10 & 66 \pm 4 & 537 \pm 36 \\ \text { Praia do Morro } & 14 & 21 \pm 7 & 4 \pm 1 & 12 \pm 5 \\ \text { Praia das Castanheiras } & 15 & 53 \pm 7 & 3 \pm 1 & 16 \pm 3 \\ \text { Praia da Areia Preta } & 16 & 669 \pm 243 & 643 \pm 48 & 7236 \pm 513 \\ \text { Espírito Santo } & & 51 & 10,2 & 12,6 \\ \text { São Paulo } & 454 & 24,1 & 45,5 \\ \text { Rio Grande do Norte } & & 809 & 14,3 & 180\end{array}$

UNSCEAR $^{4}(2008)$

Valores em destaque representam as maiores concentrações para os radionuclídeos estudados. 


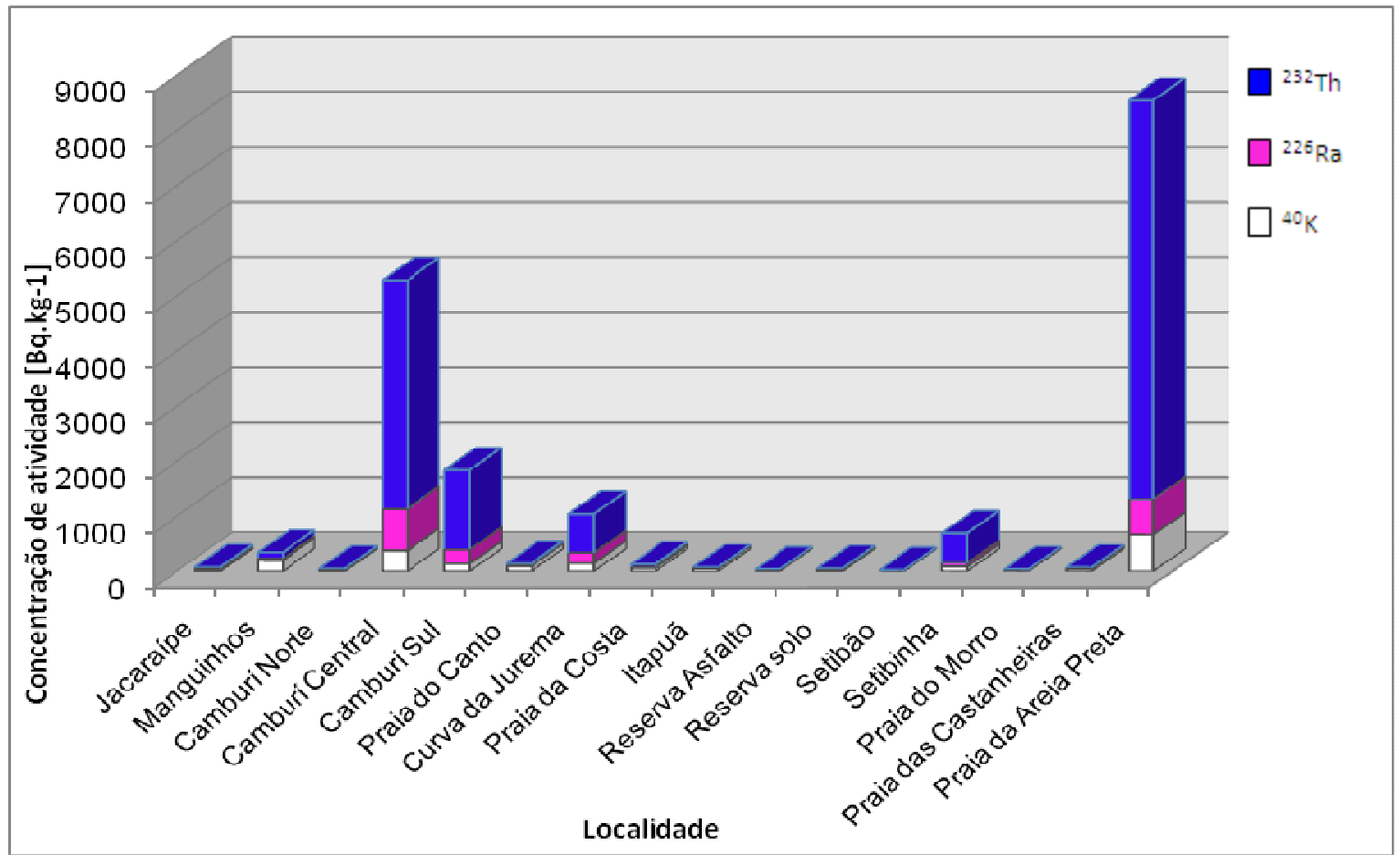

FIGURA 28 - Concentrações de atividade para as areias das praias da Grande Vitória.

Os valores em destaque na TAB.7 representam as maiores concentrações de ${ }^{232} \mathrm{Th},{ }^{226} \mathrm{Ra}$ e ${ }^{40} \mathrm{~K}$. A maior concentração de ${ }^{226} \mathrm{Ra}$ foi encontrada para a Praia de Camburí porção central o que mostra uma possível concentração de ilmenita. A maior concentração de ${ }^{232}$ Th é encontrada na Praia da Areia Preta, o que confirma a existência do mineral monazita.

A maior concentração de ${ }^{40} \mathrm{~K}$ foi encontrada para a praia da Areia Preta. É necessário pontuar que para praias com elevada concentração de tório, como a praia da Areia Preta e Camburí, a determinação da concentração de potássio é difícil de ser obtida por esta técnica devido à proximidade da transição gama do ${ }^{228} \mathrm{Ac}(1458 \mathrm{keV}) \mathrm{e}$ da transição gama do ${ }^{40} \mathrm{~K}(1460 \mathrm{keV})$. Para que fosse possível a determinação correta, as amostras foram contadas por um tempo menor (em torno de 1000s) para que a transição de $1458 \mathrm{keV}$ do ${ }^{228} \mathrm{Ac}$, com intensidade gama de $1,2 \%$ não aparecesse no espectro, permitindo que a transição gama de $1460 \mathrm{keV}$ do ${ }^{40} \mathrm{~K}$. com intensidade de $10,7 \%$ fosse facilmente observável. 
Na TAB.8 são encontrados os valores comparativos para as concentrações de atividade para os radionuclídeos nas localidades da região da Grande Vitória e outras localidades encontradas na literatura.

TABELA 8 - Faixas de concentrações de ${ }^{40} \mathrm{~K},{ }^{226} \mathrm{Ra}$ e ${ }^{232} \mathrm{Th}$ nas areias das praias da Grande Vitória (presente trabalho) e valores da literatura.

Localidade

$$
{ }^{40} \mathrm{~K}
$$

Bq. $\mathrm{kg}^{-1}$

$\mathrm{Bq} \cdot \mathrm{kg}^{-1}$

Referência

Brasil, Espírito Santo

\begin{tabular}{|c|c|c|c|c|c|c|}
\hline Serra & 42 & -202 & $8-31$ & 28 & -111 & Este trabalho \\
\hline Vitória & 29 & -377 & $6-755$ & 16 & -4155 & Este trabalho \\
\hline Vila Velha & 58 & -64 & $5-19$ & 12 & -49 & Este trabalho \\
\hline Guaraparí & 14 & -669 & $3-643$ & 9 & -7236 & Este trabalho \\
\hline Média Grande Vitória & 36 & -328 & $6-362$ & 16 & -2888 & * \\
\hline $\begin{array}{r}\text { Barra do Jucú } \\
\text { Guarapari/Meaípe }\end{array}$ & 49 & -52 & $5,7-117,5$ & 2,5 & -1256 & MALANCA, 1995 \\
\hline Grande Vitória & 27 & -127 & $34-4043$ & 77 & -55537 & VEIGA, 2006 \\
\hline Região Sul & 63 & -412 & $5-1001$ & 7 & -6422 & VEIGA, 2006 \\
\hline \multicolumn{7}{|l|}{ Outras regiões Brasil } \\
\hline Rio de Janeiro, Ilha Grande & 101 & -1082 & $13-116$ & 10 & -213 & ALENCAR, 2004 \\
\hline Rio Grande do Norte & 180 & -1142 & $9,7-75,2$ & 7,1 & $-145,5$ & MALANCA, 1993 \\
\hline Brasil & 51 & -809 & $10,2-24,1$ & 12,6 & -180 & UNSCEAR ${ }^{4}, 2008$ \\
\hline \multicolumn{7}{|l|}{ Outras regiões no mundo } \\
\hline Nigéria & 101,7 & -903 & $7,9-44,2$ & 6,2 & $-52,3$ & ADEMOLA, 2008 \\
\hline Índia, Kalpakkan & 210,1 & 607 & $9,6-53$ & 37 & -163 & SOWMYA, 2010 \\
\hline Cuba, Havana & 88 & -356 & $11,5-22,8$ & 7,1 & $-21,6$ & FLORES, 2004 \\
\hline Turquia, Kenstanbol & 1074 & -1527 & $94-637$ & 120 & -601 & CANBAZ, 2010 \\
\hline Japão & 742,4 & $-990,4$ & $10,2-33,7$ & 29,2 & 46,3 & HASSAN, 2010 \\
\hline Egito, Ganet Safaga & 707 & -947 & $163-221$ & 155 & -221 & UOSIF, 2008 \\
\hline China, Baoji & 611,2 & -1176 & $12,9-35,1$ & 17,3 & $-48,5$ & XINWEI, 2007 \\
\hline
\end{tabular}

\footnotetext{
* Valor médio considerando as faixas neste estudo para a Grande Vitória.
} 


\subsection{Equivalente em rádio e Índice de risco para as areias das praias da Grande}

\section{Vitória}

A TAB.9 sumariza os índices de avaliação das areias das praias da Grande Vitória, determinados de acordo com as expressões 9, 10 e 11 do item 2.6. Na FIG.31 está a relação entre o índice de risco interno e externo.

TABELA 9 - Equivalente em rádio e índice de risco para as areias das praias da Grande Vitória.

\begin{tabular}{|c|c|c|c|c|c|}
\hline \multirow{2}{*}{ Município / Localidade } & \multirow{2}{*}{ Classe $^{[4]}$} & \multicolumn{2}{|c|}{ Equivalente em rádio $^{[1]}$} & \multicolumn{2}{|c|}{ Índice de risco gama ${ }^{[2]}$} \\
\hline & & {$\left[\mathrm{Bqkg}^{-1}\right]$} & {$[\mathrm{n}]^{[3]}$} & $\mathrm{H}_{\mathrm{ex}} \leq 1$ & $H_{\text {in }} \leq 1$ \\
\hline Reserva Asfalto & 1 & $14 \pm 6$ & 0,04 & $0,04 \pm 0,02$ & $0,05 \pm 0,03$ \\
\hline Setibão & 1 & $16 \pm 7$ & 0,04 & $0,05 \pm 0,03$ & $0,06 \pm 0,03$ \\
\hline Praia do Morro & 1 & $22 \pm 9$ & 0,06 & $0,06 \pm 0,04$ & $0,07 \pm 0,04$ \\
\hline Itapuã & 1 & $25 \pm 8$ & 0,07 & $0,07 \pm 0,03$ & $0,08 \pm 0,04$ \\
\hline Praia das Castanheiras & 1 & $29 \pm 8$ & 0,08 & $0,08 \pm 0,03$ & $0,09 \pm 0,03$ \\
\hline Camburí Norte & 1 & $30 \pm 7$ & 0,08 & $0,09 \pm 0,03$ & $0,10 \pm 0,03$ \\
\hline Reserva solo & 1 & $31 \pm 10$ & 0,08 & $0,09 \pm 0,04$ & $0,11 \pm 0,05$ \\
\hline Jacaraípe & 1 & $49 \pm 9$ & 0,13 & $0,14 \pm 0,04$ & $0,16 \pm 0,05$ \\
\hline Praia do Canto & 1 & $63 \pm 10$ & 0,17 & $0,18 \pm 0,04$ & $0,21 \pm 0,04$ \\
\hline Praia da Costa & 1 & $89 \pm 11$ & 0,24 & $0,26 \pm 0,05$ & $0,31 \pm 0,07$ \\
\hline Manguinhos & 1 & $194 \pm 15$ & 0,52 & $0,56 \pm 0,07$ & $0,64 \pm 0,08$ \\
\hline Setibinha & 3 & $786 \pm 38$ & 2 & $2,3 \pm 0,3$ & $2,5 \pm 0,4$ \\
\hline Curva da Jurema & 3 & $1132 \pm 56$ & 3 & $3,3 \pm 0,5$ & $3,8 \pm 0,6$ \\
\hline Camburí Sul & 4 & $2180 \pm 93$ & 6 & $6,3 \pm 0,7$ & $7 \pm 1$ \\
\hline $\begin{array}{l}\text { Camburí Central } \\
\text { Praia da Areia Preta }\end{array}$ & $\begin{array}{l}5 \\
5\end{array}$ & $\begin{array}{r}6294 \pm 264 \\
10300+570\end{array}$ & $\begin{array}{l}17 \\
28\end{array}$ & $\begin{aligned} 18,2 & \pm 1,8 \\
30 & +11\end{aligned}$ & $\begin{array}{l}20 \pm 2 \\
32+12\end{array}$ \\
\hline
\end{tabular}

[1] Valores devem ser < 370Bq.kg-1 (OECD, 1979).

[2] Valores $>1$ representam risco e devem ser avaliados de forma mais criteriosa.

[3] Representa o número de vezes maior que o valor de referência [1]. $n=\frac{R a_{e q}(\text { Este.trabalho })}{R a_{e q}(\text { Val.ref. })}$

[4] Classe de utilização conforme definido na TAB.4, item 2.5. 
O índice equivalente em rádio sugere que, para a maioria das areias avaliadas, há uma possível aplicação como material de construção. O índice mostra também que para as areias da praia de Setibinha e Curva da Jurema uma aplicação possível na área de construção de estradas e pontes (ver TAB.4, item 2.5). As areias da praia de Camburí Sul possuem aplicação sugerida na construção de fundação ou aplicações não residenciais preferencialmente em locais de pouco acesso do público. Para as areais de Camburí Central e Praia da Areia Preta não existe aplicação possível a ser sugerida por este índice para a construção civil. Para estes locais a faixa limite de $370 \mathrm{~Bq} . \mathrm{kg}^{-1}$ (OECD, 1979) é superada a uma razão de 17 a 28 vezes.

Considerando que a areia é usada somente como um componente nos materiais de construção, foi feita uma tentativa de avaliação do equivalente em rádio relacionando à fração de areia utilizada, conforme sugestão de sites de construção

A TAB.10 estabelece um comparativo considerando diferentes proporções possíveis para as faixas de equivalente em rádio.

TABELA 10 - Comparativo para a contribuição do rádio equivalente para o material de construção

\begin{tabular}{|c|c|c|c|c|c|c|c|c|c|}
\hline \multirow{2}{*}{ Aplicações de areia } & \multirow{2}{*}{ Areia } & \multirow{2}{*}{ Outros* } & \multirow{2}{*}{$\begin{array}{l}\text { Fração } \\
\text { de areia }\end{array}$} & \multicolumn{6}{|c|}{$\begin{array}{l}\text { Valores de equivalente em rádio em Bq. } \mathrm{kg}^{-1} \\
\text { para as faixas e contribuição das areias. }\end{array}$} \\
\hline & & & & $14-30$ & $31-63$ & $89-94$ & $786-1132$ & 2180 & 10291 \\
\hline Contra piso & 4 & 1 & $80 \%$ & 6,4 & 12,8 & 42 & 138 & 872 & 4116 \\
\hline Reboco/Embosso interno & 3 & 3 & $50 \%$ & 4,0 & 8,0 & 26 & 87 & 545 & 2573 \\
\hline Reboco/Embosso extern & 2 & 3 & $40 \%$ & 3,2 & 6,4 & 21 & 69 & 436 & 2058 \\
\hline Chapisco de parede & 3 & 1 & $75 \%$ & 6,0 & 12,0 & 39 & 129 & 818 & 3859 \\
\hline Concreto de laje & 3 & 3 & $50 \%$ & 4,0 & 8,0 & 26 & 87 & 545 & 2573 \\
\hline Calçada & 3 & 3 & $50 \%$ & 4,0 & 8,0 & 26 & 87 & 545 & 2573 \\
\hline Piso & 3 & 3 & $50 \%$ & 4,0 & 8,0 & 26 & 87 & 545 & 2573 \\
\hline Assentamento de tijolos & 5 & 1 & $83 \%$ & 6,7 & 13,3 & 44 & 144 & 908 & 4288 \\
\hline Toda construção & 26 & 18 & $59 \%$ & 4,7 & 9,5 & 31 & 102 & 644 & 3041 \\
\hline
\end{tabular}

* Outros materiais citados correspondem a cimento, barro e aditivos.

** Os valores para as faixas aplicados aos cálculos correspondem à média aritmética simples. 
Os valores considerando as proporções usuais para areia como insumo de material de construção mostram que as faixas de 14 a $1132 \mathrm{~Bq} \cdot \mathrm{kg}^{-1}$ se agregadas a outros materiais permanecem abaixo do valor estabelecido de $370 \mathrm{~Bq} . \mathrm{kg}^{-1}$ (OECD,1979). Os valores acima de $1132 \mathrm{~Bq}^{\mathrm{kg}}{ }^{-1}$ podem ser aplicados como material classe 2 a 4 .

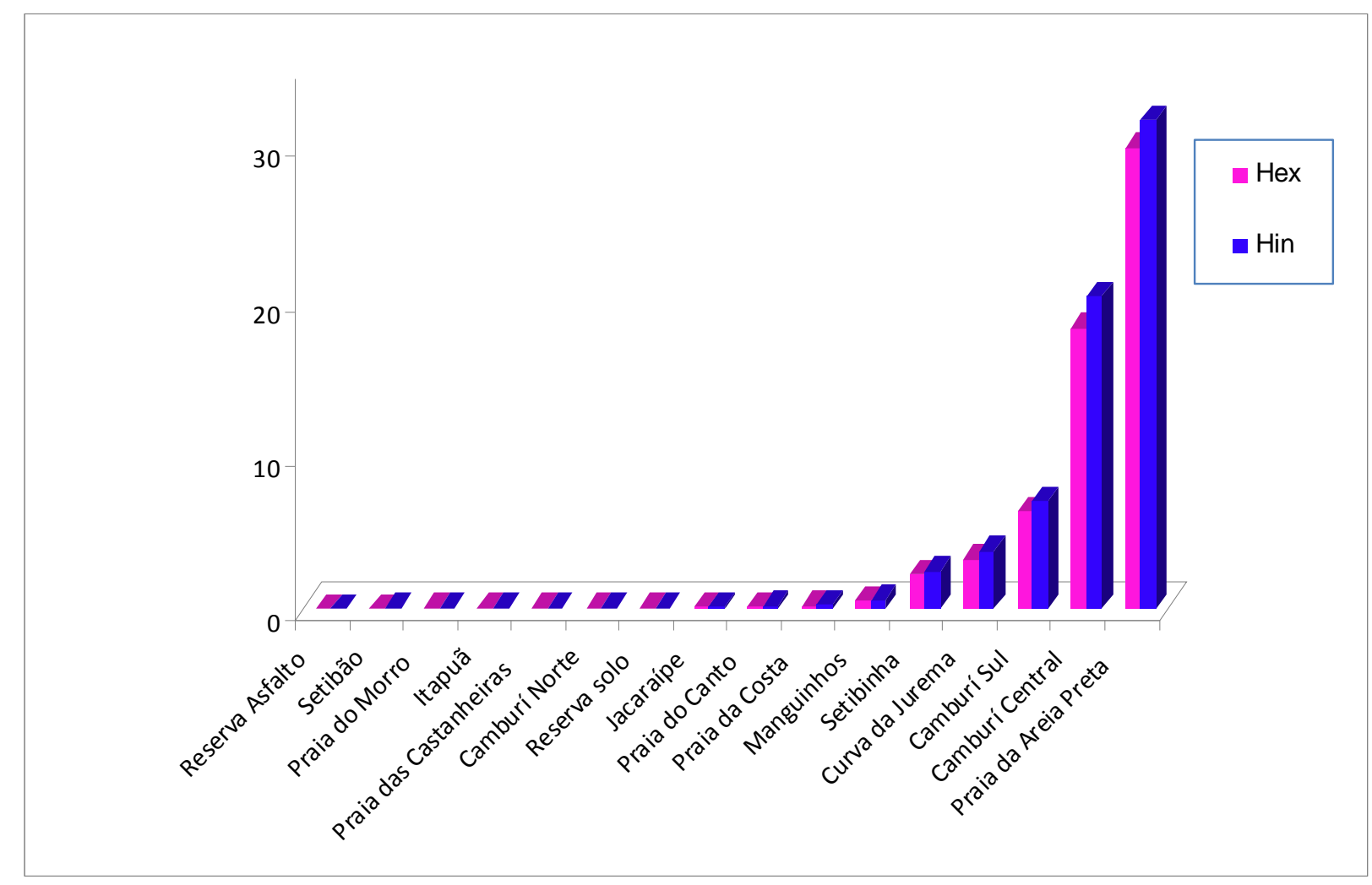

FIGURA 29 - Índice de risco interno e externo para as areias das praias da Grande Vitória.

A avaliação do índice de risco gama mostrou uma faixa de 0,04 até 0,56 para a irradiação externa, considerando a maioria das areias analisadas como dentro dos padrões de referência (menor ou igual a 1). Para as praias de Setibinha e Curva da Jurema, o índice de risco mostra uma contribuição acima do valor unitário estabelecido como referência estando estas areias na faixa de 2,3 a 3,3 para a irradiação gama externa e 2,8 a 3,8 para o risco de irradiação interna. 
Para as praias de Camburí Sul e Central e Praia da Areia Preta, o índice de risco para irradiação externa está na faixa de 6,3 a 30 e para a irradiação interna na faixa de 7 a 32 . Ambas as contribuições avaliadas para estas areias superam o valor unitário de 3 a 30 vezes, o que sugere que estes materiais podem contribuir de forma significativa para o risco de irradiação interna e externa sugerindo que a sua utilização para este fim não é adequada, conforme a quantidade de areia que for utilizada na composição do material de construção (TAB. 5, item 2.7). 


\subsection{Estimativa de dose nas areias das praias da Grande Vitória}

A TAB.11 e FIG.30 sumarizam os índices de avaliação determinados para as areias das praias da Grande Vitória conforme as expressões 11 e 12 e os tempos considerados na TAB.5, item 2.7.

TABELA 11 - Estimativa de dose em relação a atividade anual realizada

\begin{tabular}{|c|c|c|c|c|c|c|}
\hline \multirow[b]{2}{*}{ Município / Localidade } & \multirow{2}{*}{$\frac{\text { Dose }}{\text { nGy.h-1 }}$} & \multicolumn{5}{|c|}{ Fração de atividade mSv. $a^{-1}$} \\
\hline & & $80 \%$ & $20 \%$ & $50 \%$ & $42 \%$ & $8 \%$ \\
\hline Reserva Asfalto & $6 \pm 4$ & 0,03 & 0,01 & 0,002 & 0,001 & 0,0003 \\
\hline Setibão & $8 \pm 5$ & 0,04 & 0,01 & 0,002 & 0,002 & 0,0003 \\
\hline Praia do Morro & $10 \pm 6$ & 0,05 & 0,01 & 0,003 & 0,002 & 0,0004 \\
\hline Itapuã & $12 \pm 5$ & 0,06 & 0,01 & 0,003 & 0,002 & 0,001 \\
\hline Praia das Castanheiras & $14 \pm 5$ & 0,07 & 0,02 & 0,003 & 0,003 & 0,001 \\
\hline Camburí Norte & $14 \pm 5$ & 0,07 & 0,02 & 0,004 & 0,003 & 0,001 \\
\hline Reserva solo & $15 \pm 6$ & 0,07 & 0,02 & 0,004 & 0,003 & 0,001 \\
\hline Jacaraípe & $22 \pm 7$ & 0,11 & 0,03 & 0,01 & 0,01 & 0,001 \\
\hline Praia do Canto & $30 \pm 6$ & 0,15 & 0,04 & 0,01 & 0,01 & 0,001 \\
\hline Praia da Costa & $41 \pm 9$ & 0,20 & 0,1 & 0,01 & 0,01 & 0,002 \\
\hline Manguinhos & $90 \pm 11$ & 0,44 & 0,1 & 0,02 & 0,02 & 0,004 \\
\hline Setibinha & $359 \pm 51$ & 1,76 & 0,4 & 0,1 & 0,08 & 0,02 \\
\hline Curva da Jurema & $518 \pm 77$ & 2,5 & 0,6 & 0,1 & 0,11 & 0,02 \\
\hline Camburí Sul & $995 \pm 114$ & 5 & 1,2 & 0,3 & 0,21 & 0,04 \\
\hline Camburí Central & $2874 \pm 278$ & 14 & 3,5 & 0,7 & 0,6 & 0,1 \\
\hline Praia da Areia Preta & $4696 \pm 1773$ & 23 & 5,8 & 1,2 & 1,0 & 0,2 \\
\hline
\end{tabular}

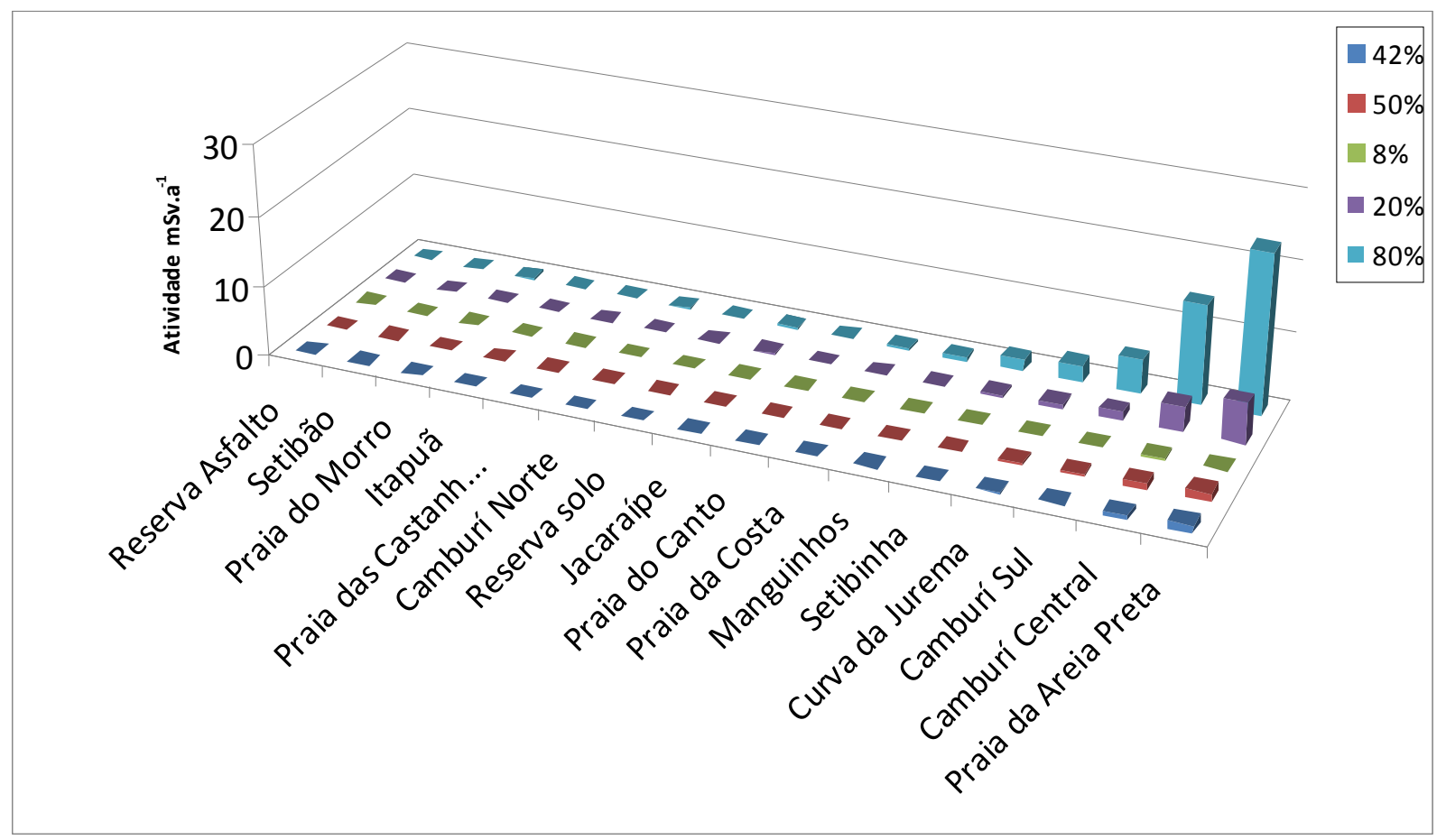

FIGURA 30 - Estimativa de dose em relação à atividade realizada. 
Considerando o valor de $1 \mathrm{mSv}^{-\mathrm{a}^{-1}}$ e os resultados apresentados na TAB.11 e FIG.32 em acordo com os valores definidos na TAB.5, item 2.7 referentes à dose para a população nativa quando interno a residência, a dose estimada para as areias das praias de Setibinha, Camburí sul, Camburí Central, Curva da Jurema e Areia Preta teriam uma contribuição na faixa de $1,76 \mathrm{mSv}^{-a^{-1}}$ a $23,05 \mathrm{mS} . \mathrm{a}^{-1}$ superando o valor limite sugerido. Para as demais localidades a contribuição mostrou-se inferior a $0,44 \mathrm{mSv} \cdot \mathrm{a}^{-1}$.

A contribuição das areias para a dose anual estimada considerando uma atividade externa a residência, conforme definido (item 2.7, TAB.5), das praias de Camburí sul, Camburí Central e Areia Preta apresentam valores na faixa de $1,22 \mathrm{mSv} \cdot \mathrm{a}^{-1}$ a $5,76 \mathrm{mSv} \cdot \mathrm{a}^{-1}$ acima do valor limite sugerido. Para as demais localidades a contribuição mostrou-se inferior a $0,65 \mathrm{mSv} \cdot \mathrm{a}^{-1}$.

No cálculo para a exposição para o turista, os valores apresentados para a dose correspondente a um período máximo de 30 dias em um ano quando interno a residência, conforme definido no item 2.7 TAB.5, os valores mostraram-se inferiores a 1 $\mathrm{mSv} \cdot \mathrm{a}^{-1}$ para todas as areias das praias da Grande Vitória, estando abaixo do valor limite de referência.

Considerando para o turista um período máximo de 30 dias no ano, externo à residência conforme definido item 2.7 TAB.5, os valores mostraram-se inferiores a $0,2 \mathrm{mSv} \cdot \mathrm{a}^{-1}$ para todas as areias das praias da Grande Vitória, estando abaixo do valor limite de referência.

Considerando uma exposição para o turista na praia, por um período de 30 dias ao ano, os valores apresentados para a dose anual, conforme definido item 2.7 TAB.5, mostram uma dose estimada para a praia da Areia Preta de $1,2 \mathrm{mSv} \cdot \mathrm{a}^{-1}$ superando o valor de referência. As demais praias da Grande Vitória apresentam valores inferiores a $0,73 \mathrm{mSv} \cdot \mathrm{a}^{-1}$ estando abaixo do valor limite de referência. 


\section{CONCLUSÕES}

A concentração de ${ }^{226} \mathrm{Ra},{ }^{232} \mathrm{Th}$ e ${ }^{40} \mathrm{~K}$ para as amostras de areias da Grande Vitória, contemplando 16 sítios de amostragem localizados ao longo de uma extensão aproximada de $90 \mathrm{~km}$ da costa capixaba, foram determinadas por espectrometria gama de alta resolução cujos resultados mostram a eficiência desta técnica para a aplicação no estudo proposto.

Para o município da Serra, porção norte da Grande Vitória, onde foram avaliadas as praias de Jacaraípe e Manguinhos, os valores determinados para a concentração de atividade do ${ }^{40} \mathrm{~K}$ variou entre $42 \pm 8 \mathrm{~Bq} \cdot \mathrm{kg}^{-1}$ até $202 \pm 10 \mathrm{~Bq} \cdot \mathrm{kg}^{-1}$, para a concentração de atividade do ${ }^{226} \mathrm{Ra}$ variou entre $8 \pm 1 \mathrm{~Bq} \cdot \mathrm{kg}^{-1}$ até $31 \pm 2 \mathrm{~Bq} \cdot \mathrm{kg}^{-1}$, para a concentração de atividade do ${ }^{232} \mathrm{Th}$ variou entre $28 \pm 1 \mathrm{~Bq} \cdot \mathrm{kg}^{-1}$ até $111 \pm 10 \mathrm{~Bq} \cdot \mathrm{kg}^{-1} \mathrm{com}$ o equivalente em rádio variando na faixa de $49 \pm 9 \mathrm{~Bq} \cdot \mathrm{kg}^{-1}$ até $194 \pm 15 \mathrm{~Bq} \cdot \mathrm{kg}^{-1}$ abaixo do limite sugerido de $370 \mathrm{~Bq} . \mathrm{kg}^{-1}$ (OECD, 1979). O índice de risco gama externo variou na faixa de $0,14 \pm 0,04$ até $0,21 \pm 0,04$ abaixo do valor unitário correspondente a $1,5 \mathrm{mSv} \cdot \mathrm{a}^{-1}$ (ICRP, 1979) e o índice de risco gama interno variou na faixa de $0,16 \pm 0,05$ até $0,64 \pm 0,08$ abaixo do valor unitário correspondente a $1,5 \mathrm{mSv} \cdot \mathrm{a}^{-1}$ (ICRP, 1979).

Para o município de Vitória, porção centro-leste da Grande Vitória, onde foram avaliadas as praias de Camburí, Praia do Canto e Curva da Jurema, os valores determinados para a concentração de atividade do ${ }^{40} \mathrm{~K}$ variou entre $29 \pm 6 \mathrm{~Bq} . \mathrm{kg}^{-1}$ até $377 \pm 20 \mathrm{~Bq} \cdot \mathrm{kg}^{-1}$, para a concentração de atividade do ${ }^{226} \mathrm{Ra}$ variou entre $6 \pm 1 \mathrm{~Bq} \cdot \mathrm{kg}^{-1}$ até $755 \pm 39 \mathrm{~Bq} \cdot \mathrm{kg}^{-1}$, para a concentração de atividade do ${ }^{232} \mathrm{Th}$ variou entre $16 \pm 4 \mathrm{~Bq} \cdot \mathrm{kg}^{-1}$ até $4155 \pm 26 \mathrm{~Bq} \cdot \mathrm{kg}^{-1} \mathrm{com}$ o equivalente em rádio variando na faixa de $30 \pm 7 \mathrm{~Bq} \cdot \mathrm{kg}^{-1}$ até $6294 \pm 264 \mathrm{~Bq} \cdot \mathrm{kg}^{-1}$ superando em cerca de 17 vezes o limite sugerido de $370 \mathrm{~Bq} \cdot \mathrm{kg}^{-1}$ (OECD, 1979). O índice de risco gama externo variou na faixa de $0,09 \pm 0,03$ até $18 \pm 2$ superando o valor unitário correspondente a $1,5 \mathrm{mSv} \cdot \mathrm{a}^{-1}$ (ICRP, 1979) e o índice de risco gama interno variou na faixa de $0,10 \pm 0,03$ até $20 \pm 2$ valor acima do valor unitário correspondente a $1,5 \mathrm{mSv} \cdot \mathrm{a}^{-1}$ (ICRP, 1979). 
A praia de Camburí foi avaliada em sua extensão, sendo dividida em três porções de amostragem onde foram determinados valores distintos para as concentrações de ${ }^{40} \mathrm{~K},{ }^{226} \mathrm{Ra}$ e ${ }^{232} \mathrm{Th}$. Tal resultado conduz a conclusão de que há uma variação mineralógica significativa. Na porção norte a concentração de atividade para os radionuclídeos é consideravelmente baixa em relação à porção sul que apresenta valores maiores de concentração de atividade que são acrescidos até a porção central desta praia. Destaca-se também para a areia da praia de Camburí, em sua porção central a maior concentração de ${ }^{226} \mathrm{Ra}\left(755 \pm 39 \mathrm{~Bq} \cdot \mathrm{kg}^{-1}\right)$ em relação as outras areias avaliadas para as praias da Grande Vitória. A concentração de ${ }^{232}$ Th é de grande relevância $\left(4155 \pm 39 \mathrm{~Bq} \cdot \mathrm{kg}^{-1}\right.$ ) mostrando que a porção central de Camburí comporta o segundo maior depósito de areias monazíticas da região da Grande Vitória. Tais valores foram negligenciados em outros trabalhos pesquisados com, por exemplo, MALANCA (1995) e VEIGA (2006).

Para o município de Vila Velha, porção sudeste da Grande Vitória, onde foram avaliadas as praias da Costa e Itapuã, a concentração de atividade do ${ }^{40} \mathrm{~K}$ variou entre $58 \pm 7 \mathrm{~Bq} \cdot \mathrm{kg}^{-1}$ até $64 \pm 8 \mathrm{~Bq} \cdot \mathrm{kg}^{-1}$, a concentração de atividade do ${ }^{226} \mathrm{Ra}$ variou entre $5 \pm 1 \mathrm{~Bq} \cdot \mathrm{kg}^{-1}$ até $19 \pm 2 \mathrm{~Bq} \cdot \mathrm{kg}^{-1}$ e a concentração de atividade do ${ }^{232} \mathrm{Th}$ variou entre $12 \pm 4 \mathrm{~Bq} \cdot \mathrm{kg}^{-1}$ até $49 \pm 7 \mathrm{~Bq} \cdot \mathrm{kg}^{-1}$ com o equivalente em rádio variando na faixa de $25 \pm 8 \mathrm{~Bq} \cdot \mathrm{kg}^{-1}$ até $89 \pm 11 \mathrm{~Bq} \cdot \mathrm{kg}^{-1}$ abaixo do valor limite sugerido de $370 \mathrm{~Bq} \cdot \mathrm{kg}^{-1}$ (OECD, 1979). O índice de risco gama externo variou na faixa de $0,07 \pm 0,03$ até $0,26 \pm 0,05$ abaixo do valor unitário correspondente a $1,5 \mathrm{mSv} \cdot \mathrm{a}^{-1}$ (ICRP, 1979) e o índice de risco gama interno variou na faixa de 0,08 $\pm 0,04$ até $0,31 \pm 0,07$ abaixo do valor unitário correspondente a 1,5mSv.a ${ }^{-1}$ (ICRP, 1979).

E notado na areia da Praia da Costa um padrão de mancha similar às areias avaliadas de regiões como Camburí, Curva da Jurema e Setibinha, onde foram determinadas concentrações de atividade significativa. Entretanto os valores para as concentrações de atividade de ${ }^{40} \mathrm{~K},{ }^{226} \mathrm{Ra}$ e ${ }^{232} \mathrm{Th}$ são relativamente baixos comparados aos sítios de maior concentração destes radionuclídeos. A densidade aparente da amostra e atenuação gama leva a conclusão que as manchas encontradas poderiam ser formadas a partir de pó de minério de ferro oriundos da atividade de mineradoras na região, trazida pelas correntes marítimas e depositada na areia(GAZETAONLINE, 2010). 
Para o município de Guaraparí, porção sul da Grande Vitória, onde foram avaliadas as areias da reserva Paulo Cesar Vinha, Praia de Setibão, Praia de Setibinha, Praia do Morro, Praia das Castanheiras e Praia da Areia Preta, a concentração de atividade do ${ }^{40} \mathrm{~K}$ variou entre $26 \pm 6 \mathrm{~Bq} \cdot \mathrm{kg}^{-1}$ até $699 \pm 243 \mathrm{~Bq} \cdot \mathrm{kg}^{-1}$, a concentração de atividade do ${ }^{226} \mathrm{Ra}$ variou entre $3 \pm 1 \mathrm{~Bq} \cdot \mathrm{kg}^{-1}$ até $643 \pm 48 \mathrm{~Bq} \cdot \mathrm{kg}^{-1}$ e a concentração de atividade do ${ }^{232} \mathrm{Th}$ variou entre $7 \pm 3 \mathrm{~Bq} \cdot \mathrm{kg}^{-1}$ até $7236 \pm 513 \mathrm{~Bq} \cdot \mathrm{kg}^{-1} \mathrm{com}$ o equivalente em rádio variando na faixa de $14 \pm 6 \mathrm{~Bq} \cdot \mathrm{kg}^{-1}$ até $10291 \pm 569 \mathrm{~Bq} \cdot \mathrm{kg}^{-1}$, superando em cerca de 28 vezes o limite sugerido de 370Bq.kg-1 (OECD, 1979). O índice de risco gama externo variou na faixa de $0,04 \pm 0,02$ até $30 \pm 11$ superando 0 valor unitário correspondente a 1,5mSv.a ${ }^{-1}$ (ICRP, 1979) e o índice de risco gama interno variou na faixa de $0,05 \pm 0,03$ até $32 \pm 12$ valor acima do valor unitário correspondente a 1,5mSv. $\mathrm{a}^{-1}$ (ICRP, 1979).

No município de Guaraparí é encontrada a maior concentração de atividade de atividade de ${ }^{232} \mathrm{Th}$ par a região da Grande Vitória $\left(7236 \pm 513 \mathrm{~Bq} \cdot \mathrm{kg}^{-1}\right)$, e segundo maior depósito de ${ }^{226} \mathrm{Ra}\left(643 \pm 48 \mathrm{~Bq} \cdot \mathrm{kg}^{-1}\right)$.

Os valores encontrados mostram uma região de anomalia de radioatividade natural com considerável concentração de elementos como o ${ }^{222} \mathrm{Rn},{ }^{214} \mathrm{~B}$ e ${ }^{214} \mathrm{~Pb}$ provenientes do decaimento radioativo do ${ }^{226} \mathrm{Ra}$ que podem contribuir para o aumento da incidência de câncer de pulmão (NRC, 1999), entretanto, a incidência de câncer de brônquio e pulmão a partir da idade para homens e mulheres em uma população de 100 mil habitantes, mostra Vitória como sendo a região de menor taxa de incidência deste mal. Os índices encontrados na base de dados dos registros de câncer populacional mostram valores de 0 a 4,8 anos para mulheres e 0 a 9,4 anos para homens (INCA,1997-2000) considerando esta modalidade de câncer. Para a cidade de São Paulo esta taxa está na faixa de 0 a 13 anos para mulheres e 0 a 38,2 anos para homens, Belo Horizonte esta taxa está na faixa de 0 a 16,6 anos para mulheres e 0 a 36,6 anos para homens e Porto Alegre com o maior índice de incidência estando este na faixa de 0 a 21,2 anos para mulheres e 0 a 70,2 anos para homens(INCA, 19972000). 
A avaliação do rádio equivalente mostrou que não há aplicações possíveis para a areia da Praia da Areia Preta (10291 \pm 569Bq. $\mathrm{kg}^{-1}$ ) se aplicada diretamente, sem mistura, a qual supera em cerca de 28 vezes o valor estabelecido como limite 370Bq. $\mathrm{kg}^{-1}$ (OECD, 1979), entretanto considerando que ela possa ser utilizada como parte do material agregado, há aplicação possível como fundação. Contudo, devido sua contribuição para a radiação total estar próximo do valor limite para tal aplicação e considerando que haverá contribuições de outros materiais conclui-se que seu uso é inadequado. O mesmo pode ser dito da areia da Praia de Camburí Central.

As demais areias avaliadas mostram possíveis aplicações para a área de construção civil.

Os resultados para o fator de atenuação mostraram que para conjunto de amostragem realizado para localidades distintas, o mesmo deve ser recalculado. Como o fator está ligado a composição mineralógica da areia, para casos onde ocorra variação na concentração mineral desta areia seja por fatores antropogênicos ou antropomórficos, o fator de atenuação deverá ser recalculado mesmo para a mesma localidade. 


\section{SUGESTÃO PARA NOVOS TRABALHOS}

Realizar uma estimativa de dose sistemática para exposição gama em ambientes externos e internos e para indivíduos trabalhadores e eventuais, considerando o tempo de permanência no setor de trabalho buscando explorar as localidades com maiores níveis de radioatividade natural, considerando residências mais realistas.

Estudar a composição mineralógica das areias utilizando técnicas de raio-x ou ativação por nêutrons buscando estabelecer uma correlação com os índices de radioatividade.

Aprofundar Estender o estudo considerando a coleta de areia em diferentes estações ao longo do ano e estende-lo para outras praias da região.

Estudar a dose gama externa e interna por inalação de radônio em residências e tentar conciliar com o possível uso de areia (mesmo que não regulamentado) das praias com altos níveis de radioatividade natural.

Realizar estudo epidemiológico mas regiões de areias com alta radioatividade de fundo. 


\section{REFERÊNCIAS BIBLIOGRÁFICAS}

ADEMOLA J. A., Determination of Natural Radionuclides Content in Some Building Materials in Nigeria by Gamma-ray Spectrometry. Health Physics, v.94, p.43-48, 2008.

ALAM M.N., CHOWDHURY M.I., KAMAL M., GHOSE S., ISLAM M.N., MUSTAFA M.N. MIAH M.M.H. ANSARY M.M., The 226Ra, 232Th ans 40K activities in beach sand minerals and beach soils of Cox's Bazar, Bangladesh, Journal of environmental radioactivity, v.46, 243-250, 1998.

ALENCAR A.S. e FREITAS A.C., Reference levels of natural radioactivity for the beach sands in a Brazilian southeastern coastal region, Radiation Measurements, v.40, 7383, 2004.

AQUINO, R. R. e PECEQUILO B.R.S., ${ }^{226} \mathrm{Ra},{ }^{232} \mathrm{Th}$ and ${ }^{40} \mathrm{~K}$ analysis in sand samples from some beaches of Geat Vitória, Espírito Santo, Brazil:Preliminary results, In: 2009 INTERNATIONAL NUCLEAR ATLANTIC CONFERENCE - INAC 2009, 2009, Rio de Janeiro, Anais...INAC

BERETKA, J. e MATHEW, P.J. Natural Radioacivity of Australian building materials, industrial wastes and by-product. Health Physics, v. 48, p.87-95, 1985.

CANBAZ B., FÜSUM N. C., YAPRAK G. e CANDAN O., Natural Radioactivity $\left({ }^{226}\right.$ Ra, ${ }^{232} \mathrm{Th}$ and, ${ }^{40} \mathrm{~K}$ ) and assessment of radiological hazards in the Kestanbol Granitoid, Turkey, Radiation Protection Dosimetry, v. 141, p.192-198, 2010.

CUTSHALL, N.H., LARSEN I.L., OLSEN C.R. Direct analysis of ${ }^{210} \mathrm{~Pb}$ in sediment samples: Self-absorption corrections. Nuclear Instruments and Methods in Physics Research, v. 206, p.309-312, 1983.

DICKSON B.L., SCOTT K.M., Interpretation of aerial gamma-ray surveys-adding the geochermical factors. AGSO Jornal of Autralian Geology \& Geophysics, v.17, 187200, 1997.

EISENBUD, M. Environmental radioactivity. $2^{\text {nd }}$ ed. Academic Press, Orlando, 1987.

EMCAPA/NETUP, Empresa Capixaba de Pesquisa Agropecuária. Zonas naturais do Espírito Santo, 1999. Disponível em: <http://www.es.gov.br>, acesso em 01/06/2010.

EVANS, R.D. The Atomic Nucleus. McGraw Hill, New York, 1972.

FLORES O. B., ESTRADA A. M. e ZERQUERA J.T., Natural radioactivity in Some Building Materials in Cuba and Their Contribution to the Indoors Gamma Dose Rate, Radiation Protection Dosimetry, v.113, 218-222, 2004.

GAZETAONLINE. População não sente, mas Vale anuncia a redução do pó preto, Vitória, 03 fevereiro 2010. disponível em: <http://www.gazetaonline.com.br>. Acesso em: 10/12/2010 
HASSAN N.M. , ISHIKAWA T., HOSODA M., SORIMACHI A., TOKONAMI S., FUKUSHI M. e SAHOO S.K., Assessment of the natural radioactivity using two techniques for the measurement of radionuclide concentration in building materials used in Japan, $\mathbf{J}$

Radioanal Nucl Chem , v. 283 p. 15-21, 2010

IBGE, Instituto Brasileiro de Geografia e Estatística. Censo 2010, 2010. Disponível em: < http://www.ibge.gov.br/censo2010>, acesso em 04/11/2010.

ICRP, 1977, International Commission on Radiological Protection, Recommendation of ICRP, pulicação 26, Ed. Pergamon Press, Oxford, 1977.

INCA, Instituto Nacional de Câncer. Perfil de incidência nas cidades com RCBP ativo, 1997-2000. Disponível em: <http://www.inca.gov.br>, acesso em 26/11/2010.

ISINKAYE M. O. e SHITTA M. B. O., Natural Radionuclide Content and Radiological Assessment of Clay Soils Collected From Different Sites in Ekiti State, Southwestern Nigéria, Radiation Protection Dosimetry, 2009.

KNOLL, Glenn F., Radiation Detection and Measurement, John Wiley \& Sons, New York, NY, USA. (1999). $3^{\text {rd }}$ ed.

KRIEGER R., Radioactivity of Contruction Materials, Betonwerk Fertigteil Techn, v. 47, p.468-473, 1981 em Hassan, 2010.

MALANCA A., PESSINA V., e DALLARA G., Radionuclide Content of Building Materials and Gamma Ray Dose Rates in Dwellings of Rio Grande Do Norte, Brazil, Radiation Protection Dosimety, v. 48, p.199-203, 1993.

MALANCA A., PESSINA V., DALLARA G., LUCE C. N. e GAIDOLFI L., Natural radioactivity in building materials from the Brazilian state of Espírito Santo, Applied Radiation and Isotopes, v.46, p.1387-1392, 1995.

MACHADO, F.B.; MOREIRA, C.A.; ZANARDO, A; ANDRE, A.C.;GODOY, A.M.; FERREIRA, J. A.; GALEMBECK, T.; NARDY, A.J.R.; ARTUR, A.C.; OLIVEIRA, M.A.F.de. Enciclopédia Multimídia de Minerais. [on-line].ISBN: 85-89082-113 Disponível na Internet via WWW. URL: http://www.rc.unesp.br/museudpm. Arquivo capturado em 12 de julho de 2009.

MEDHAT M.E. Assesment of Radiation Hazards Due to Natural Radioacivity in Some Building Materials Used in Egyptian, Radiation Protection Dosimetry, v. 133, p.177185, 2009

MOURA, J.C. Estudo da Variação Sazonal dos Níveis de Radiação Gama da Praia da Areia Preta, Guaraparí, Espírito Santo, Brasil: Radiometria e Análise de Risco. Dissertação de mestrado apresentada ao Programa de Pós Graduação da Engenharia Ambiental do Centro Tecnológico da Universidade Federal do Espírito Santo (PPGEA/CT/UFES), Vitória. 2003. 
NNDC - National Nuclear Data Center, Brookhaven National Laboratory, base em ENSDF, Nuclear Wallet Cards (1996-2003). disponível em: <http://www.nndc.jbl.gov> , acesso em: 10/08/2010

NRC - National Research Council. Committee on the Biological Effects of lonizing, Radiations. Health Effects of Exposure to Radon. BEIR VI. National Academy Press:Whashington, D.C. 1999.

OECD, 1979. Organization for Economic Cooperation and Development. Exposure to radiation from natural radioactivity in building materials. Report by a Group of Experts of the OECD Nuclear Energy Agency, OECD, Paris, 1979.

ORTEC, InterWinnerTM6.0 MCA Emulation, Data Acquisition, and Analysis Software For Gama and Alfa Spectroscopy, TOMCOM Software Ltd., 2004.

PHILANDER, $C$ and ROZENDAAL, A. Mineral intricacies of the Namakwa Sands mineral resource. The 7th International Heavy Minerals Conference 'What next', The Southern African Institute of Mining and Metallurgy, 2009

PINIWEB. PINI WEB O portal da construção, São Paulo, 12 dez. 2000. disponível em: $<$ http://www.piniweb.com.br/construcao/noticias/e-possivel-usar-areia-de-praia-paraexecutar-concreto-83790-1.asp>. Acesso em: 10/08/2010

RIEDEL, W.; EISENMENGER, A Problems in monitoring for thorium intakes by workers. KERNTECHNIK, v. 64, n. 1-2, p. 72-85, 1999.

SABOL, J. e WENG, P. S. Introduction to Radiation Protection Dosimetry, Singapore: World Scientific, 1995.

SOWMYA M. , SENTHILKUMAR B., SESHAN B. R. R., HARIHARAN G., PURVAJA R. , RAMKUMAR S. e RAMESH R., Some natural radioactivity and associated dose rates in soil samples from Kalpakkam, South India. Radiation Protection Dosimetry, v.141, 239-247, 2010.

STEINHÄUSLER F., HOFMANN W. e LETTNER H., Thoron exposure of man: Negligible issue?, Radiation Protection Dosimetry, v.56, 127-131, 1994.

STRADEN, E., Radioactivity of building materials and the gamma radiation in dwellings, Phys. Med. Biol., v.24, 921-930, 1979.

TAUHATA, L.; VIANNA, M.E.C.; OLIVEIRA, A.E.; FERREIRA, A.C.M.; CONCEIÇÃO, C.C.S. Appl Radiat Isot. 56, 409-414, 2002.

UNSCEAR $^{1}$, Sources and effects of ionizing radiation. United Nations Scientific Committee on the Effects of Atomic Radiation, United Nations, New York, 1988.

UNSCEAR $^{2}$, Sources and effects of ionizing radiation. United Nations Scientific Committee on the Effects of Atomic Radiation, United Nations, New York, 1993. 
UNSCEAR $^{3}$, Sources and effects of ionizing radiation. United Nations Scientific Committee on the Effects of Atomic Radiation, United Nations, New York, 2000.

UNSCEAR $^{4}$, Sources and effects of ionizing radiation. United Nations Scientific Committee on the Effects of Atomic Radiation, United Nations, New York, 2008.

UOSIF M.A.M., A. EL-TAHER A. e ABBADY A.G. E.,. Radiological Significance of Beach Sand Used For Climatotherapy From Safaga, Egypt, Radiation Protection Dosimetry, v.131, 331-339, 2008.

VEIGA R., SANCHES N., ANJOS R.M., MACARIO K., BASTOS J., IGUATEMY M., AGUIAR J.G., SANTOS A.M.A, MOSQUERA B., CARVALHO C., FILHO M.B. e UMISEDO N.K., Measurement of natural radioactivity in Brazilian beach sands. Radiation Measurement, v. 41, p.189-196, 2006

VENTURINI L. , NISTI M.B., Correção de auto-absorção na espectrometria gama de amostras ambientais, IV ENAM,1997

XINWEI L. e XIAOLAN Z., Radionuclide Content and Associated Radiations Hazards of Building Materials and By-Products in Baoji, West China, Radiation Protection Dosimetry, v.128, p.471-476, 2007. 


\section{ANEXO I - Curvas características de atenuação gama.}

Atenuação gama para amostra da Praia de Jacaraípe

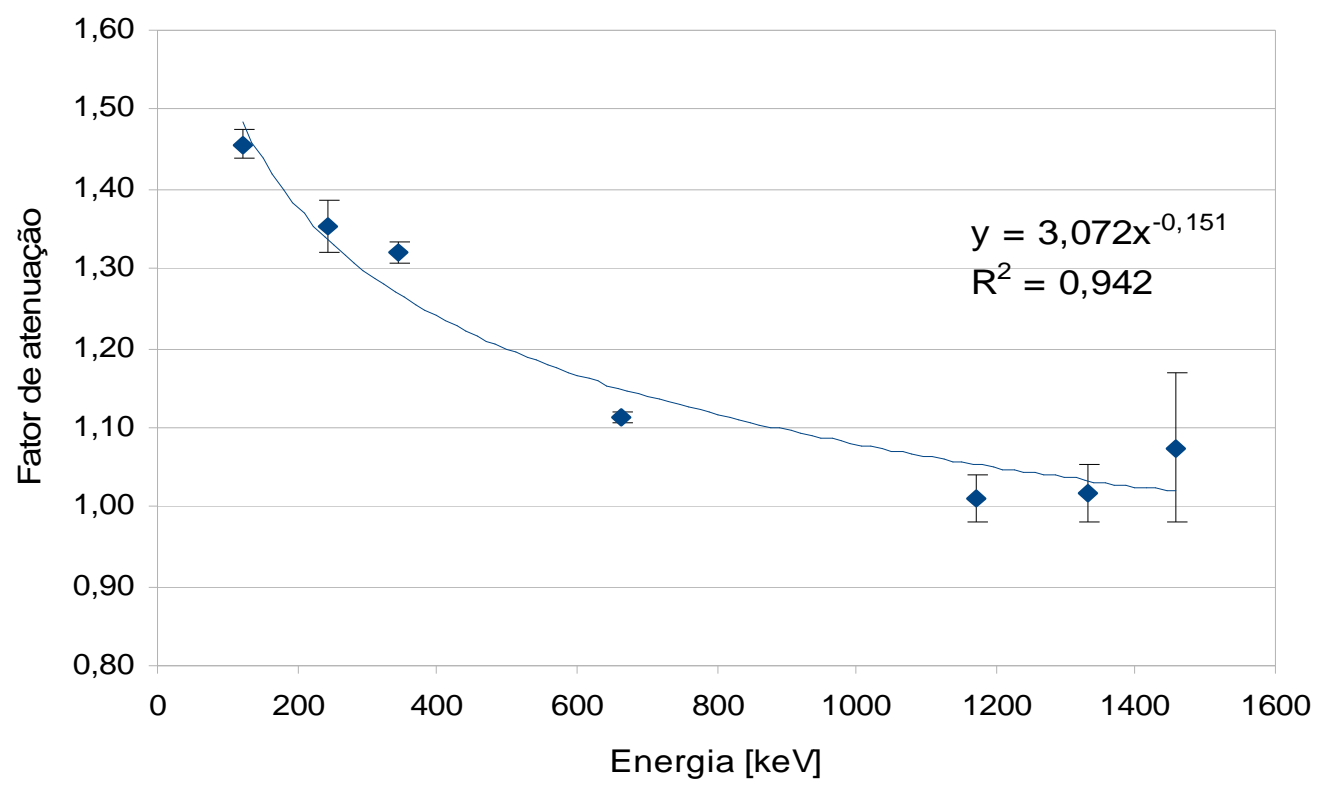

Atenuação gama para amostra da Praia de Manguinhos

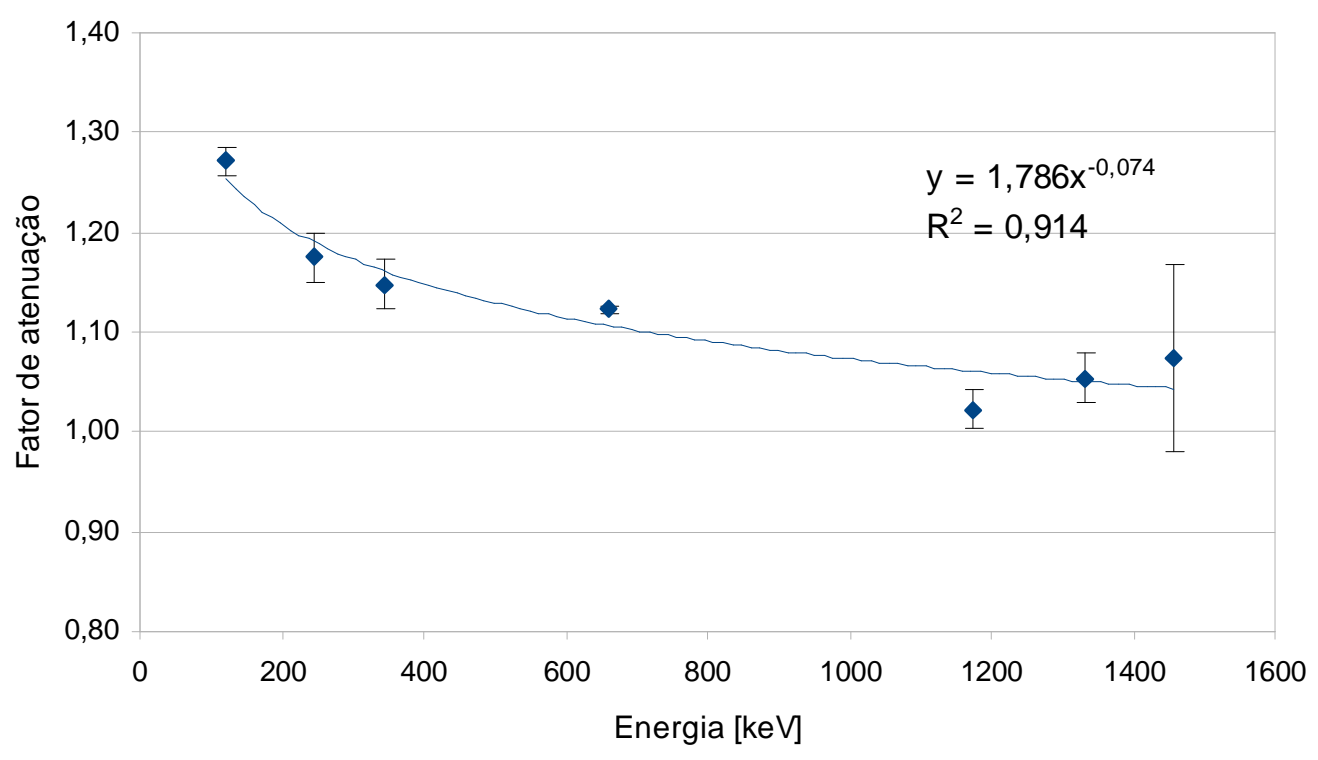


Atenuação gama para amostra da Praia de Camburí Norte

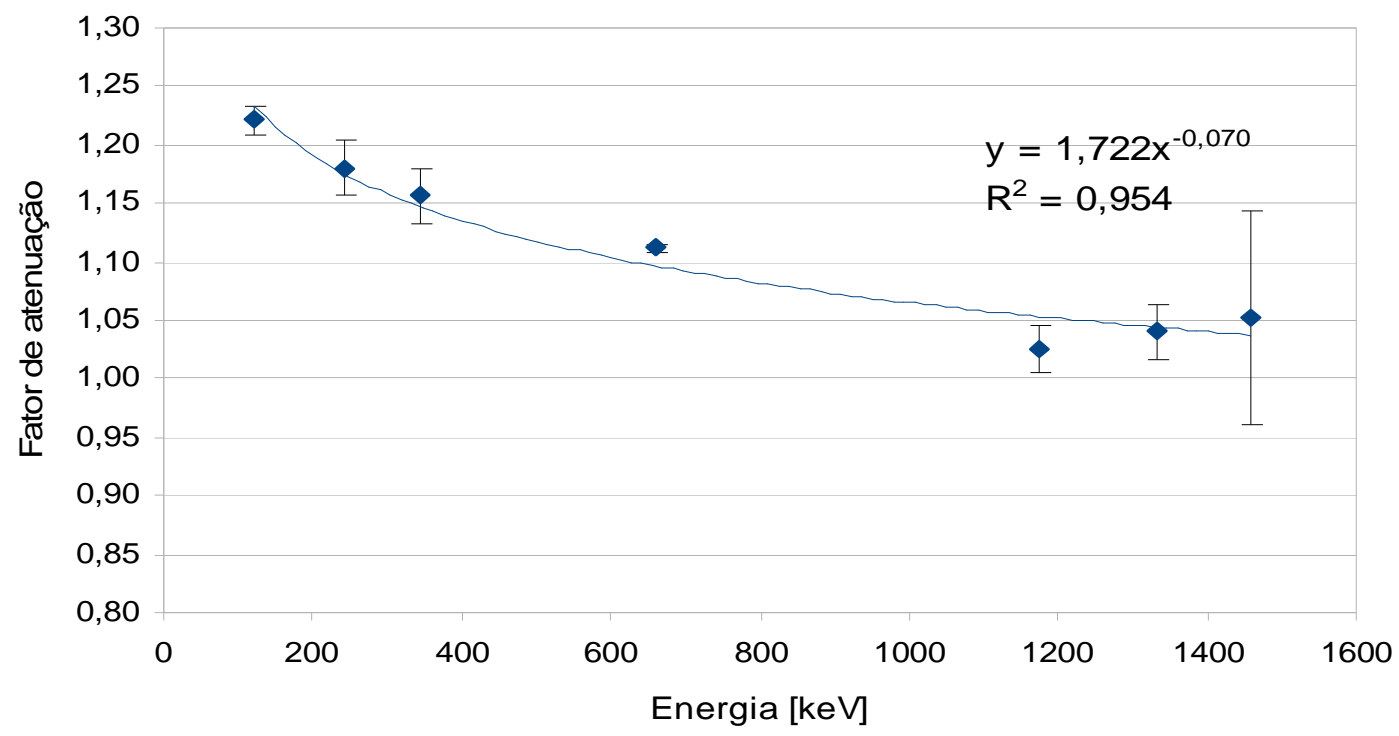

Atenuação gama para amostra da Praia de Camburí Centro

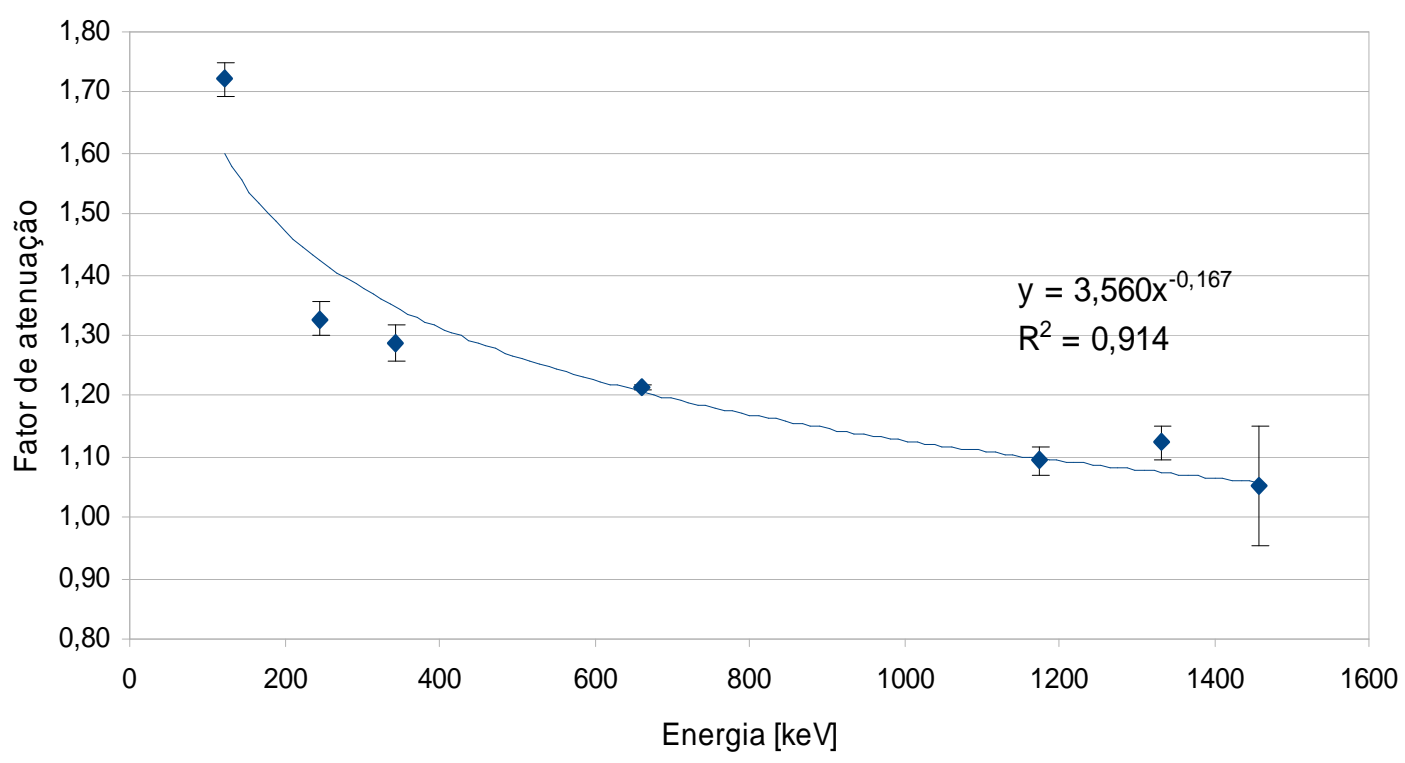


Atenuação gama para amostra da Praia de Camburí Sul

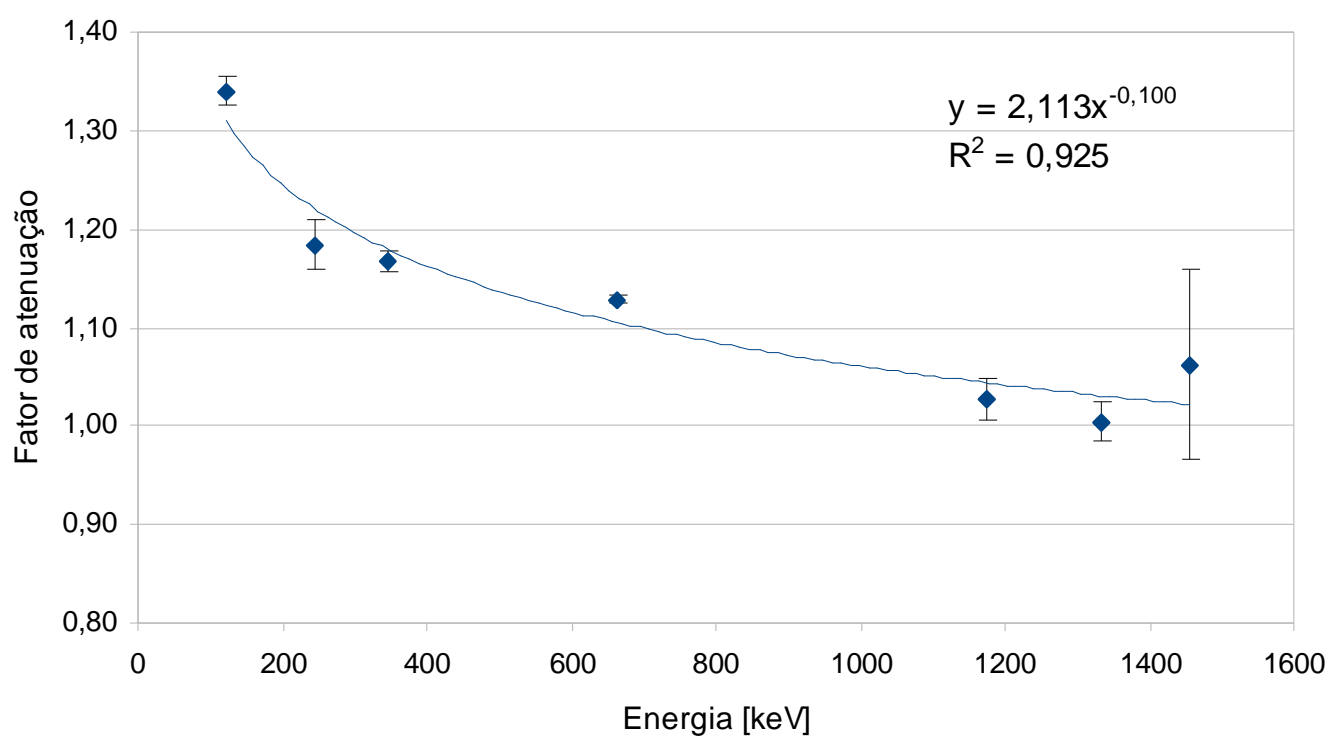

Atenuação gama para amostra da Praia do Canto

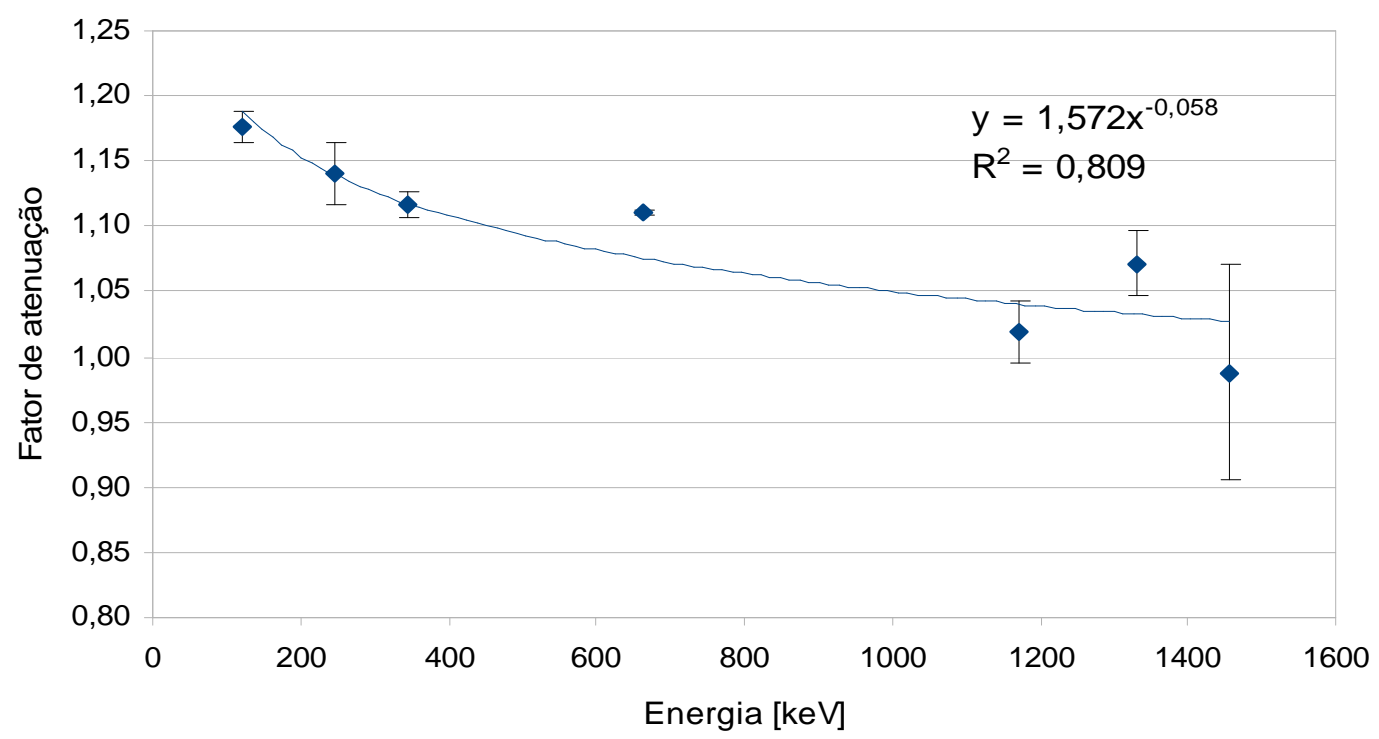


Atenuação gama para amostra da Curva da Jurema

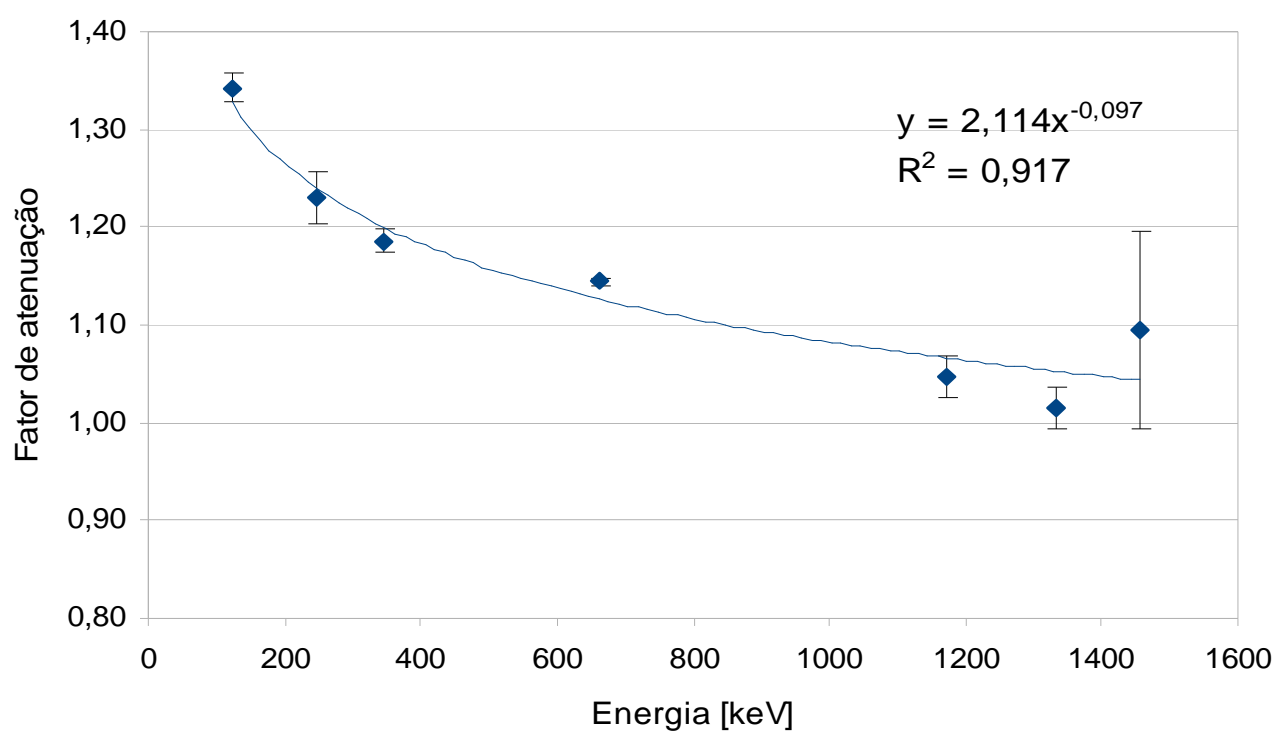

Atenuação gama para amostra da Praia da Costa

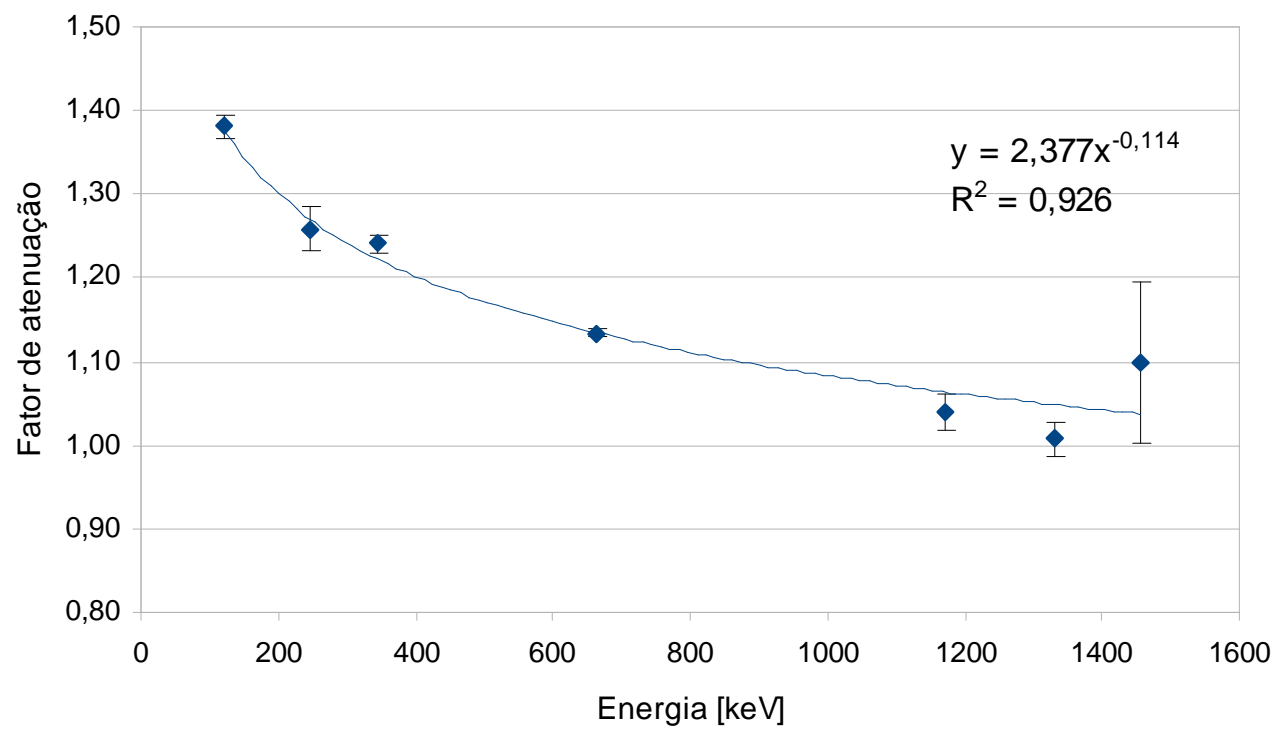


Atenuação gama para amostra da Praia de Itapuã

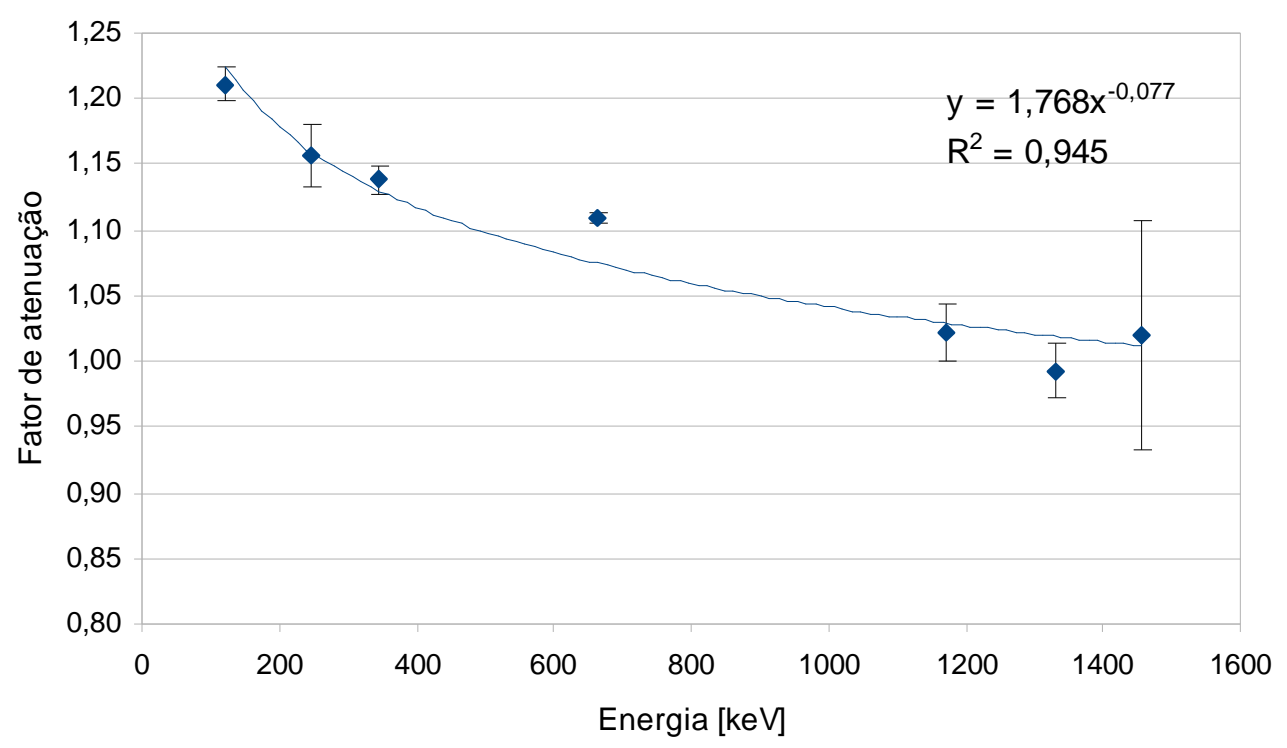

Atenuação gama para amostra da reseva aslfalto

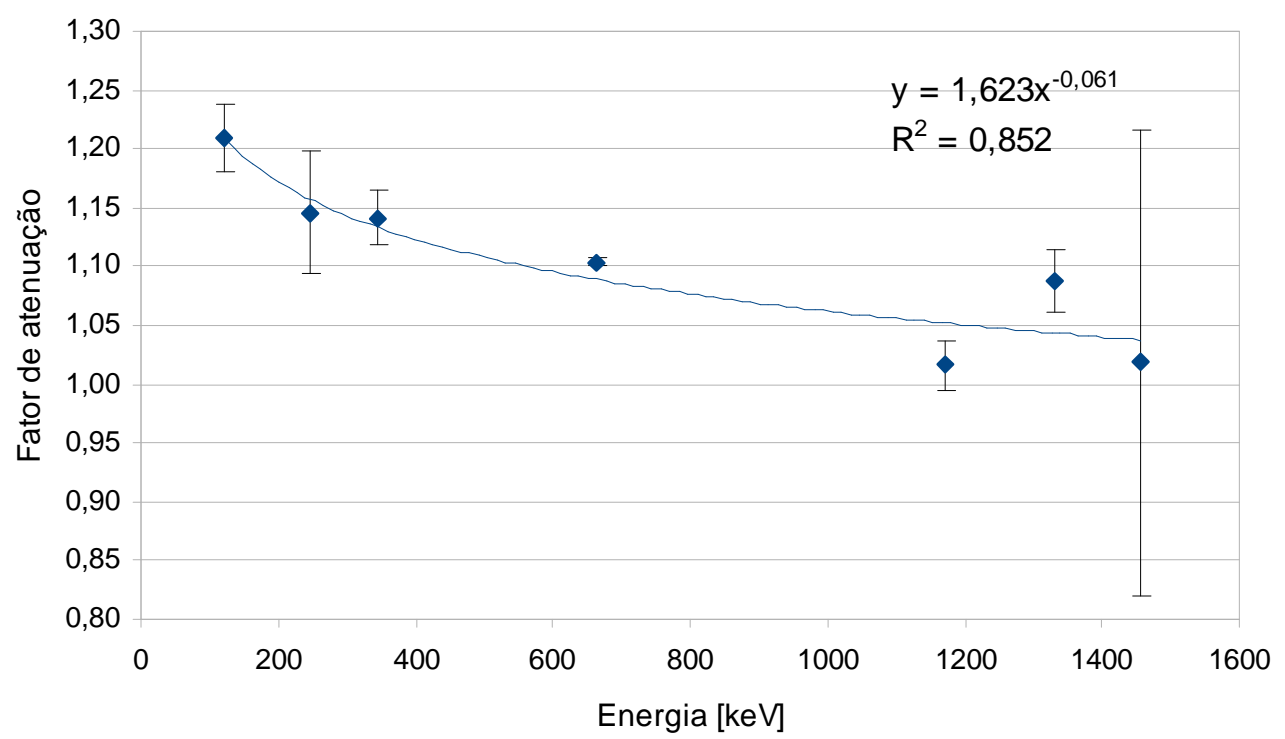


Atenuação gama para amostra da Reserva Solo

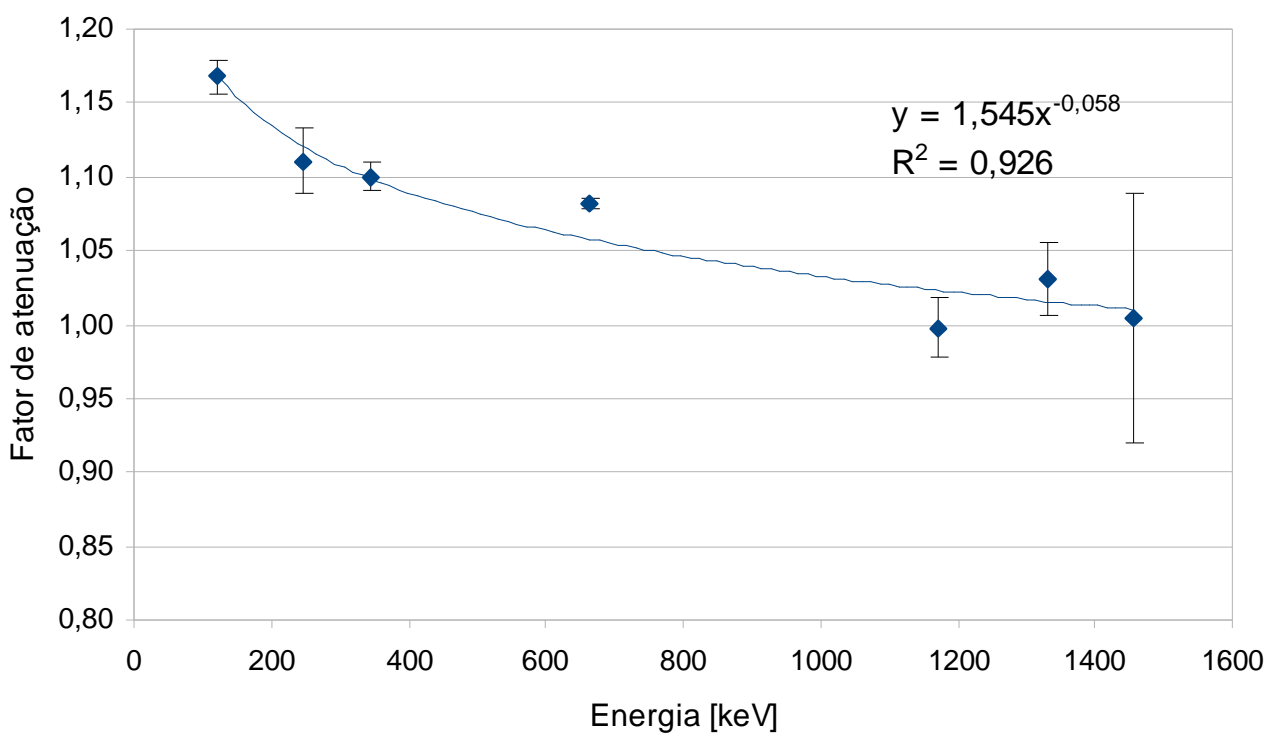

Atenuação gama para amostra da Praia de Setibão

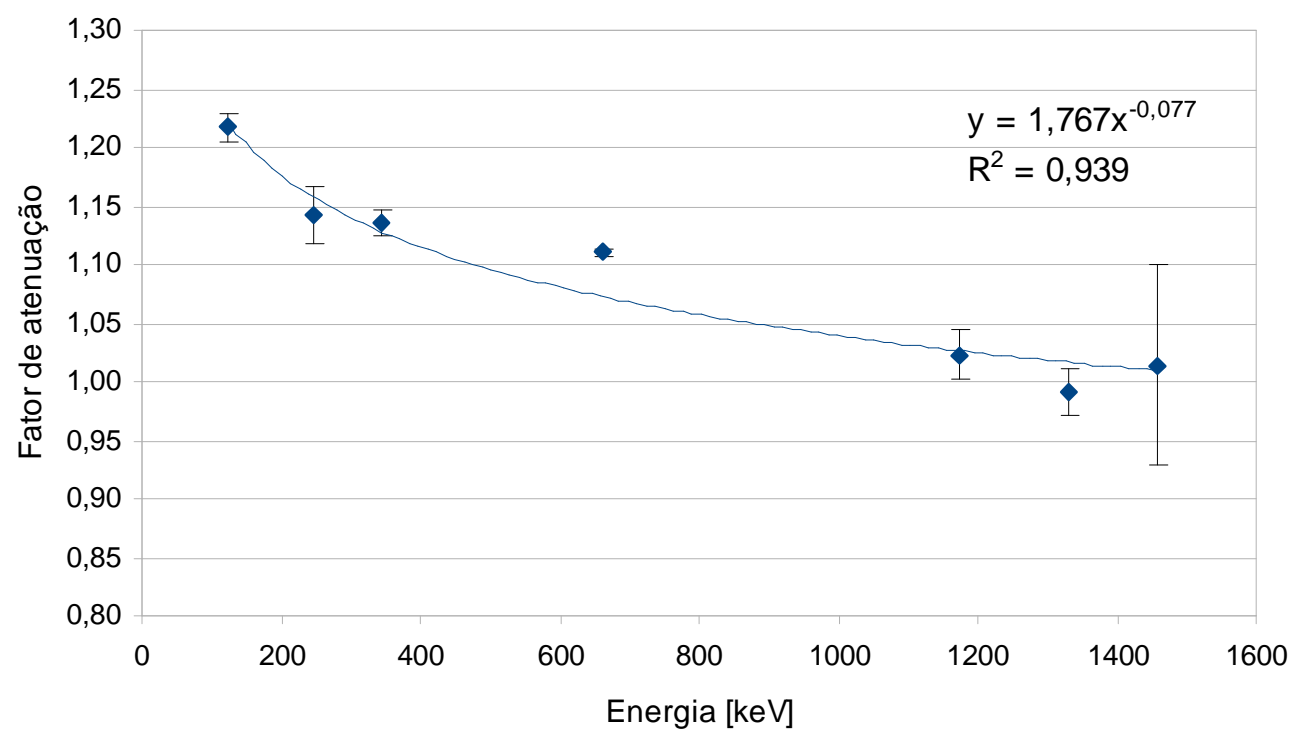


Atenuação gama para amostra da Praia de Setibinha

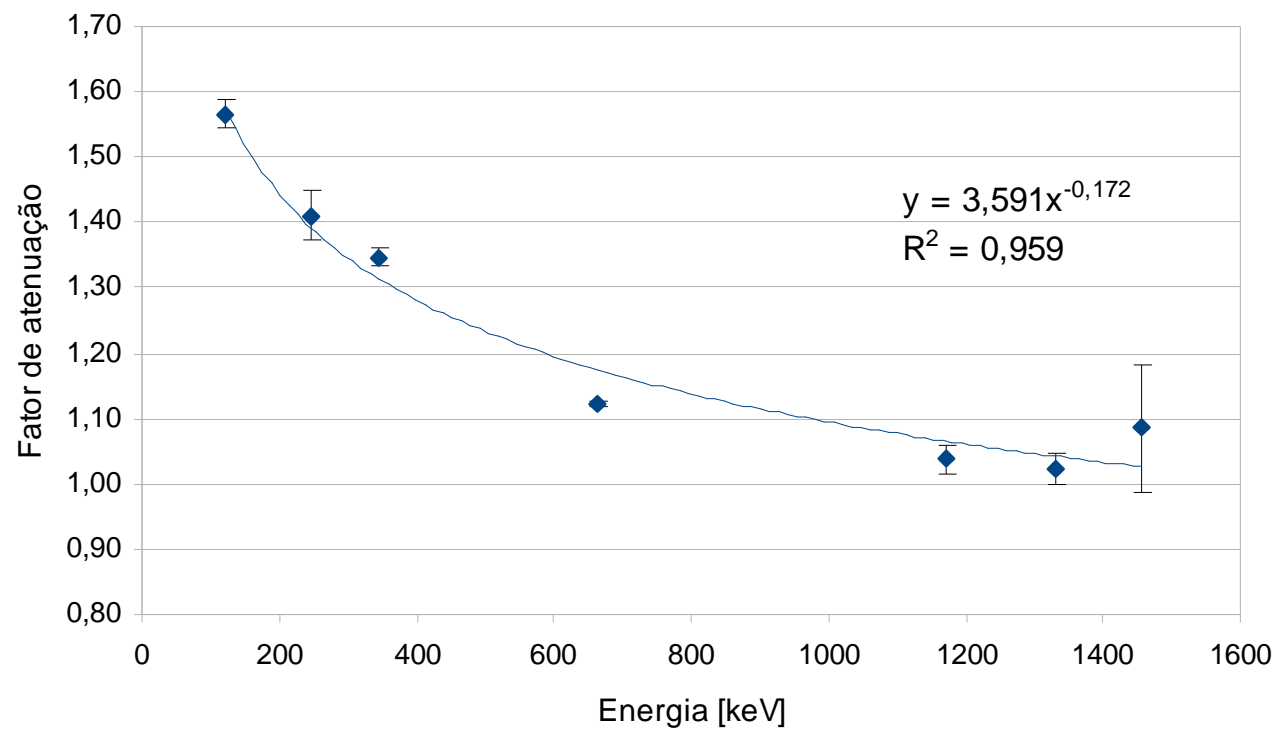

Atenuação gama para amostra da Praia do Morro

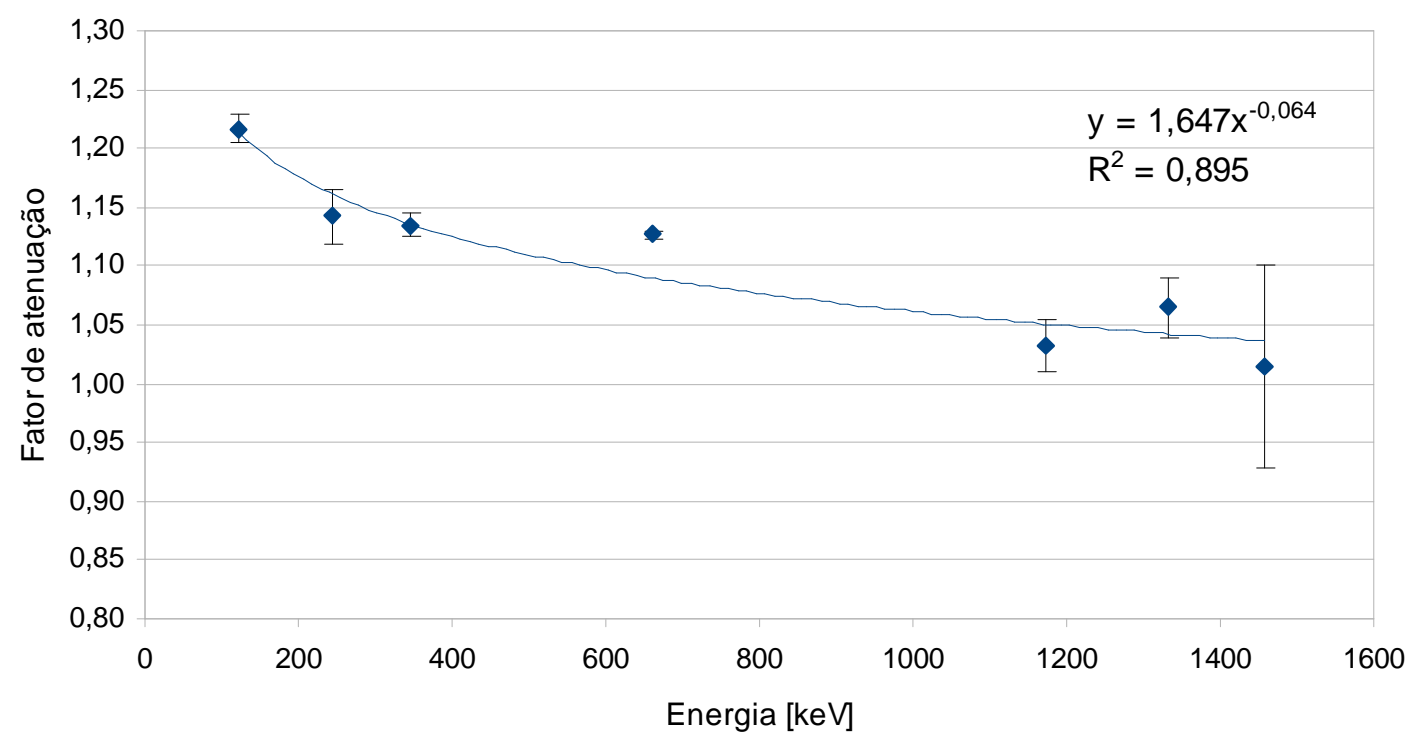


Atenuação gama para amostra da Praia das Castanheiras

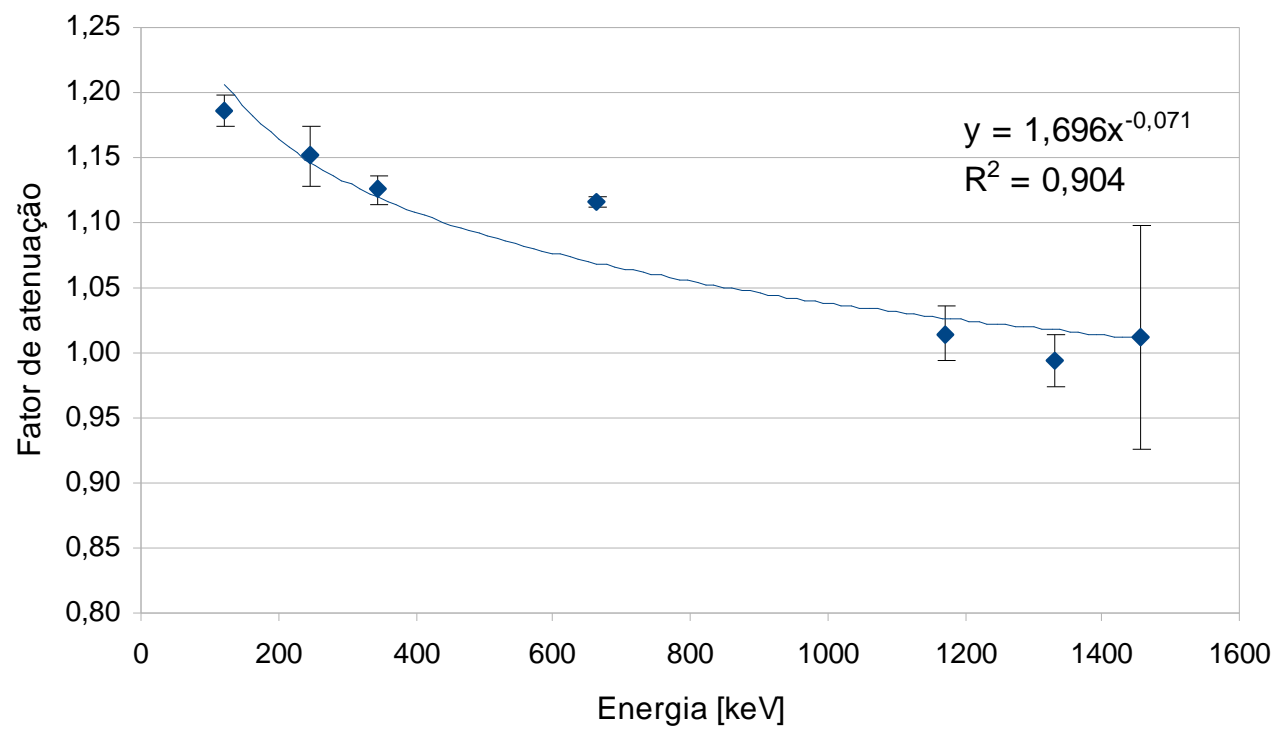

Atenuação gama para amostra da Praia da Areia Preta

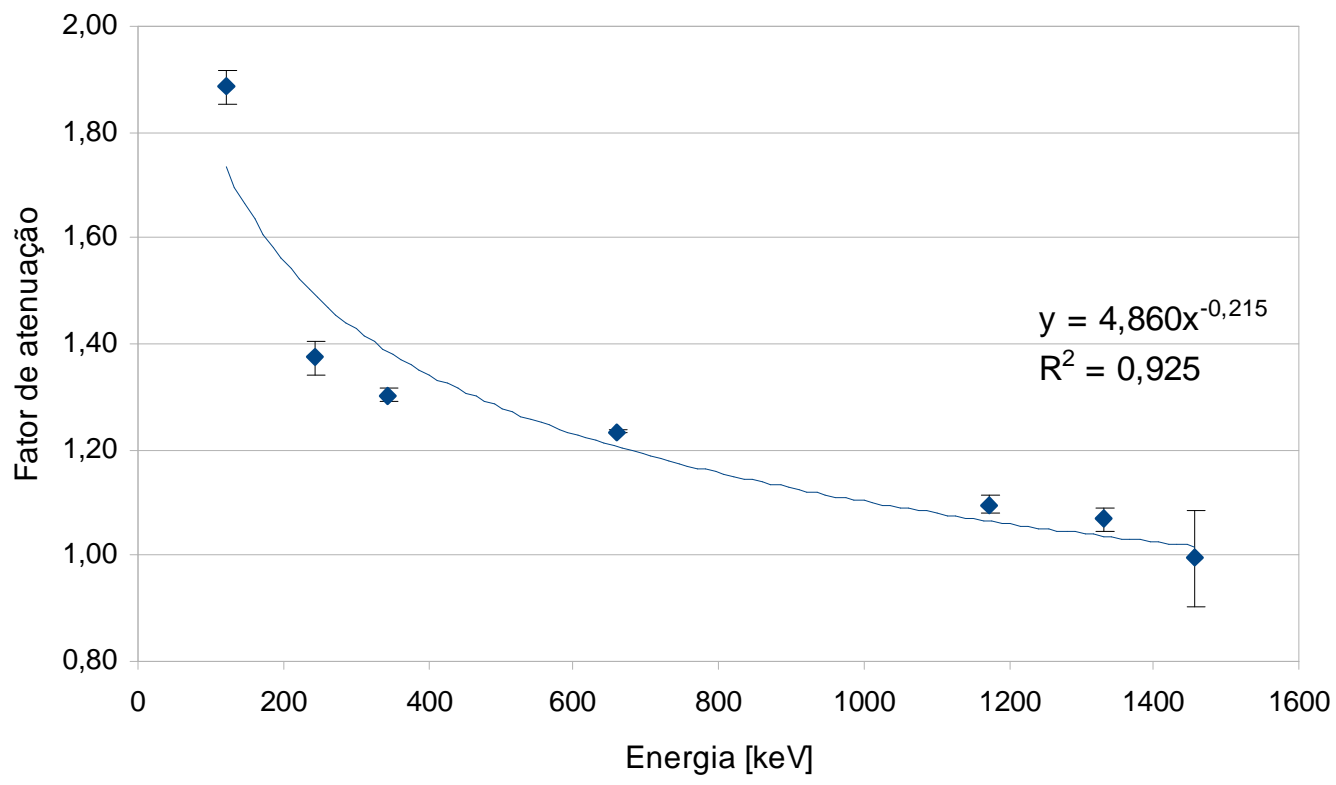

